\title{
DESIGN HANDBOOK FOR CANADIAN CO-HOUSING
}

by

Kristi Van Delft

A thesis submitted to the Faculty of Graduate and Postdoctoral Affairs in partial fulfillment of the requirements for the degree of

Master

in

Architecture

Carleton University

Ottawa, Ontario

(C) 2019

Kristi Van Delft 


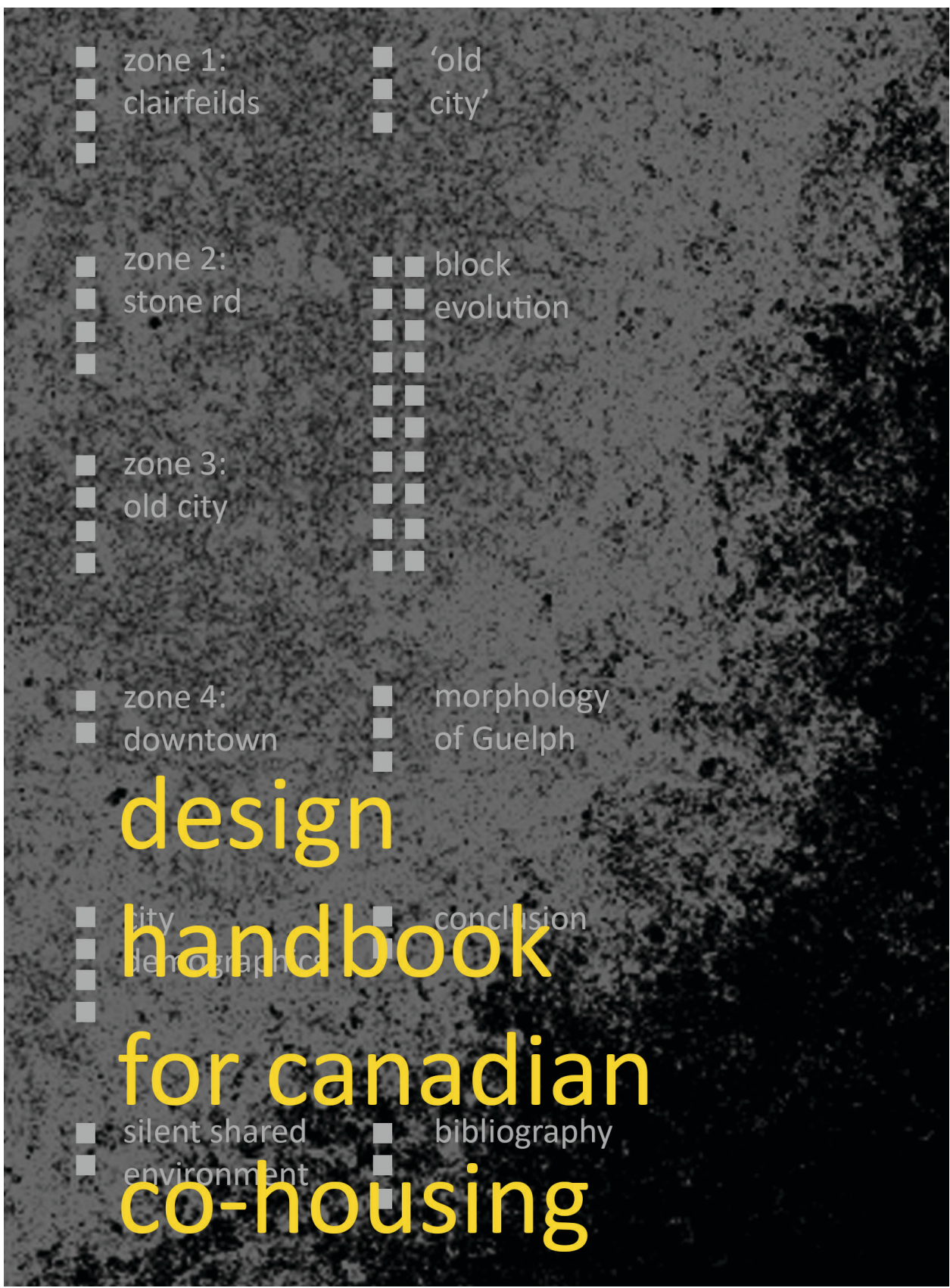




\section{ABSTRACT}

In Canada today, many popular housing typologies do not foster the idea of community. As a result, inhabitants may be subject to a sense of loneliness, as the architectural design promotes living in social isolation. This thesis will explore ways to combat social isolation using an alternative form of housing, one which promotes social interactions and communal involvement. This form of housing is referred to as "co- housing". Co-housing, although a popular idea in parts of North America, has proven difficult to be successfully integrated within Canadian society. Currently, in Canada, only 13 co- housing projects have, both, completed construction and then have continued on to be successfully run ${ }^{1}$. Since the land and the living spaces in a co-housing project are typically shared, and the residents must be a part of the design and build of the communities, the process rarely proceeds smoothly. Within this thesis, I will develop a Co-housing Design Handbook for new co-housing groups that would facilitate the process of planning and designing 'retrofit' co-housing for communities - a model which has yet to be experimented with in Canada. I will specifically be analyzing the city of Guelph, Ontario to exemplify how existing neighbourhoods could become retrofit co-housing communities and enhance the current social and urban fabric of the city.

${ }^{1}$ Canadian Co-housing Network, 2018 


\section{ACKNOWLEDGMENTS}

Firstly, I would like to express gratitude to my thesis advisor, Federica Goffi, for the guidance throughout the past year. Your thoughtful and kind way of sharing knowledge and sparking creativity is an inspiration and has made a great contribution to my thesis. Thank you, Federica.

To my dear friend, Gina Rehbein, for the endless support, love and laughter over these past seven years. I would not have made it through architecture school without you.

To my love, Jordan Bails, for your all the happiness you bring to my life. Thank you for the inspiration and support throughout my thesis and entire education.

Finally, to my family, for the support throughout my education and always being there to put a smile on my face when I need it the most, thank you. 


\section{TABLE OF CONTENTS}

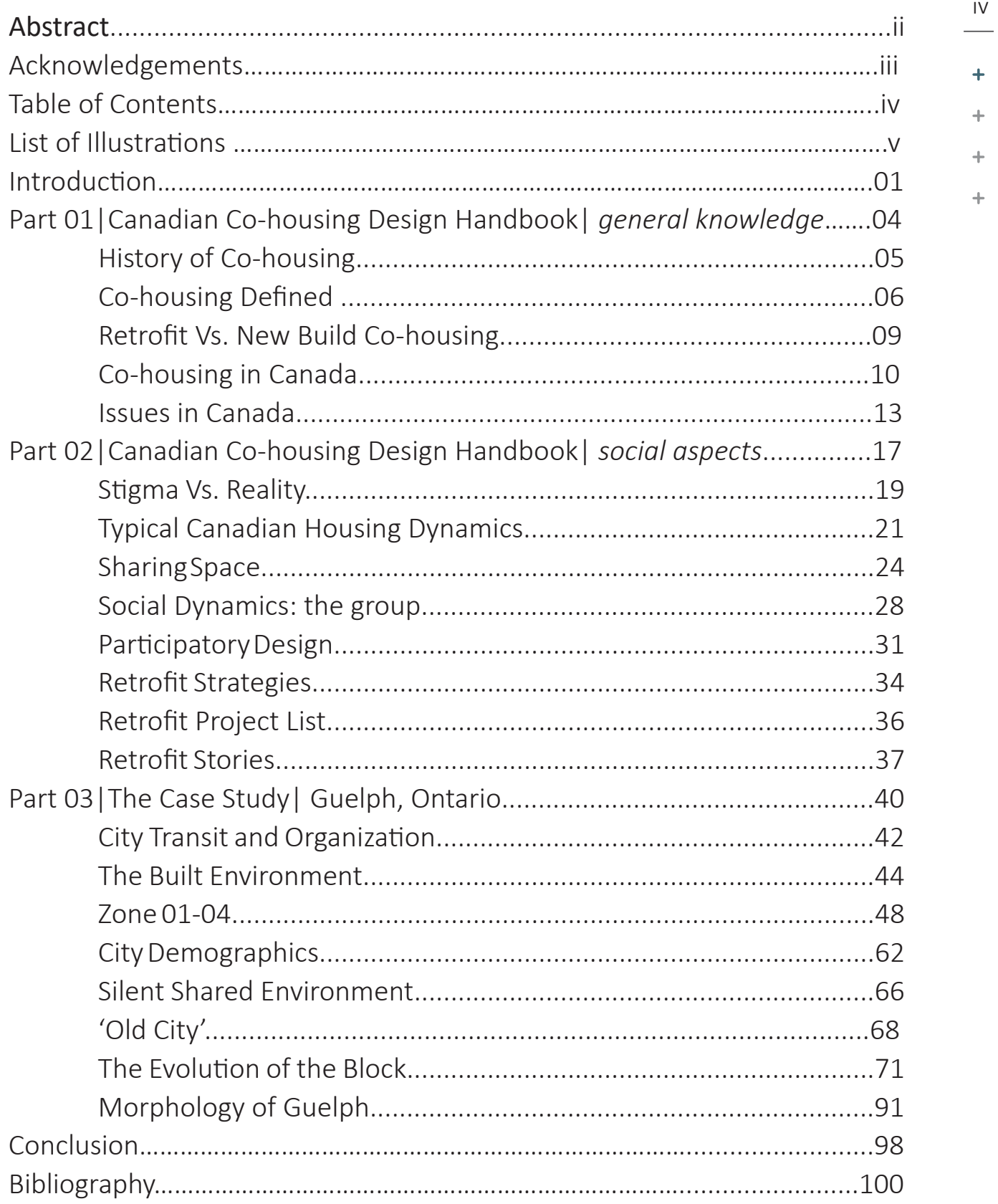




\section{LIST OF ILLUSTRATIONS}

Figure 01.

Figure 02.

Figure 03.

Figure 04.

Figure 05.

Figure 06.

Figure 07.

Figure 08.

Figure 09.

Figure 10.

Figure 11.

Figure 12.

Figure 13.

Figure 14.

Figure 15.

Figure 16.

Figure 17.

Figure 18.

Figure 19.

Figure 20.

Figure 21.

Figure 22.

Figure 23.

Figure 24.

Figure 25.

Figure 26.

Figure 27.

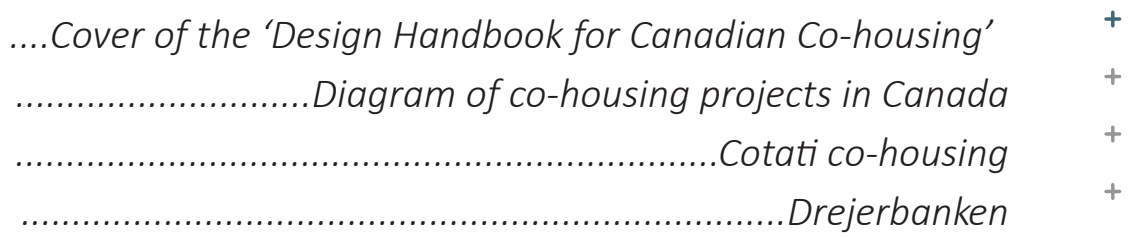

Vrijburcht co-housing community Housing in Canada time line Single detached interaction diagram Low-rise attached interaction diagram High-rise interaction diagram Spheres of sharing 'One Shared House' data Co-design activity Woongroep Lavendelstraat Haarlem Group growing diagram ....Co-design activity $\mathrm{N}$-Street co-housing $\mathrm{N}$-Street co-housing, community garden Guelph, ON aerial photograph Transit map of Guelph Built environment map of Guelph Dense area plans of Guelph .Clair neighborhood sketch Clair neighborhood plan Clair existing elevation Clair retrofit elevation Clair existing single detached neighborhood plan Clair retrofit project implemented on site 
Figure 28. Stone neighborhood sketch

Figure 29. Stone neighborhood plan

Figure 34. Stone existing elevation

Figure 30. Stone retrofit elevation

Figure 31. Stone existing low-rise attached neighborhood plan Stone retrofit project implemented on site old City sketch

Figure 35. Old City neighborhood plan

Figure 36. Old City existing elevation

Figure 37. Old City retrofit elevation

Figure 38. Figure 39.

Figure 40.

Figure 41.

Figure 42.

Figure 43.

Figure 44.

Figure 45.

Figure 46.

Figure 47.

Figure 48.

Figure 49.

Figure 50.

Figure 51.

figure 52. Existing Site Plan

Figure 53.

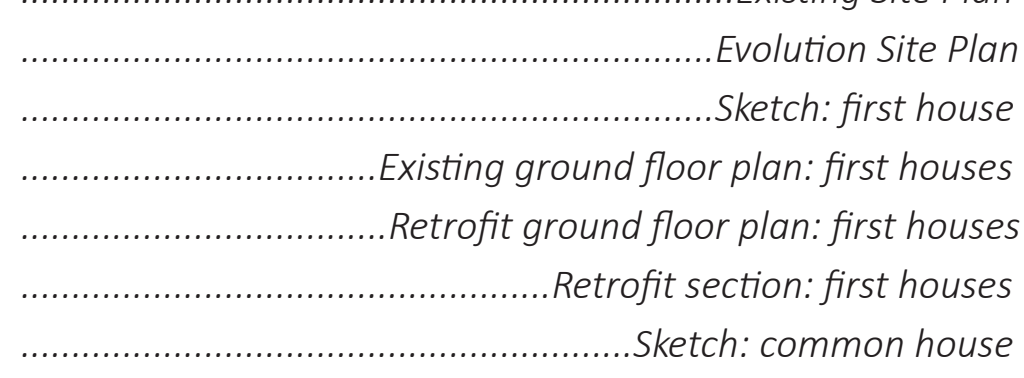

Figure 54.

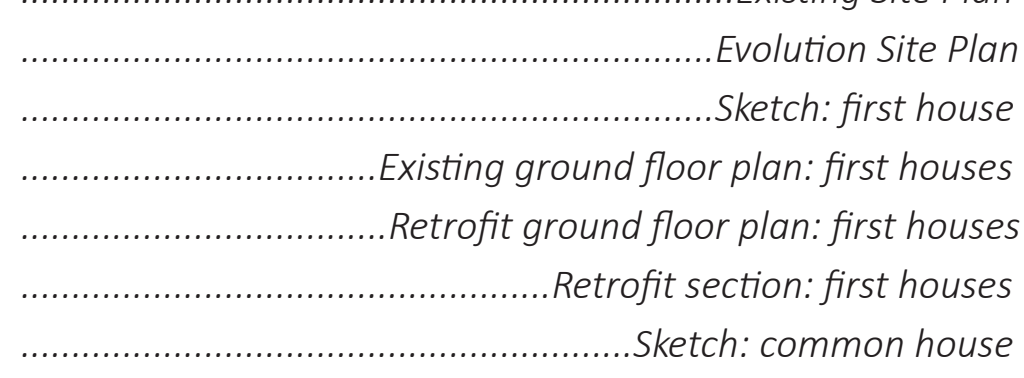

Figure 55.

Figure 56.

Figure 57. Old City existing single detached neighborhood Old City retrofit project implemented on site Two rivers sketch Two Rivers neighborhood plan Two Rivers existing warehouse plan Two Rivers retrofit project implemented on site Age Demographic map of Guelph .Economic map of Guelph Shared space map Construction dates in 'Old City' Past and expected changes in population of 'Old City' Map of 'Old City' Suburb Sketch of Glasgow // Northumberland St block 
Figure 58. Existing ground floor plan: common house

Figure 59. Retrofit Ground floor plan: common house

Figure 60. Existing Second floor plan: common house

Figure 61. Retrofit Second floor plan: common house

Figure 62. Retrofit section: common house

Figure 63.

Figure 64. Sketch: shared yard

Figure 65. Existing yard plan

Figure 66.

Figure 67. Retrofit yard plan

Figure 68. Retrofit section of yard

Figure 69. Morphology model photo Morphology map, zone 1

Figure 70. Morphology map, zone 2

Figure 71. Morphology map, zone 3

Figure 72. .Morphology map, zone 4 Morphology drawing 


\section{INTRODUCTION}

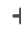

The design of a Co-housing Design Handbook has the purpose of showing the many faces of co-housing with a focus on the idea of retrofit co-housing, a model that has not yet been used within Canada. The handbook is meant to help ease the co-housing creators through the most difficult initial stages of becoming a strong cohousing group, especially via 1) participating in the process of design and 2) helping transition the group to living in a co-housing community. The handbook is meant to be used as an open source of information for Canadians interested in the concept of cohousing and/or the forming of a retrofit co-housing community.

The Handbook will lay out guidelines so that a new co-housing group can most effectively execute the necessary stages that exist in the pre-construction phase of the project. In order to determine what these stages need to be, much information will be derived from researching the popular literature on designing co-housing communities. As well, information comes from personal experience of having visited completed projects during the early developments of this thesis. The use of the knowledge gained from both sources will provide a valuable stepping-stone outline for others starting out on this journey. The Co-housing Design Handbook will include two main parts. Part one will give guidance to Canadians looking to gain helpful information about starting and living in a retrofit co- 
housing community within Canada. Part two, the case study, will look closely at a chosen Canadian city, to express ideas on how cohousing could be implemented into a city's fabric to consider how retrofit communities could arise. Within this thesis, the Guelph case study in Ontario, will be explored to show design ideas that work well in Guelph and have the possibility to be helpful for other locations. Guelph is my hometown and is very important to me as my family laid roots there in the mid 1950's, but the main reason for choosing to use Guelph as a case study is because of its need for a change from its current housing patterns. In the future, additional handbooks for different Canadian cities could also be added. housing community within Canada. Part two, the case studies, will

The Co-housing Design Handbook will touch on common issues faced by co-housing groups like: legal issues, economic issues, and housing policy. The Handbook's focus, however, will be on the relationship of design to the social issues within co-housing. The exploratory research done in creating the Handbook helped to gain insights on the social interactions that occur in co-housing groups and, also, to create a set of "desired and actual social relationships"1. As well, insights into the process of groups transitioning from typical housing to co-housing were gained. I will be focusing on the meaning of, both, common spaces and private spaces and how the careful design of

${ }^{1}$ Peplau \& Perlman, 1982 
the relationship between the two contributes to the success of the + community. I will be looking at sub questions within this greater topic; 3

i. How does the building(s) contribute to or reduce social interaction within +

a community?

ii. What are the formal and informal communal spaces needed within a co-housing community?

iii. How can traditional housing retrofit to co-housing? 


\section{1 / Design Handbook for Canadian Co-housing}

$+$

The first part of the Design Handbook will look at co-housing within Canada as a whole. It will cover issues ranging from understanding what co-housing is and how it may help Canada's current housing typologies to looking at the issues that have and may arise when creating co-housing in Canada; the first section of the book is important to understand pros and cons before considering creating co-housing in Canada.

The first section will include understanding the importance of group dynamics within a co-housing community in the design, construction and living of co-housing. It will also include strategies for the design of retrofit co-housing, to better the social interactions within a community. There are stories of retrofit co-housing success and failure as well as resources to help with the initial design stage in a co-housing community. After reading section one, readers will find that the remainder of the hand book deals with the case study section, which looks specifically for this thesis at Guelph, Ontario, but could in theory be expanded to look at different cities within Canada. 


\section{History of Co-housing}

Although the understanding and knowledge of co-housing is just beginning to gain popularity within Canada, in many other places it is not a new way of living. The concept of co-housing has many ties to the past where "most people lived in villages or tightly knit urban neighborhoods where they worked together to build a schoolhouse, raise a barn, grow crops, and celebrate the harvest" 2 . The collaborative process of living in co-housing is very similar to the past way of life to work as a group to achieve practical necessities. The first official community that was termed co-housing began in 1962, when six Danes began creating the bofællesskab or "living community", Saettedammen. To no surprise, it soon grew in popularity as many families were looking ways to relieve the tasks and pressures within the home in such an industrial age.

2 Durrett \& McCamant, 2011 


\section{Co-housing Defined}

Co-housing is a word used to describe a housing choice; to live in an environment that fosters community and collaboration. There are different forms of co-housing today, but a traditional co-housing community shares common spaces and amenities while providing privacy in separate living areas, or units. Much of co-housing research is derived from the European model, but there are many existing co-housing communities in parts of North America, outside of Canada, which may be more realistic to consider. The Co-housing Association of the United States (Coho-US), defines co-housing in the following way:

"Co-housing is an intentional community of private homes (or units) clustered around shared space. Each attached or single-family home (or unit) has traditional amenities, including a private kitchen. Shared spaces typically feature a common house (or common room), which may include a large kitchen and dining area, laundry, and recreational spaces. Shared outdoor space may include parking, walkways, open space, and gardens. Households have independent incomes and private lives, but neighbours collaboratively plan and manage community activities and shared spaces." ${ }^{3}$

The definition of co-housing is not fixed as the members of a co-housing community will each have their own understanding and meaning of the word. What seems to stay consistent is that co-housing projects are typically formed by a

3 "The Cohousing Association, 2018 
group of people who are "consciously committed to living as a community." ${ }^{\text {In }}$ mostcases, residents of co-housing groups participate in design, development and construction of the ongoing operation and upkeep of their community.

Retrofit Cohousing:

In this thesis I will be focusing on retrofit co-housing, which refers to creating co-housing by reusing the existing housing stock. In retrofit co-housing, residents of communities use the existing built environment to remodel, add on and take away building spaces in order to create the necessary spaces needed to live communally ${ }^{5}$. Retrofit co-housing can be used to transform neighbourhoods or areas to provide a stronger sense of community.

A key factor that may limit the popularity of newly built co-housing projects in Canada is the competitiveness of traditional housing developments that are in the current housing industry when acquiring new land. Traditional housing forms have proven to succeed and be a low-risk investment within Canada, but newly built co-housing communities strike developers as a higher risk process. It is hard to compete when starting out a new build co-housing project. Where as with retrofit, the initial stages have a different approach. Retrofit co-housing will still have some of the same difficulties in terms of zoning and conventional codes; however, because retrofit communities are adapted from the base of

\footnotetext{
${ }^{4}$ Belk, 2006

${ }^{5}$ Strobel, 2006: 13-18
} 
conventional housing, there may be less shared ownership than a newly built co-housing community ${ }^{6}$.

By dispersing co-housing communities into the existing housing stock social connections are made between the co-housers and their surrounding neighbours, who are living in typical housing. This relationship can create gradual growth of the greater community. Researcher, Angela Sanguinetti explains, "Non-members see and hear about a nearby cohousing community; become interested; visit; participate in community activities; rent a unit or become an affiliated member; then eventually join the community, buy a unit, or perhaps create another cohousing community"7. Implementing retrofit projects in traditional neighbourhoods can begin the opportunity of germinating co-housing attributes throughout the city.

There are different approaches to forming retrofit co-housing community as it can organically grow over a long amount of time. In communities the houses in a neighborhood will not all be side by side, they can be spread out over a block or two as it is usually a slower more organic shift into the co-housing lifestyle. The hand book gives an idea of how this type of co-housing could be achieved in cities within Canada.

\footnotetext{
${ }^{6}$ Sanguinetti, 2014: 86-96

${ }^{7} \mathrm{lbid}$
} 


\section{Retrofit vs. New-build Co-housing}

Traditional, new-build, co-housing projects that currently exist are criticized on account of their homogeneity; co-housers are typically known to

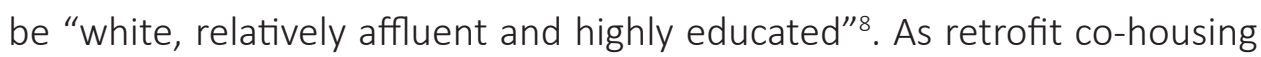
tends to be more accessible to a variety of people, retrofit communities have proven to be in more diverse neighborhoods housing a more diverse group of people (people who may be younger, lower income, have fewer assets, racial minorities, and those with less formal education) $)^{9}$. The retrofit model has proven to be an easier option for more people to start up compared to new-build co-housing as it "requires less resources" like finance, expertise, and time. The simpler, more organic, nature of the retrofit model allows people to have a taste of the co-housing lifestyle without making the large leap of commitment that a new build co-housing community requires.

\footnotetext{
${ }^{8}$ Sanguinetti, 2014: 86-96

${ }^{9}$ Ibid
} 


\section{Co-housing in Canada}

Within Canada, there is an effort to make co-housing communities more widely know and common. The Canadian Cohousing Network (CCN) is a non-profit organization that "promotes the creation of cohousing communities as a model for sustainable development by raising public awareness about cohousing and by bringing people together to form communities $^{\prime 10}$ and is working to connect people who are interested in the lifestyle. However, due to its complex nature, it has been a slow process to create communities, resulting in only 13 of which have completed construction, many of which are in Canada's west coast, (see figure 02). It is important to note that the retrofit model has not been officially created within Canada. Retrofit co-housing is an approach that has worked well in the US and is a viable option for people interested in co-housing in Canada to consider.

For most of recent Canadian history, cities have typically expanded outward, or horizontally, as people sought homes in the ever-growing suburbs. Today, however, urban growth within busier metropolitan centres is moving upward, vertically, due to an increase in multi-family dwelling. Surrounding these busier urban centres, suburban neighbourhoods are still being developed rapidly ${ }^{11}$. The growth in both the urban centres and suburban surroundings reflects a multitude of

\footnotetext{
${ }^{10}$ Canadian Cohousing Network, 2018

${ }^{11}$ Canadian Geographic, 2016
} 
population, economic and social changes within Canada. One very real social issue associated with both common styles of living in Canada is that they often foster feelings of isolation and loneliness in their inhabitants. By normalizing an antidote to this isolation within the home, co-housing, the enhanced social interactions within communities can become a part of day to day life ${ }^{12}$.

Thus far in Canada, there are only few newly built co-housing projects, as the retrofit model has not yet been adopted. The issues and reasons why co-housing has not become popular within Canada are only applicable when referring to newly built co-housing. Implementing small attributes of co-housing into our already built environment could be the start of a shift towards strengthening existing communities.

${ }^{12} \mathrm{Kim}, 2017$ 


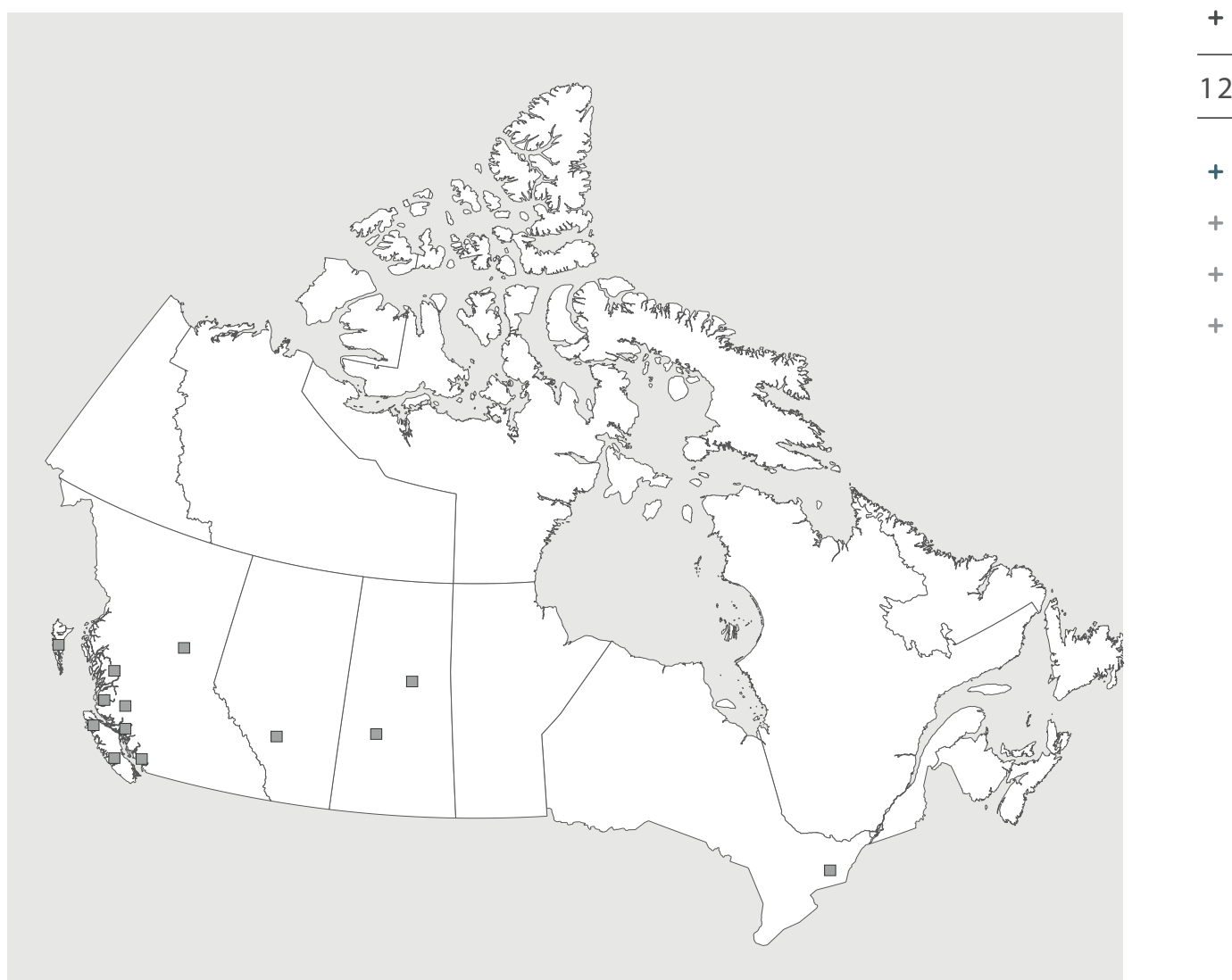

figure 02. diagram of co-housing projects in Canada 


\section{Issues within Canada}

Within Canada, there is a lack of alternative housing typologies for a multitude of reasons. In a broad sense the main reasons revolve around economic, political and social issues. Within Canada, nearly $70 \%$ of citizens own their own home, which is statistically similar in the US, UK, and $A U^{13}$. Whereas, some European countries, like Switzerland, have home ownership rates amongst their citizens that are closer to 30\%. Within Canada, it can be said that it is important to most citizens to own a home, rather than to rent or to share a dwelling. Many Canadian citizens have become accustomed to the idea and the goal of individual home ownership. For this reason, in the past, the need for alternative housing typologies had been minimal. Today, however, there is an increase in the need and want for diverse housing typologies, as there is an extraordinary rise in the number of people living alone within Canada; more than $30 \%$ of the population is living in solitude ${ }^{14}$. The current trend towards living alone is amongst the most significant social changes in the modern world - it leads to many of these people feeling socially isolated. Alternative housing typologies, like co-housing communities that are formed in a way that creates a sense of community for the residents, are becoming desired within Canada. The reasons as to why the creation of co-housing communities has proven difficult thus far within Canada vary greatly, and in this thesis, I will try to explain some of the reasons by looking

\footnotetext{
${ }^{13}$ Statistics Canada, 2017

${ }^{14}$ The Globe and Mail, 2017
} 
specifically at legal issues, economic issues, and the actual housing policy within Canada and I will look more closely at the inherent social issues.

Legal Issues

There are strict building code regulations which make it difficult to establish and run a co-housing project. In past co-housing ventures, it has proven that creating a community often occurs illegally. As Co-housing communities are often formed in an organic way, not according to typical building standards, those issues pertaining to the law need to be examined. As Chris Roth, the editor of 'Community' magazine and a member of an intentional community, explains about intentional communities, "they were built without permits and not according to the code. They lacked many bells and whistles that building codes generally require.... They were do-it-yourself dwellings whose construction and occupancy were basically victimless crimes." ${ }^{15}$. He later explains that the issues arise when the community's plans, in its attempt to do things legally and apply for the proper permits, get brought to the government agency's attention. Tensions often arise in the community because, in the past, certain community members may have pressured the group to do things that others were not comfortable with or were, in fact, illegal and contrary to the local building code. In turn, those members can hold the group ransom by threatening to expose the community or to turn the community in for any number or type of infractions in the past. In these instances, the law is being used as a means to threaten, or as a weapon, or a defense tool.

\footnotetext{
${ }^{15}$ Roth, 2015: 8-10
} 
The legal structure of a co-housing community will greatly impact the amount and type of funding they will be able to gain from chartered banks. Currently, North American banks are not comfortable with the concept of co-operative housing projects. A cooperative (co-op) model refers to residents owning shares of a building ${ }^{16}$, so banks would have to give out 'shareloans' rather than offering a traditional mortgage. Whereas a condo model is a building, or complex of buildings containing several individually owned apartments or houses. Most of the co-housing projects that do exist in North America today are using a condo structure within their community ${ }^{17}$. This is mainly because, currently, banks are not willing to make loans to coop groups unless they are non-profit rentals for low income housing (which would be subsidized by the government). The only lending institutions that are willing to loan to co-ops are a few independent credit unions. However, that itself represents a certain risk for the residents, and does not ensure financial support further down the road, as the credit unions are typically small and may not even exist after a long amount of time. Over time if co-housing in Canada becomes a more typical form of housing, banks may be more willing to support a co-operative model and provide shared loans. If you choose to use a condo structure, your co-housing group does not have a legal right to choose who lives in the houses, or units, but with co-op they do (though it has not seemed to be a large issue in the past; as most condo units in co-housing projects get sold through friends of the community).

\footnotetext{
${ }^{16}$ Jacobs, 2013

${ }^{17}$ Durrett \& McCamant, 2011
} 
Housing Policy Issues

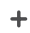

Understanding Canadian housing policy, and the way it is making the integration of co- housing communities into the fabric of our cities difficult, is an important issue. Homeownership is important to Canadians, as close to $70 \%$ of the population is part of the housing market ${ }^{18}$. Steve Pomeroy, a housing consultant and research associate at Carleton University, shows that home ownership rates among people aged 25 to 34 rose from 45.8 percent in the mid-1990s to a historic peak of 52.4 per cent in $2011^{19}$. Home ownership levels in the entire population also increased, but not by quite as much. Although co-housing promotes using land sustainably and creating strong communities, the government does not try to help subsidize co-housing communities, as the government's focus is on helping to create additional "low income" housing units in our communities. The government's housing sector has a close connection to the social service sector, both by emphasizing reducing homelessness and by improving housing availability for low-income residents. This emphasis on low income housing is important, but the remainder of the country who don't fall under the low-income demographic, which represents $6 \%$ of the housing market ${ }^{20}$, are not being addressed.

\footnotetext{
${ }^{18}$ Globe and Mail, 2018

${ }^{19} \mathrm{lbid}$

${ }^{20}$ Speer, 2017
} 


\section{2 / Social Aspects of Co-housing}

The major issues that this thesis will focus on are the social aspects of co-housing. There is a strong relationship between how co-housing communities are designed and the way the group will function socially. Social issues have prevented co-housing from becoming a commonly used housing typology within Canada, and they need to be addressed to understand the difficulty of integrating co-housing communities into our existing city fabric. Social issues within co-housing include: the stigma of the concept, the change in social dynamics of living in co-housing and the social dynamic of designing your home in a group. 


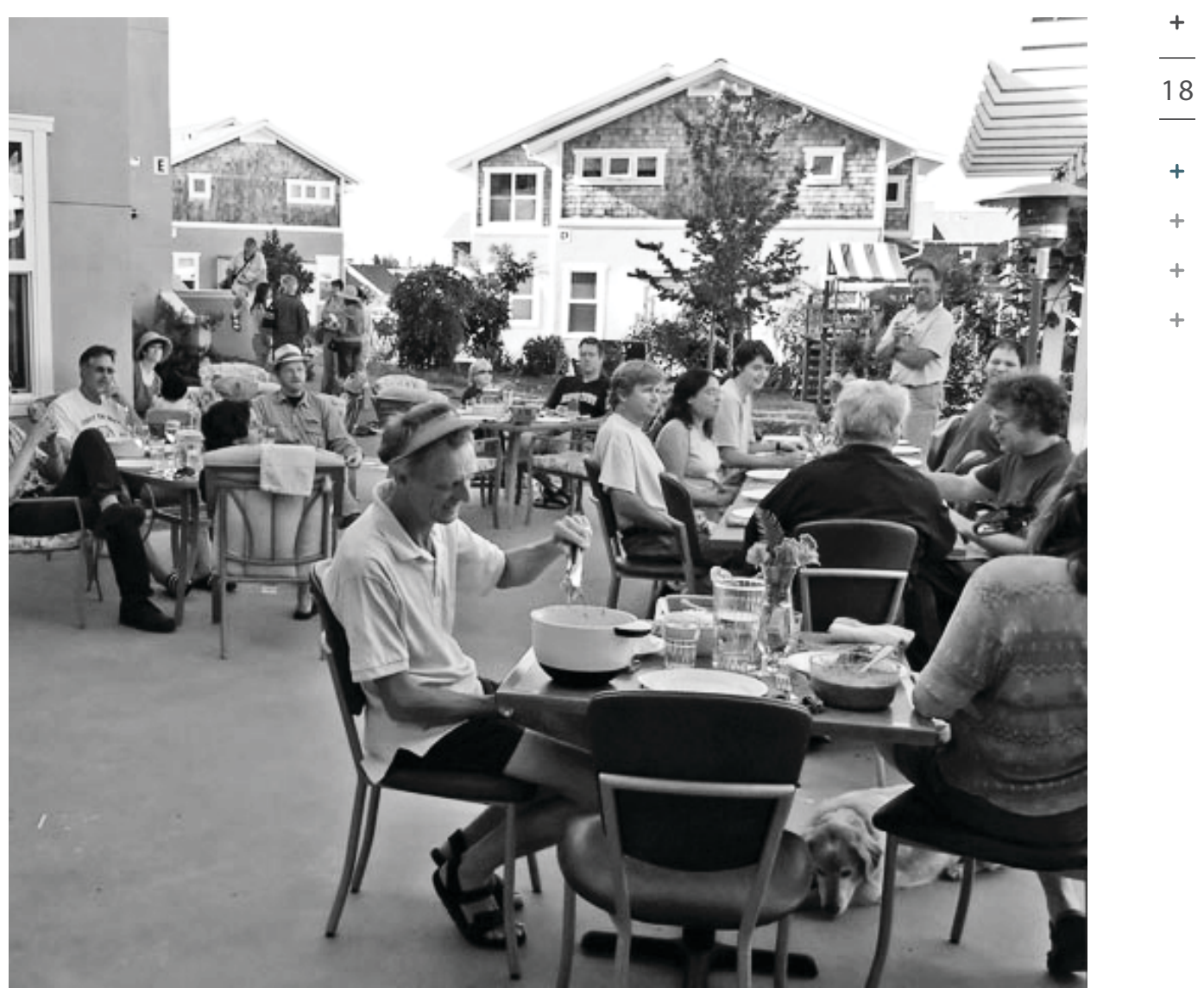

figure 03. Cotati co-housing

Durrett \& McCamant, 2011 
Stigma vs Reality

Stigma

Although co-housing is a popular housing typology in many parts of the world, like Holland, Denmark, Germany and the US, co-housing in Canada has the tendency to generate a bias thinking of being predominately for low-income housing, or for free-spirit individuals, or free-thinkers. The reason for the stigma is partially because there are so few co-housing projects built here, so it is still seen as 'taboo'. So, like the way it became popular in other countries, the more we see co-housing integrated into other types of housing, the more accepted and normalized it will become.

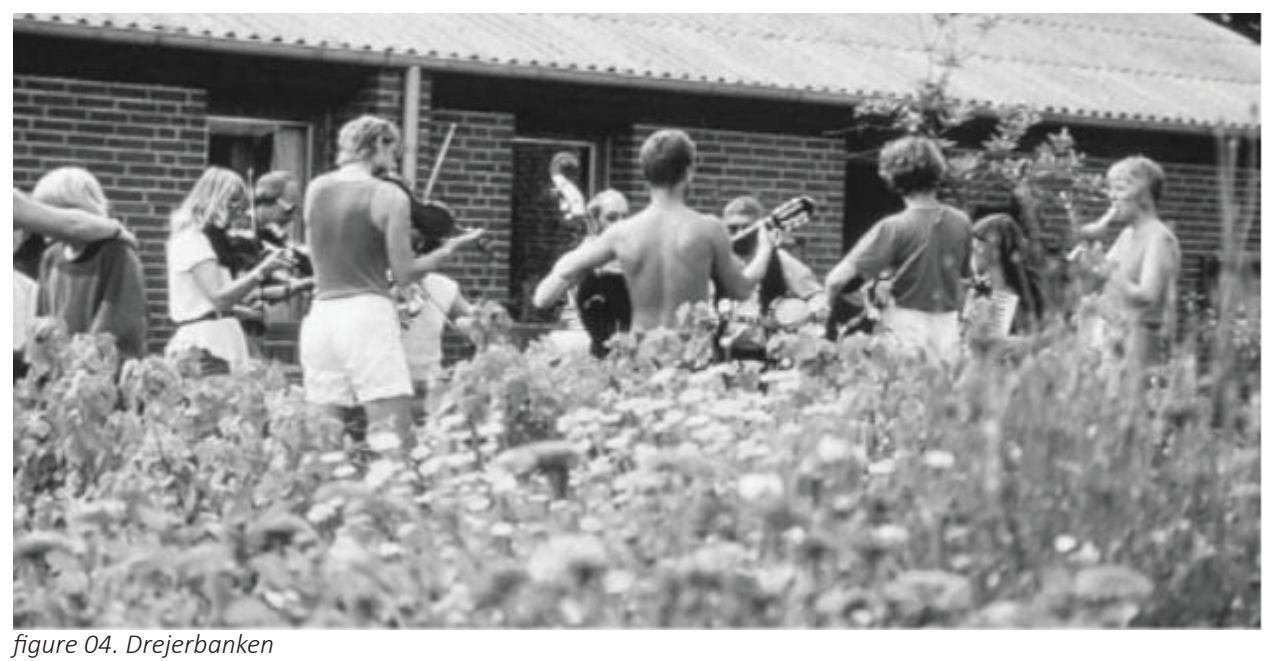

Durrett \& McCamant, 2011 
Reality

"People who choose co-housing do not seek the isolation of ideological purity, no matter how liberal, or conservative its orientation"21. Rather, they seek a sense of place that highlights an inclusive lifestyle that can include regular shared dinners; common space with cars parked at the periphery to make room for pedestrian spaces; and property shared in common or owned individually depending on preference. Co-housing is a housing choice that offers a way to make sharing spaces comfortable. Living in co-housing can mean sharing the building that your unit is in or sharing the land which your single home is on. What many people don't realize is that a family can still live in their own home and have privacy, while living in a co-housing community.

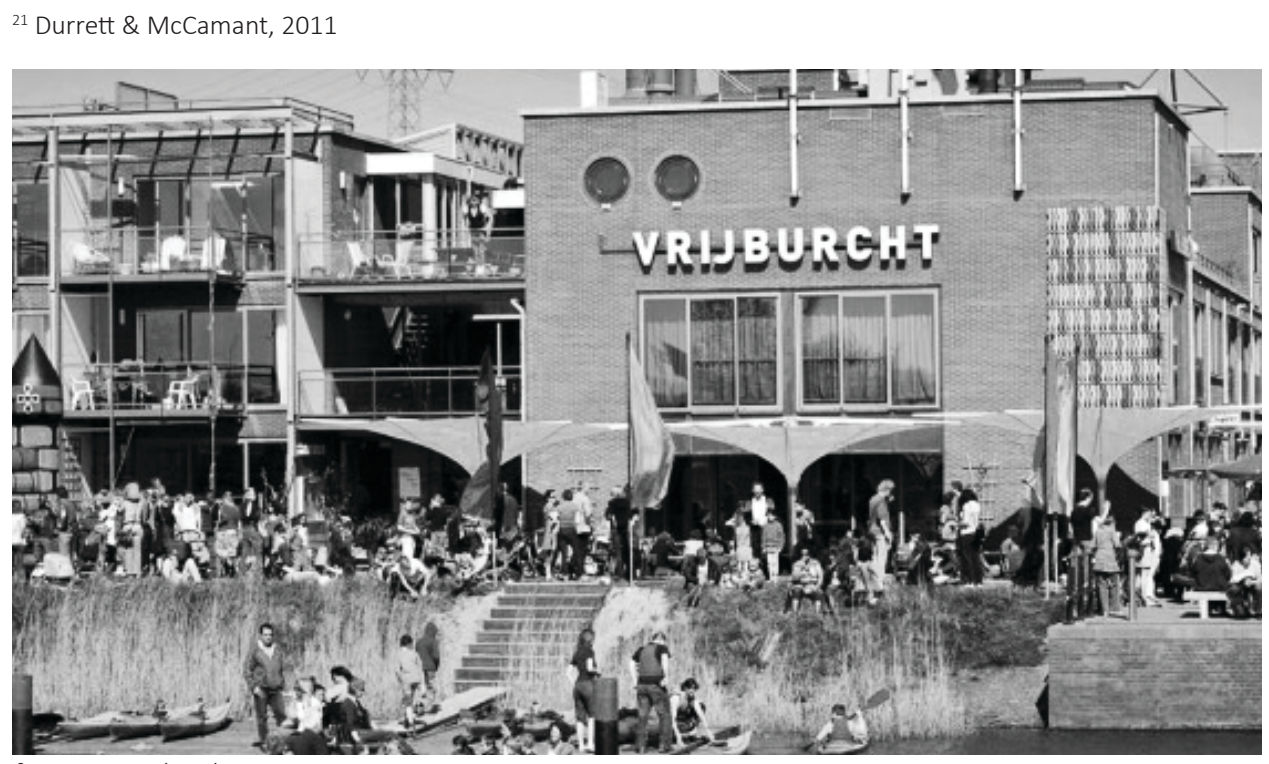

figure 05. Vrijburcht

Vrijburcht, Amsterdam 


\section{Typical Canadian Housing Dynamics}

In past Canadian history cities have typically grown outward, especially in the age of the baby boomers. Much of this growth has been in single detached houses in the suburbs. Recently the growth has been moving vertically in apartments and apartment-condominiums. This vertical growth reflects life choice, demographics, economic and social changes. Some of these changes include "increasing immigration, declining household size, changing household characteristics, an aging population, high prices of single-family homes in some areas, land shortages and development policies in Canada's major cities". ${ }^{22}$ Since 2012, apartments and apartment condominiums have become the most constructed residential building, this change has not occurred since 1973. Over the past 40 years, apartments and single-family homes have accounted for $85 \%$ of new construction. For a visual representation, refer to the time line in figure 06.

${ }^{22}$ Statistics Canada, 2017

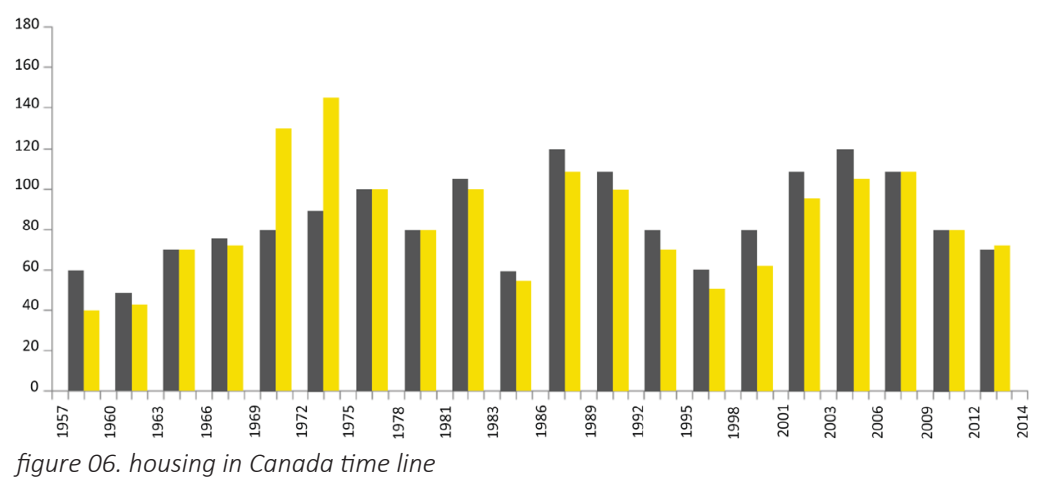


Statistics Canada shared data that within Canada the single detached, low rise attached, and high-rise apartments or condos are the most popular housing $+$ typologies to live in. These typical housing typologies do not foster as much social interactions within their built environment as a co-housing setting does.

Figure 07 explains the interactions which occur in a neighborhood of single detached homes. Each house typically has its own driveway, mailbox, backyard and house. This housing typology does not have space for many informal interactions to occurs (aside from running into neighbors on the sidewalk / street). Figure 08 explains low rise attached homes. They usually do have some shared outside elements like a parking area, garbage area, or the mailbox, so in those designated spaces there is a higher chance of inhabitants having informal interactions. Figure 09 explains the high-rise apartment, or condo, where we see more informal interaction spaces like the parking area, garbage area, mailbox, elevator and hallways. As well as semi-formal interaction space-like a gym, shared rooftop space, or event room (where inhabitants can either have informal interactions, or planned interactions within their community). 


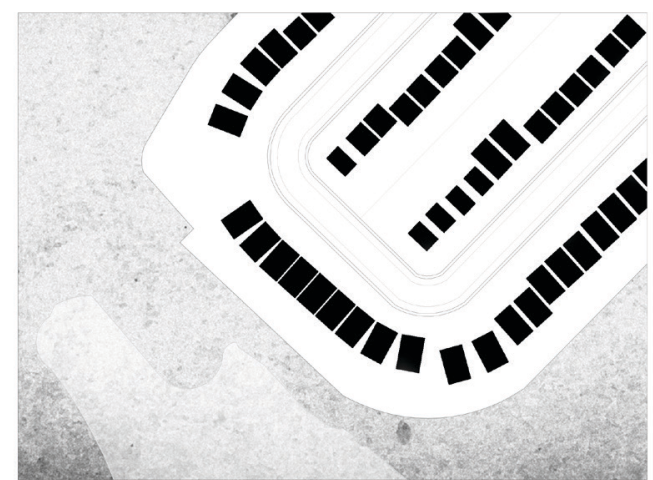

figure 07. single detached interaction diagram

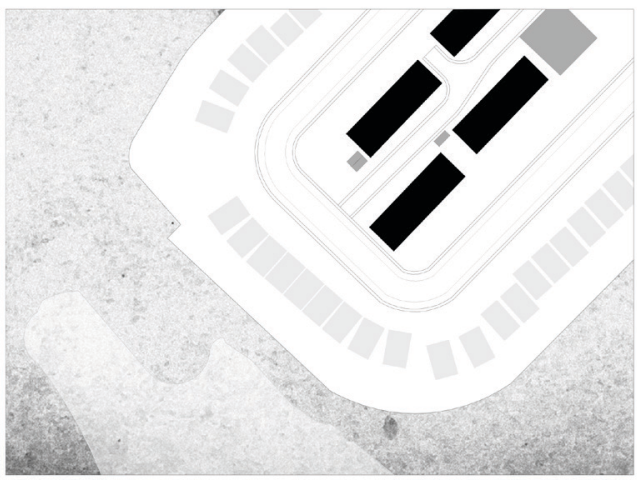

figure 08. lowrise attached interaction diagram

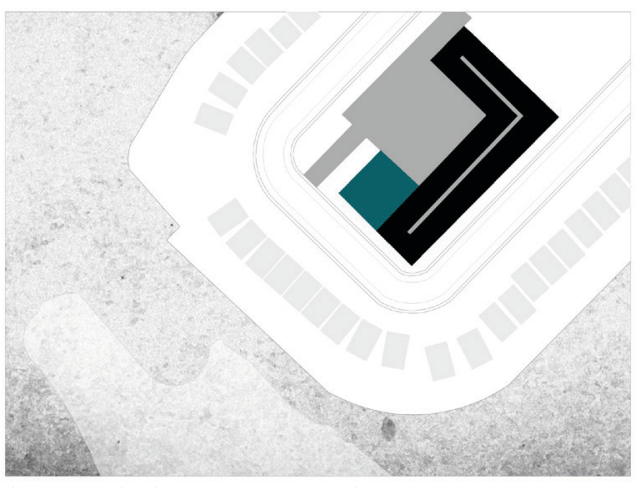

figure 09. high rise interaction diagram 


\section{Sharing Space}

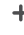

Within co-housing, private, informal, and semi-formal interactions do occur, along with a new form of interaction: formal interactions. This diagram, figure 10, explains these different interactions present and what architectural spaces we could see these interactions occur within. In figure 11 , the spheres show a percentage of people willing to share each space. When starting to co-design a community, talking about this is important.

The following activity in, figure 12, the handbook, entitled 'what would you share in your home?', is for a group to fill out together. Groups of participants would be asked to circle the place on the yellow line that fits the entire groups response the most. The possible answers include: NO- no one in the group would share this; MAYBE- half of the group would share this; SHARE-the whole group would like to share this space or activity. For example, if 12 out of the 20 people in your group would want to share a studio space, circle 1 point past maybe.

A groups definition of community will likely vary from others and that is why it is important to do activities like the one mentioned above to determine what works well. However, there are communities that have shared their knowledge of what has worked and what hasn't. The information below are features that the Canadian Cohousing Network notes to be essential when defining a cohousing community ${ }^{23}$.

${ }^{23}$ Canadian Cohousing Network, 2018 
1. Participatory Process: "Residents participate in the planning and design development of the community so that it directly responds to their needs." Within this handbook there are worksheets to help groups collaborate more during the design process.

2. Neighbourhood Design: "The physical design encourages a sense of community as well as maintaining the option for privacy... it is important that residents are involved in the decision making and the intent must be to create a strong community with design as one of the facilitators."

3. Private Homes Supplemented by common facilities: "Common facilities are designed for daily use; they are an integral part of the community and typically include a dining area, sitting are, children's play room, guest room, as well as garden and other amenities."

\section{Resident Management}

5. Non-hierarchical Structure and Decision-making: "There are leadership roles, but not leaders. The community is not dependent on any one person." 

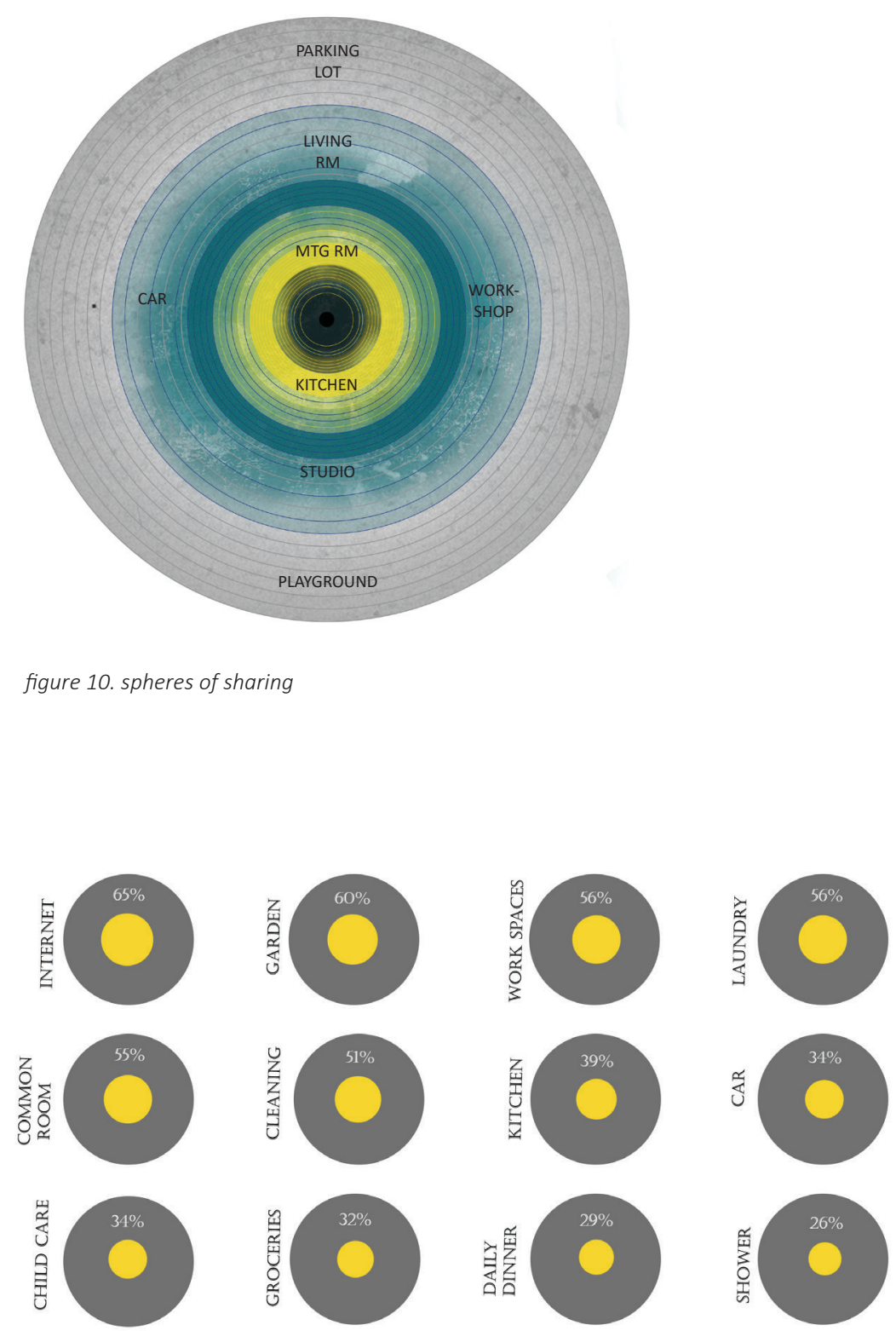

figure 11. what items people will share 


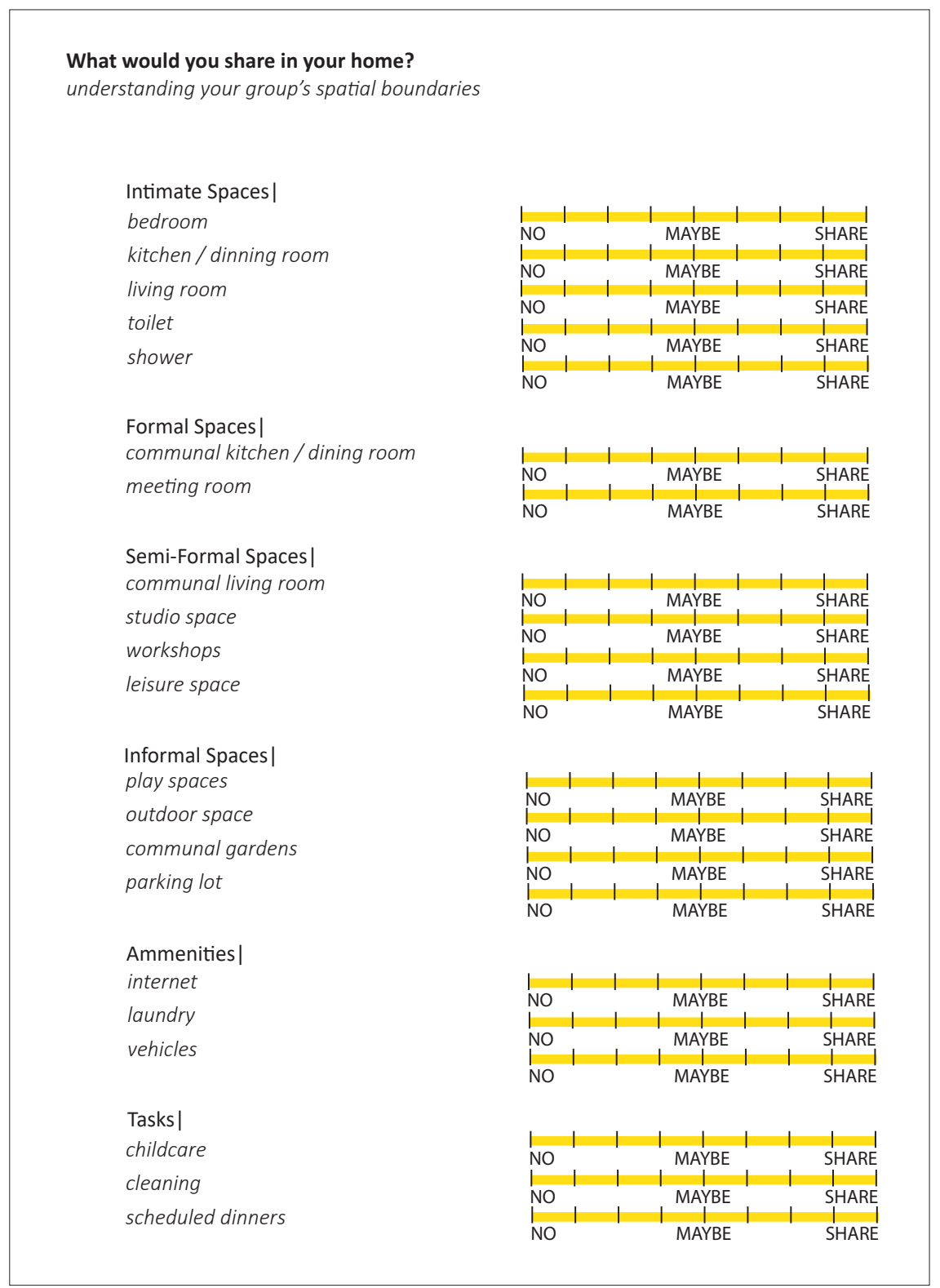

figure 12. co-design activity 


\section{Social Dynamics: The Group}

The most important aspect of co-housing is, of course, the people involved i.e. the group. The group's success will determine if the co-housing project will 1) be created and 2) function well once it is built. When building the initial group, the age, set of values, goals and behavior of new co-housing members are all factors to consider, as they will have an influence on the success of your co-housing community ${ }^{24}$. There is no one right answer for a group's success, as the group dynamic is determined case by case, depending on the people who encompass it. A strategy for those interested in starting a co-housing project is to learn from the stories of the many projects that are successful. A group that has been functioning since 1982, Woongroep Lavendelstraat Haarlem, is a project to learn from.

At the beginning of the thesis, during the month of October 2018, I was able to travel to Holland to learn the Dutch approach to co-housing and gain a better understanding of the life style. While I was there one of the founders of Woongroep showed me around the building and let me take part in an average day in the community. From the outside, Woongroep looks like many urban mid-rise apartment buildings' in the area and blends into its surrounding neighbourhood. Yet, on the inside, it is a combination of a few different accommodation types designed around a naturally-lit internal

\footnotetext{
${ }^{24}$ Durrett \& McCamant, 2011
} 
street. The community was created with both architect, Menno Vissers, and + contractor, Joop Klein as group members from the $\operatorname{start}^{25}$. So they were able 29 to grow the community organically over the years with the help of community members, friends and family. The community has extensive common space and provides space for helping up to six non community members in need at a time ${ }^{26}$. Woongroep is a great example of high-density living in co-housing.

25 Woongroep Lavendelstraat Haarlem, 2018

${ }^{26}$ Killock, 2013 


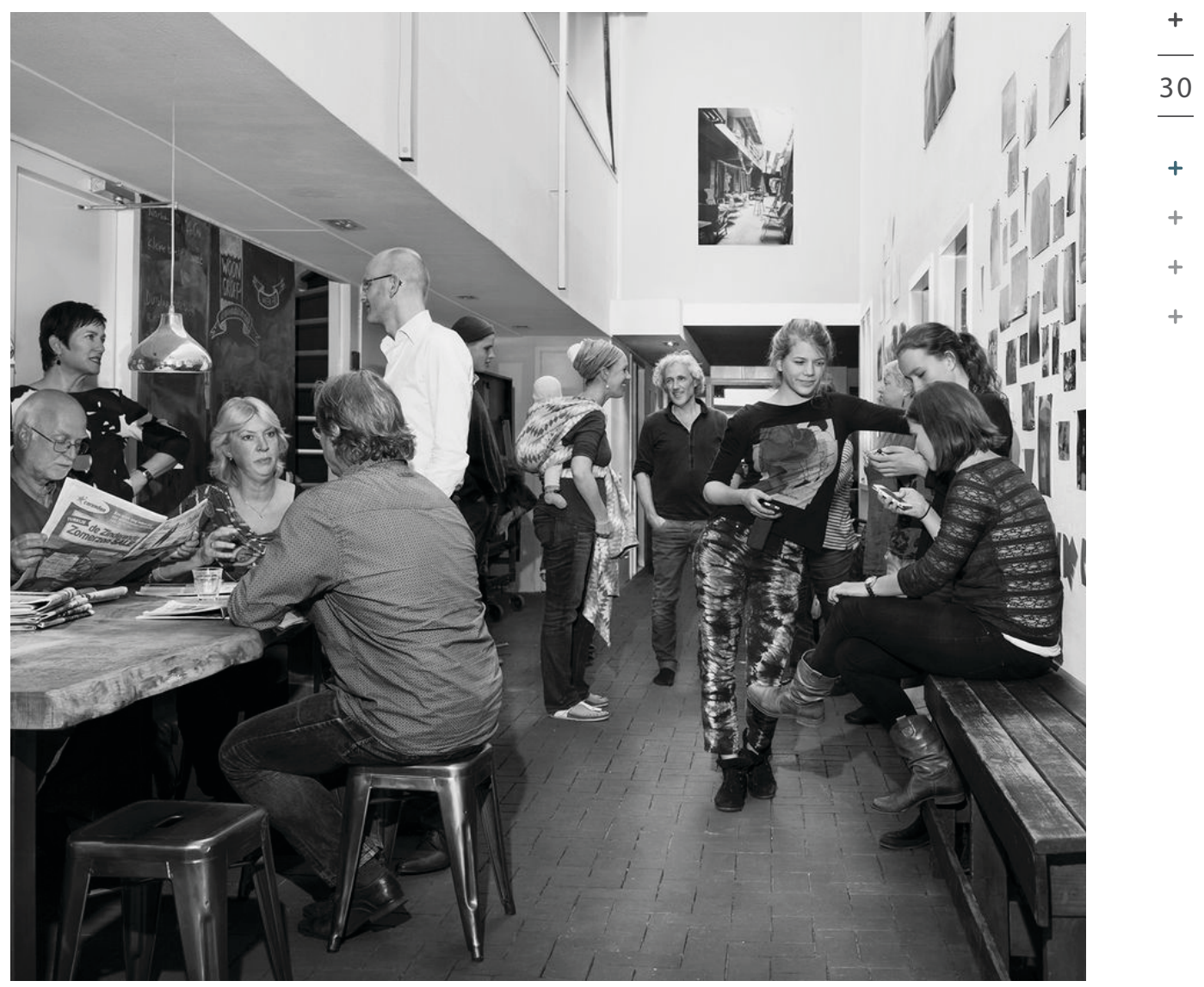

figure 13. Woongroep Lavendelstraat Haarlem

Woongroep Lavendelstraat Haarlem, 2018 


\section{Participatory Design}

A predominant feature of co-housing is that the group takes responsibility for the planning, developing and managing of their community. Of course, if the group does not include participants with a background in the knowledge needed to successfully design, or build something, external sources will be obtained, but it is still the group that chooses them and works with them. Co-housing is planned in various stages. Typically, these stages are:

1. Research and Planning | Together a group can investigate past co-housing ventures to understand what has been successful or not. This planning will include researching many factors like raising funds, finding the correct site, the size of the group, etc.

2. Design | This stage can last a very long time (usually several years), as all of the group members most likely will not have the exact same vision. It is important to work as a group in this manner and decide what makes the most sense.

3. Construction | During the planning and building stages, the group develops a feeling of community ${ }^{27}$. It is an integral part of living in co-housing, as the experience of creating together becomes part of the history of the group, which builds on the sense of community.

${ }^{27}$ Durrett \& McCamant, 2011 
Building and expanding the community is also something that will need to be achieved as a group. Group dynamic thinking can be difficult when a community is constantly changing, by gaining and losing members. Having a time line for when your community will stabilize is important. For example, if one year the community is growing and adding new members, it is intelligent that the following year (or however much time is needed), the group takes time to stabilize and learn how to work well together before making more changes. See figure 14 for a group working in this way. Figure 15 is a group activity to use when you are looking to ways to get to know the new members of the community. Activities like this can be used when you are in the building and expanding time period.

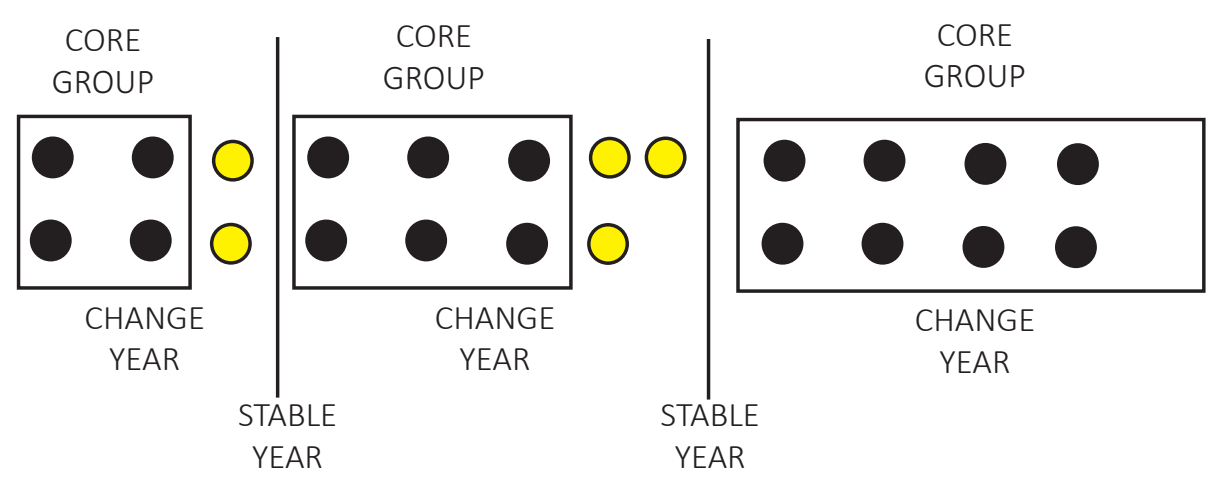

figure 14. Group growing diagram 
Group Activity: Scavenger Hunt

1. Has lived in a co-housing community before

2. Knows another language other than English

3. Has studied outside of Canada

4. Is the youngest sibling

5. Was not born in Canada

6. Has had a pet rabbit

7. Grew up spending summers at their grandparents

8. Knows a musical instrument

9. Went to a grade school with a graduating class of less that 20 people

10. Has been to South East Asia

*Adapted from tee group, https://treegroup.info

figure 15. co-design activity 


\section{Retrofit Strategies}

'Retrofit co-housing' is a term not broad enough for its description and meaning. Simply turning existing land into a co-housing community is not the typical description of 'Retrofit co-housing'. The community can grow over a long amount of time, and the houses in a neighborhood do not all need to be side by side, the houses can be spread out even over a block or two. A better term may be 'neighborhood co-housing'28.

An individual living in N Street co-housing explains, "It can be a long time before you take over a block. It can be 10 to 20 years before you have all the houses on the block all together so in the meantime you might have houses that are non contiguous or they may be in the neighborhood but they eventually maybe have one common house, that they have the shared tools in, they have shared meals, they have their guest bedrooms, but it doesn't have to be contiguous to everybody else's house in the neighborhood so it broadens the vision of what we're really talking about ${ }^{29 \prime \prime}$.

Co-housing communities can be retrofitted into many different housing typologies, but there are factors that make it a smoother process. 'House Planning Help' has noted that these factors include:

${ }^{28}$ Durrett \& McCamant, 2011

${ }^{29}$ House Planning Help, 2013 
To live in co-housing is long a process that takes a lot of work as a group. If you move into one large existing building, this often is harder than a neighborhood for two reasons. 1) The cost of a large building occurs all at once (so there needs to be a large amount of start-up funding) and is much bigger than a single home. 2) The construction work to turn it into the space your community wants is much greater and will take more resources and funds.

2. Houses Where the kitchens or living rooms face the back yard This is the space of the home that will face the shared space (joined backyards), people are more likely to interact in these rooms if they see other neighbors walking by. Also having the bedrooms facing the shared space would be tough to provide privacy.

\section{Amenities Nearby}

This includes good schools, proximity to public transit and close public areas like shops or libraries.

\section{Rundown Homes}

Finding homes in an area that is rundown has benefits. In a high-income area, people do not move very often and there are also fewer rental opportunities. A lower income area where there are more properties to rent means that the community can grow quicker. Additionally, the houses can be improved over time. 


\section{Retrofit Project List}

RETROFIT PROJECT |

Los Angeles Eco-Village 1985

LA, CA

45

Over time

\begin{tabular}{lllrr} 
& & LINK: http://laecovillage.org/ \\
\hline N Street Co-housing & 1986 & Davis, CA & 18 & Over time
\end{tabular}$+$

LINK: http://nstreetcohousing.org/

\begin{tabular}{lllll}
\hline Doyle Street Co-housing & 1992 & Emeryville, CA 12 & At once
\end{tabular}

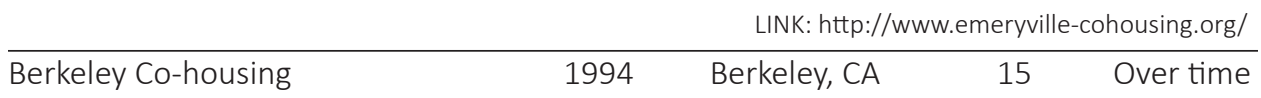

LINK: https://www.cohousing.org/Berkeley

\begin{tabular}{lllll}
\hline Andersen Lane Co-housing & 1994 & Minneapolis, MN & 4 & Over time
\end{tabular}

LINK: http://mn.cohousing.org/retrofit/andersenlane

\begin{tabular}{lllll}
\hline Hidden Creek Co-housing & 2005 & Oakland, CA & 11 & Over time
\end{tabular}

LINK: http://www.hiddencreekcommunity.com

\begin{tabular}{lllll}
\hline New Brighton Co-housing & 2007 & Aptos, CA & 7 & Over time
\end{tabular}

LINK: http://www.newbrightoncohousing.org/about-us/

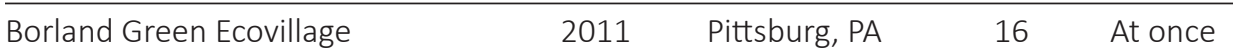

LINK: http://mn.cohousing.org/retrofit/borland.htm

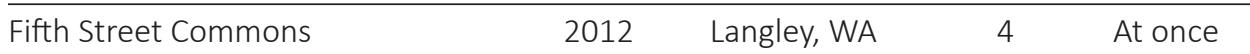

LINK: https://fifthstreetcommons.com/

The Orchard

2012

Oakland, CA

Over time

LINK: http://orchardhousingsociety.co.uk 


\section{Retrofit Stories}

$N$ Street Co-housing is a project that consists of 21 single detached homes. It started out as two neighbors taking down the fence that separated their homes and sharing the yard and outdoor chores. When this happened, other neighbors on the block liked the idea and wanted to join in. Those who joined also began sharing meals together and decided that they wanted to form a co-housing community together.

The way the group grew was by making it clear to neighboring homeowners in the area that should they want to sell their houses, someone from N Street Co-housing would be interested in buying. This was tempting for some neighbors as it meant that they could sell the home without having to use a real-estate agent, resulting in saving money ( $6 \%$ of the house cost). Another way that many other members joined was through renting a portion of one of the houses on the street, this was common as there were many rental properties on the block. N Street co-housing continues to grow slowly, adding one house at a time. They currently have expanded to 20 houses, 13 homes on "N" Street that back up to 7 homes on the adjacent street. By removing the fences in their backyards they are able to share a vegetable garden, play structure, hot tub, chicken coop, pond and more. Four times per week the community shares meals together in their common house ${ }^{30}$.

30 N Street Cohousing, 2018 

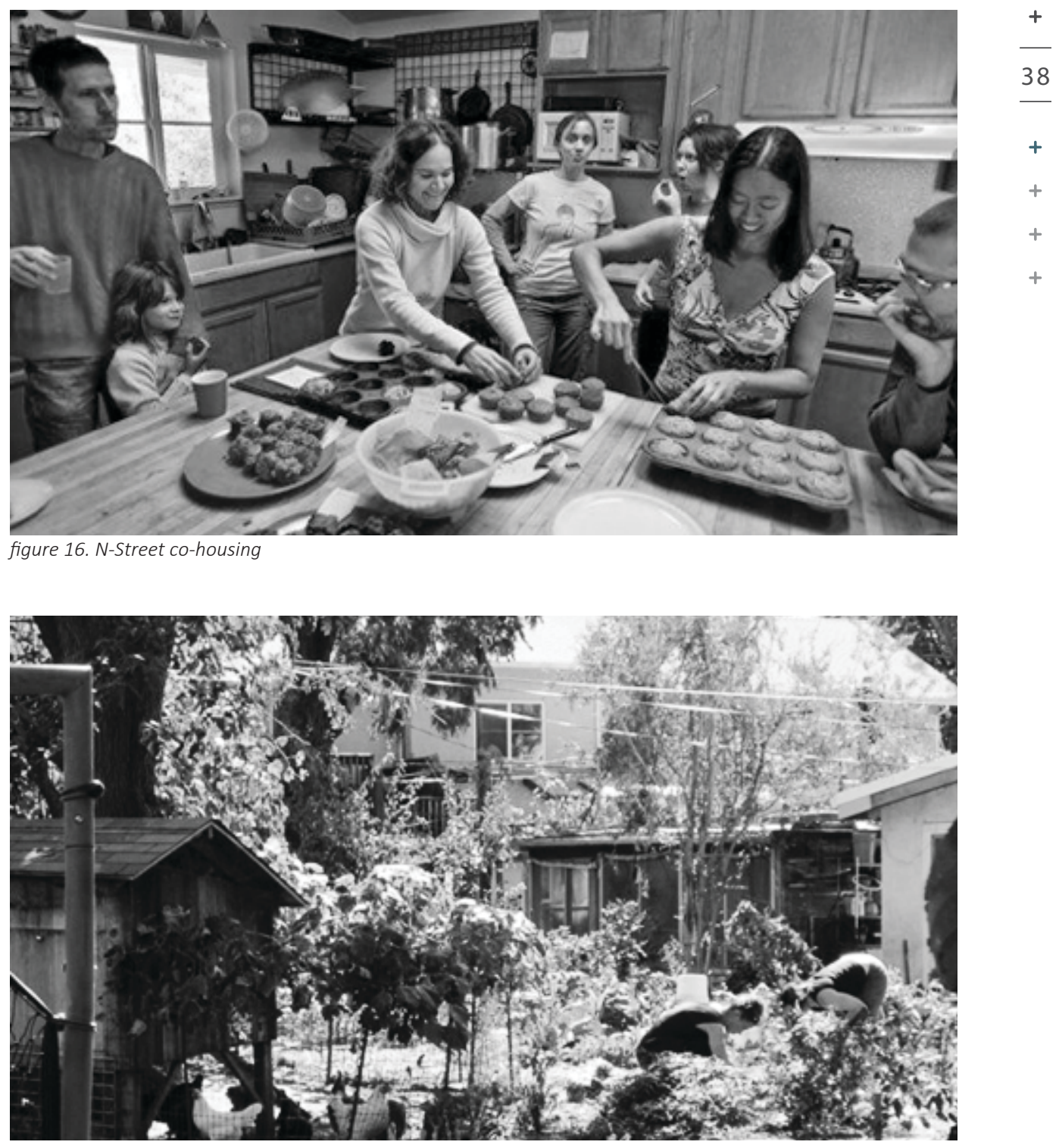

figure 17. N-Street co-housing, community garden

Durrett \& McCamant, 2011 
Kollontai +

As well as looking at success stories, it is important to look at the projects 39 that did not work. Kollontai is a co-housing project that started in Amsterdam in 1980 and only lasted for 5 years. It housed 8 single women and their children. The group was formed by creating ads in a local paper in search for women to join the house. This is where the problems in the house stand out, instead of a group forming organically, and being designed together, the members of the house started living together as complete strangers. Almost all the rooms in the house were shared: including kitchen, bathrooms, and storage. The only private space was in individual bedrooms. The lack of privacy was the major reason that the project failed. The group got along only for the first few months and then slowly broke apart losing one member at a time until it shut down in $1985^{31}$. 


\section{3 / Case Study, Guelph Ontario}

With the ease that the design handbook provides, co-housing could be widely integrated into existing neighborhoods to combat social isolation for many Canadian cities. The city of Guelph, Ontario will be used as a case study. I will use the existing neighborhoods in Guelph to show that co-housing can improve the current fabric of the city by retrofitting communities within existing housing typologies. Although Guelph was founded in the mid-1800s, a large part of its urban space was created after the Second World War. The built environment created displays the characteristic low-density "suburban sprawl" 32 land use. Many Canadian cities also have been developed in this sprawling manner, in these cases we need to make greater choices in housing to better meet the needs of the current changing demographics. Aside from the need for an urban fabric alteration, Guelph also has groups that are already interested in living in co-housing. In 2017 I was working for an architecture firm that was in conversation with a group of people interested in creating a co-housing project and recently, the Guelph Mercury has put out an article showing that there is currently a proposal for a 21-unit co-housing apartment building. The apartment building is planned to replace 3 existing single detached homes with a multi-unit residential apartment. The proposal is soon to have a public meeting at city hall and is pending approval for the development ${ }^{33}$.

\footnotetext{
${ }^{32}$ Nechyba \& Walsh, 2004

${ }^{33}$ Mcnaughton, 2019
} 


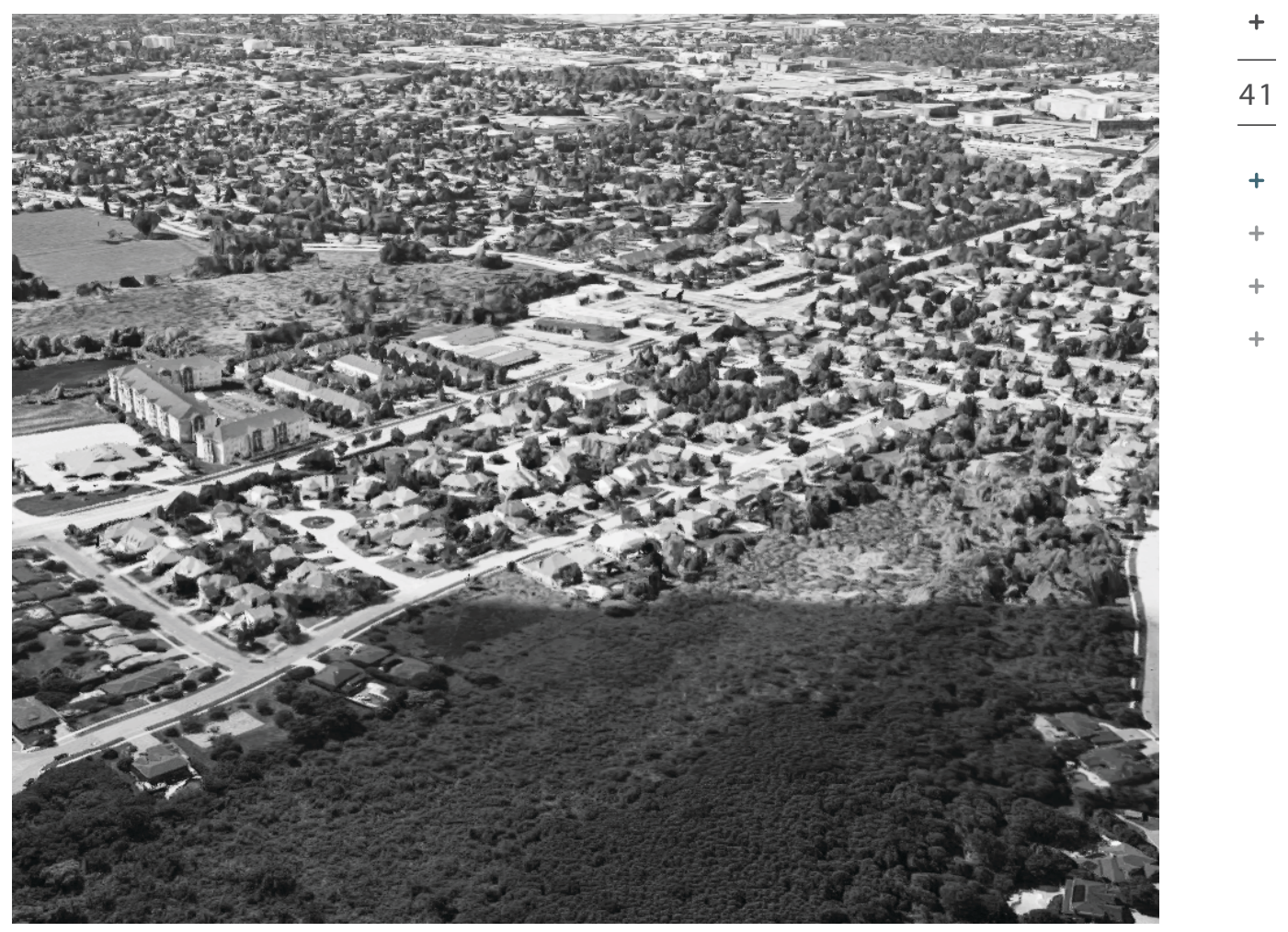

figure 18. Guelph, ON aerial photograph 


\section{City Transit and Organization}

Guelph Ontario is a city approximately 100 kilometers southwest of Toronto. Guelph is geographically isolated fromboth the GreaterTorontoArea(GTA)and the Kitchener-Waterloo-Cambridge Tri-City, the largest nearby urban hubs. Due to this isolation, Guelph can represent a typical North American metro area in microcosm- large enough to have many of the features of larger cities, but small enough (home to 130,000 people) ${ }^{34}$ to make a case for smaller cities.

The city does have public transit, which is outlined on the map, figure 19 , in thick black lines. The Yellow route is the most used transit road in Guelph, where many of the buses drive down at some point in their route. The city is more commonly explored by personal vehicle than public transit. There is a major highway, the Hanlon, which is shown on the map in blue. The map also shows the major areas of the city, in text. As well as having "+" symbols to express where the projected growth areas of the city are.

${ }^{34}$ Mcnaughton, 2019 


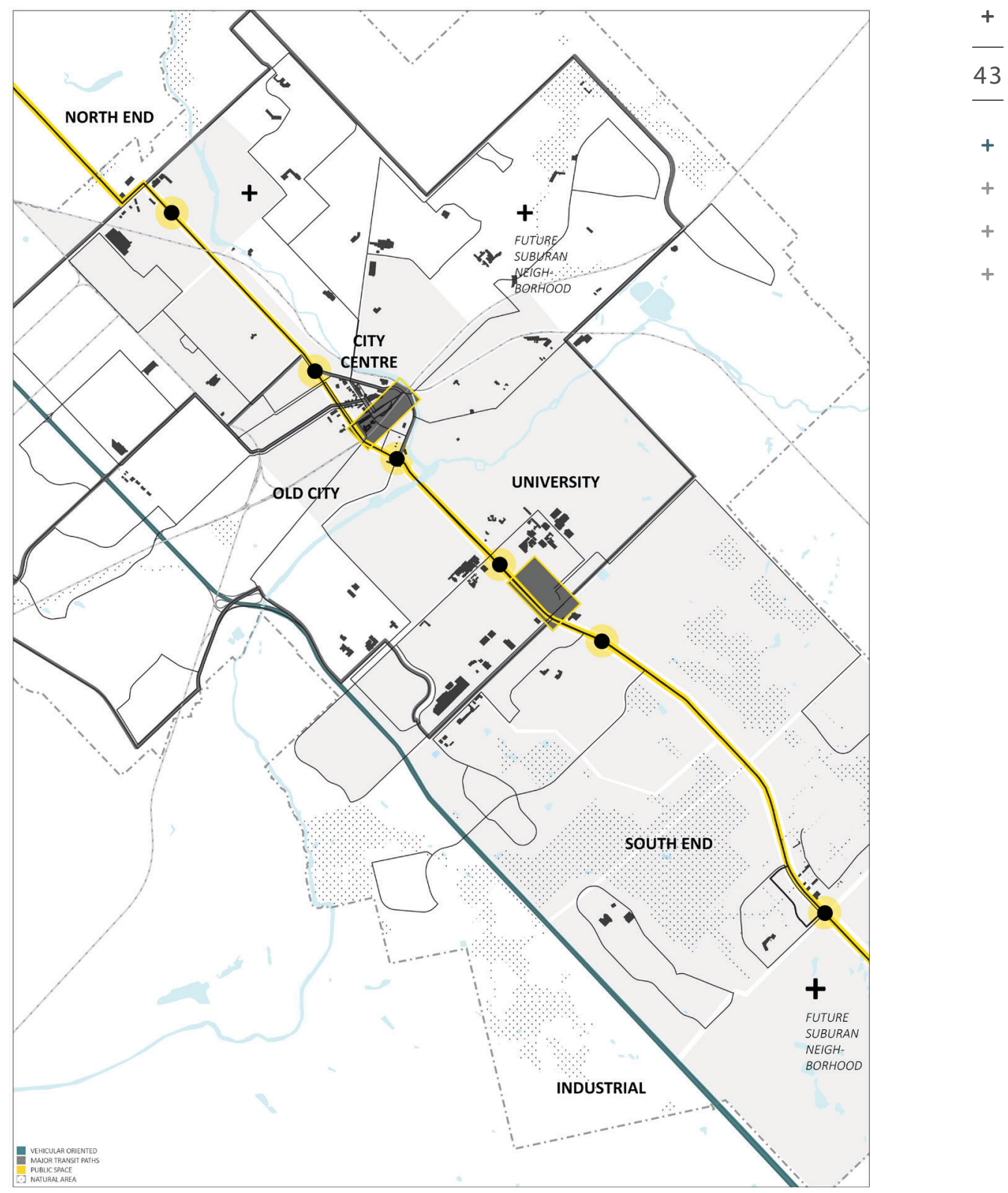

figure 19. transit map of Guelph 


\section{Built Environment}

outward growth of many single detached homes. Due to this growth many of these suburban neighborhoods are isolated from the communal cores within Guelph and lack a sense of community. By introducing co-housing, instead of continuing this form of housing growth, residents will be able to experience life communally instead of in isolation.

In figure 20, I created a map of today's built environment, the public areas (highlighted in yellow), is a space where new, or more spontaneous interactions are likely to occur. The highlighted areas were deemed "public" buildings as they are spaces which can hold three types of interactions; formal interactions, semi-formal interactions and informal interactions. Theses spaces were mainly commercial, recreational and communal buildings. The map highlights the ends of the city that have grown outward - the south and east ends. By highlighting the public areas, we start to see the dense nodes of the city. This map highlights four specific suburbs that are close to these public areas and would be viable options to retrofit co-housing communities into these existing neighborhoods. These four zones will be looked at in greater detail to decipher which areas are most suitable to implement retrofit co-housing communities into. 
The nodes of the city that were the densest in terms of shared or public space, outlined in figure 20, are where I will show a representation of a retrofit co-housing community. Figure 21 shows a larger scale of each of these suburbs, highlighting the location of the designed communities. In all cases a different housing typology will be used as the existing model to display the different possibilities of how a retrofit community could be implemented on each site. Zones 1-4 will be tested in the following pages. 


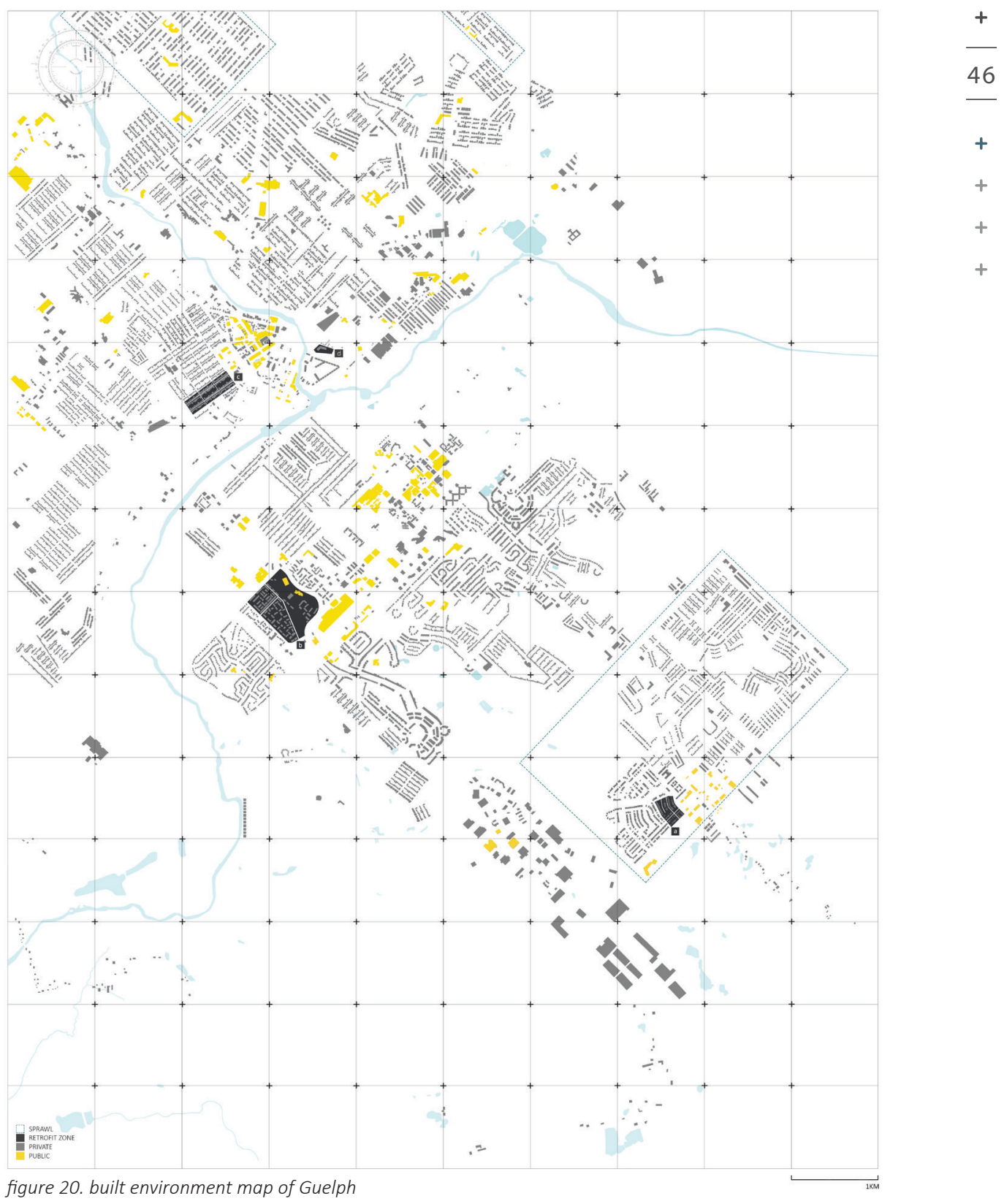



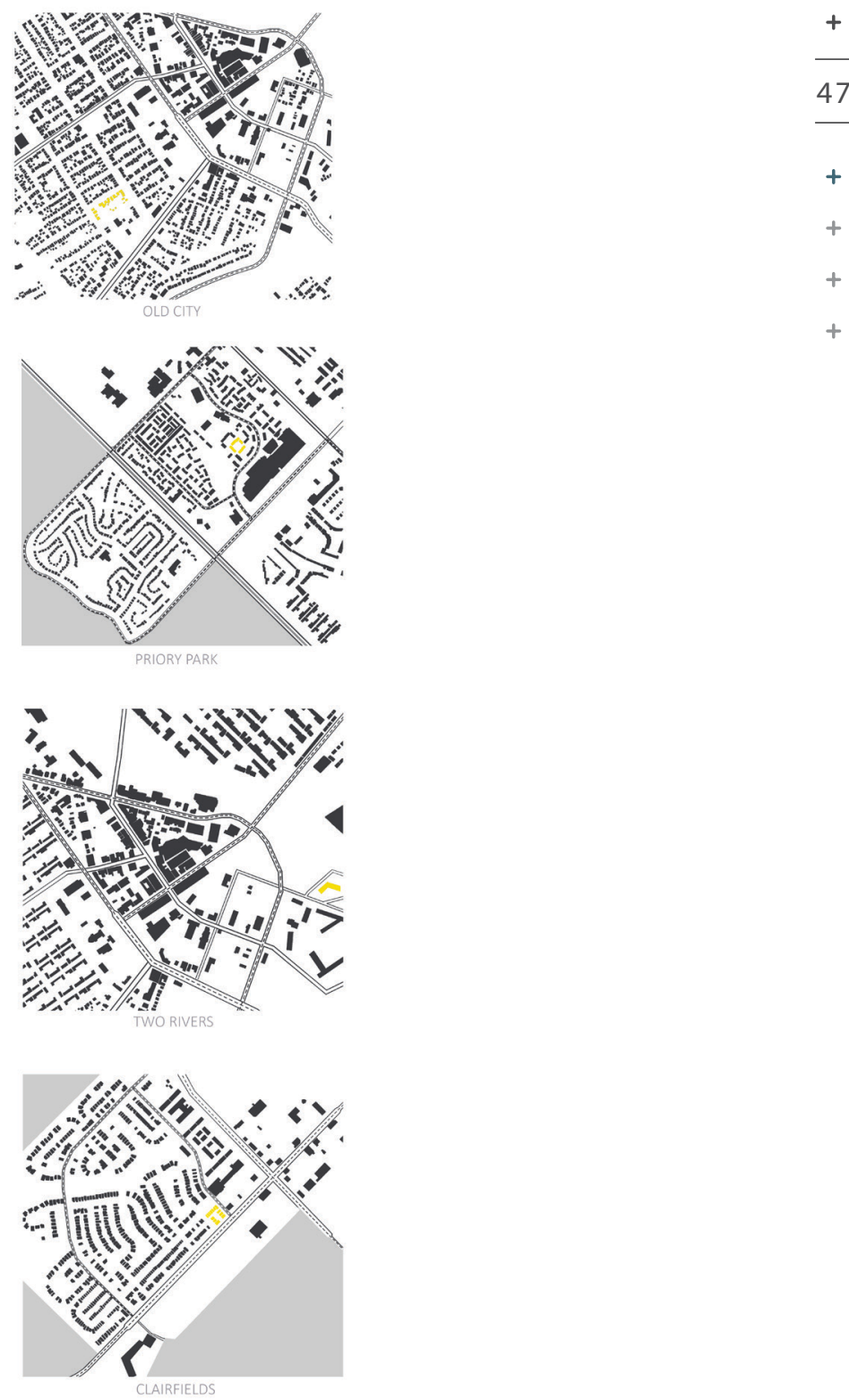

figure 21. dense area plans of Guelph (NTS) 
The Clair area, shown in figure 22, is a suburb developed in the early 2000's. It is in the south end of Guelph, close to amenities like, grocery stores, restaurants, libraries and schools. Within this neighborhood, there is a mix of housing from mid rises, town houses and single detached homes.

The block of focus, in figure 23, has 12 single detached homes. The houses each have a driveway, garage and fenced in backyard. The homes are close together, leaving no room to retrofit with infill housing between the homes. With the new retrofit plan, I have drawn 20 units, shared parking at the periphery of the site (making the community pedestrian oriented), changing the orientation the entrance to the shared garden core instead of the vehicular oriented streets, and one smaller house is converted into the common house.

This is the south end of Guelph, with the homes that were developed in the suburban sprawl. Instead of continuing the outward growth, I will be introducing co-housing into these existing neighborhoods. The houses on the block are oriented towards the street, which is more of a vehicular used road. I am proposing that the front door orientation should be moved to the opposing side of the house, towards the shared external space. 
The possible opportunities for a co-housing community: make additions on top of existing homes (instead of infilling, as there is limited space), take away separate driveways to make additional shared outdoor space. If this occurs, essentially the front door become the back, leading out to the communal outdoor space. This will be helpful for the community as it creates an outdoor space that is open to the rest of the neighborhood. Without this space, there may be a negative connotation that this is a private and secluded community. In order to successfully integrate co-housing projects in the existing neighborhoods of Guelph, connection to the rest of the suburb is important.

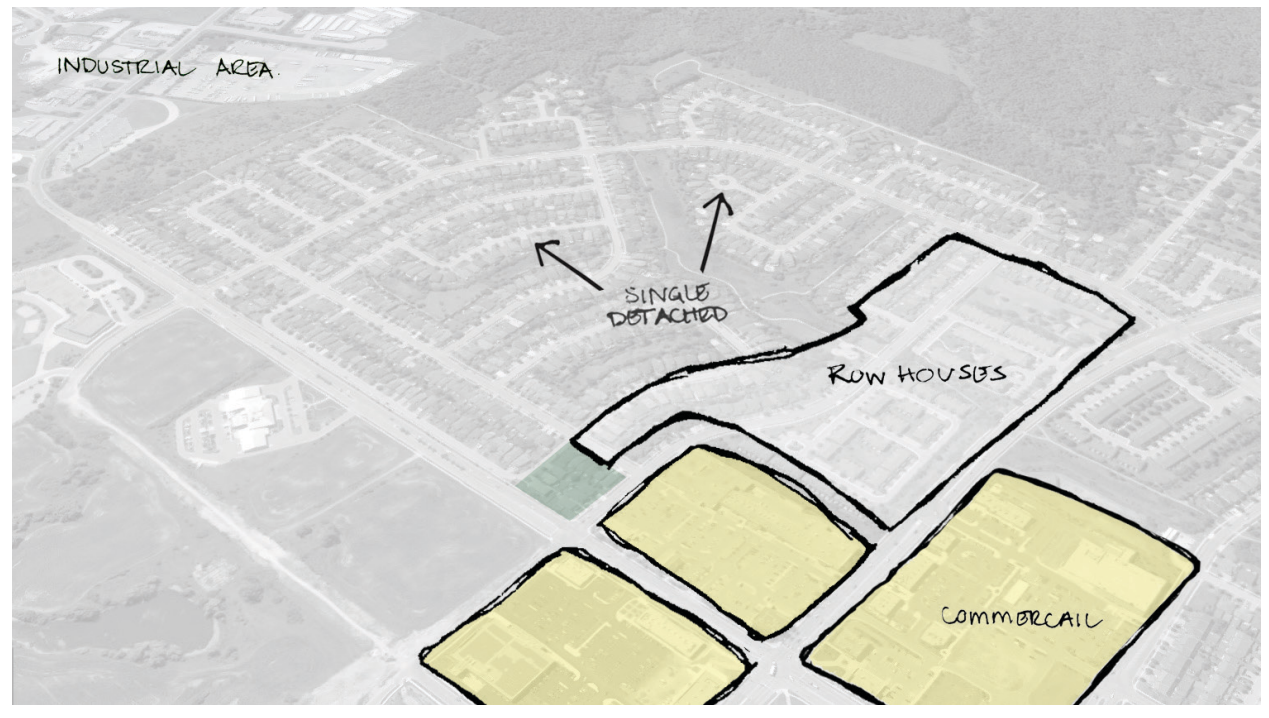

figure 22. Clair neighborhood sketch 


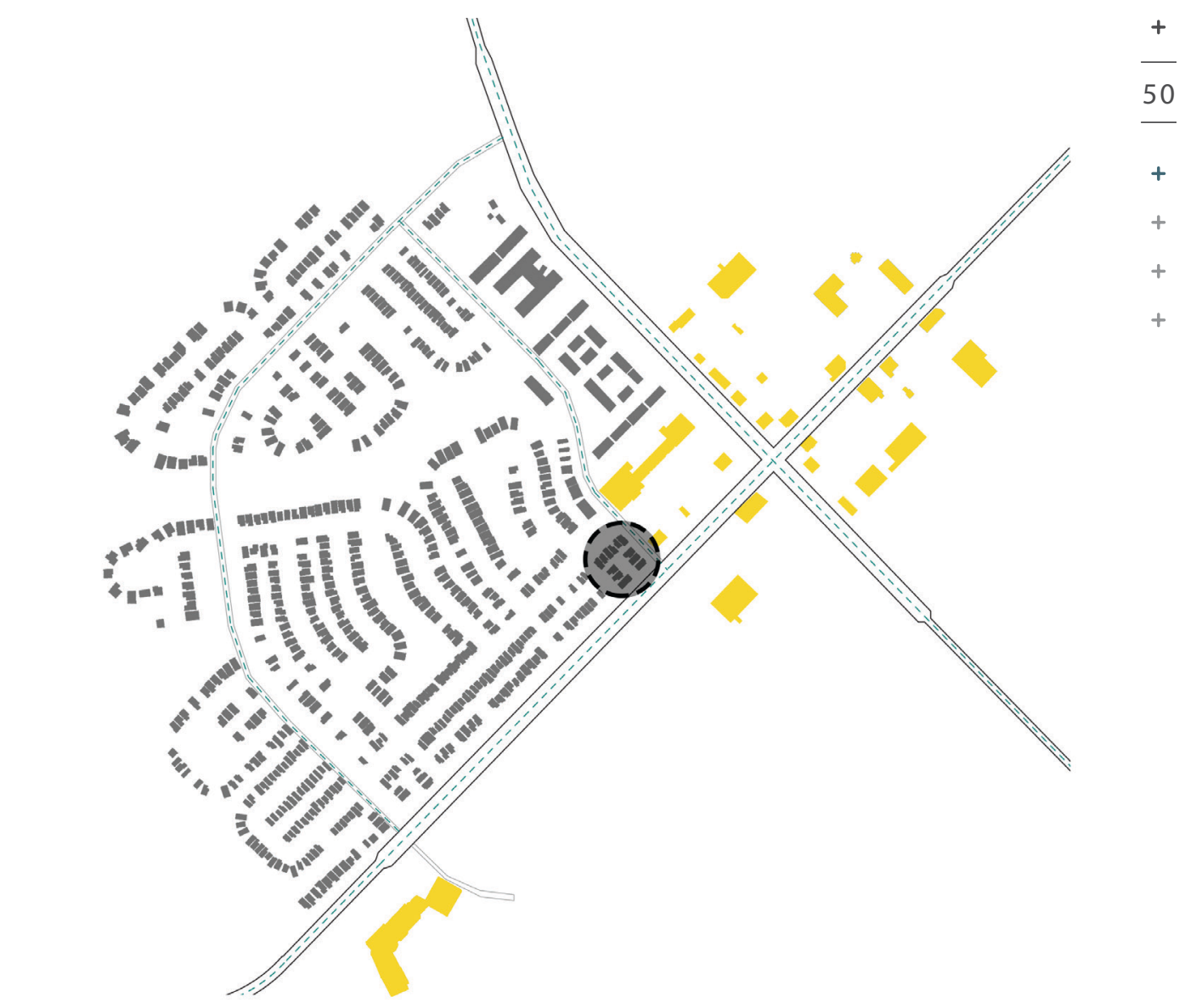

figure 23. Clair neighborhood plan

(NTS) 


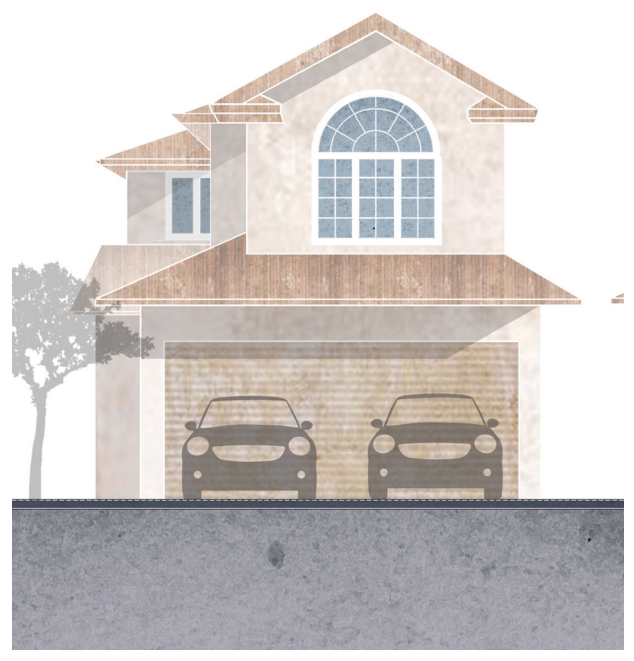

figure 24. existing elevation (NTS)

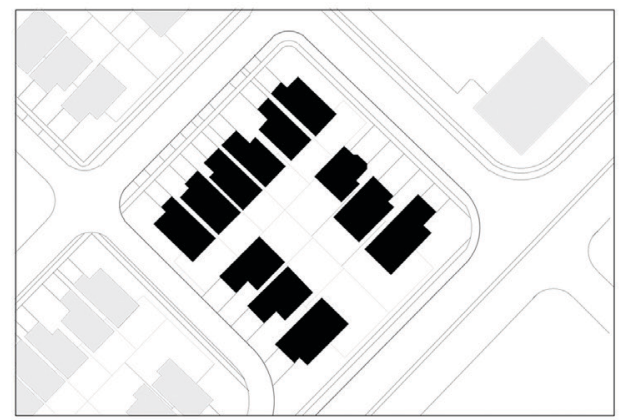

figure 26. existing single detached neighborhood (NTS)

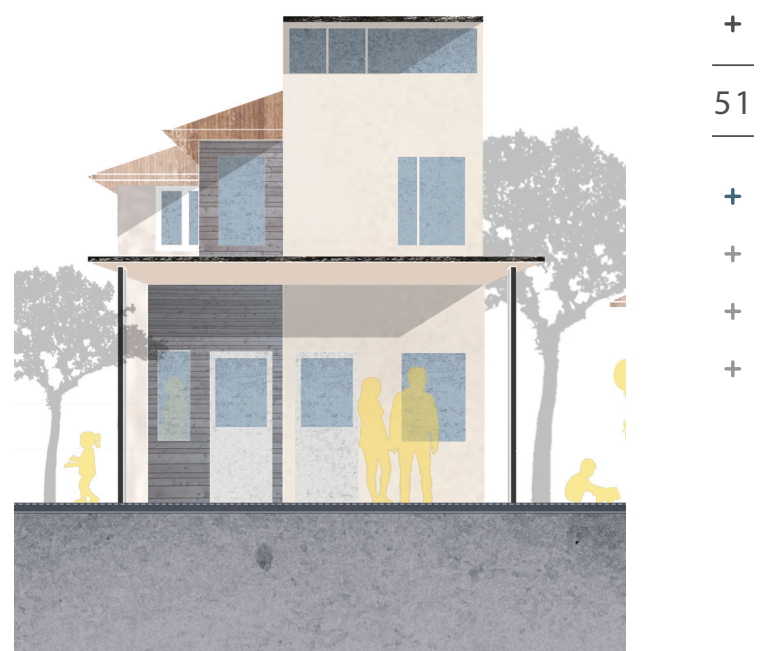

figure 25. retrofit elevation (NTS)

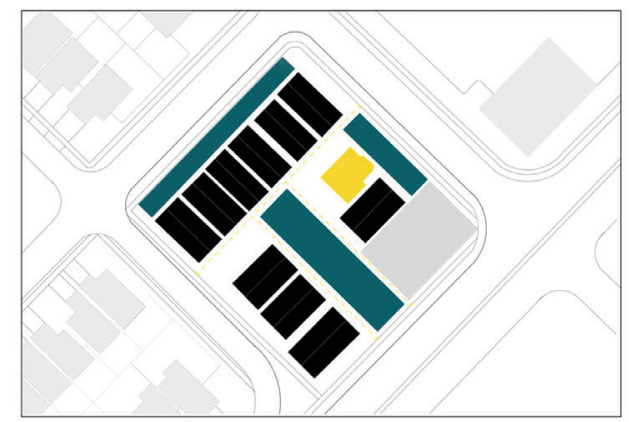

figure 27. retrofit project implemented on site (NTS) 
The Stone Rd area, shown in figure 28 , is an older suburb. It is close to all necessary amenities and plenty of public transit lines. Within this neighborhood, there is mainly low-rise apartments and town houses. This area is one of the low-income areas of the city, and it could be difficult to create funding for a retrofit co-housing neighborhood, unless subsidized by the government.

The block of focus has three town house complexes. On the site, there are existing shared parking lots spread out, centering the three complexes. To retrofit a co-housing project on this site, the parking must be condensed to add a common house and additional outdoor shared amenities. In this case, the houses are more difficult to retrofit because it is a low-rise apartment (and not detached homes) but additional shared outdoor space is a possibility of the site, as well as a common house.

In this instance, the retrofit design aspects include shared outdoor porches, creating a middle zone between the shared outdoor space and the private dwellings. The central outdoor core includes a playground, outdoor dining area and small communal gardens. Parking will be condensed to one larger lot instead of having a small lot in front of each row of houses. Having a shared parking lot at the periphery of the site, 
will provide opportunities for informal interactions while walking to the parking lot; it will promote ride shares, or carpooling between community members.

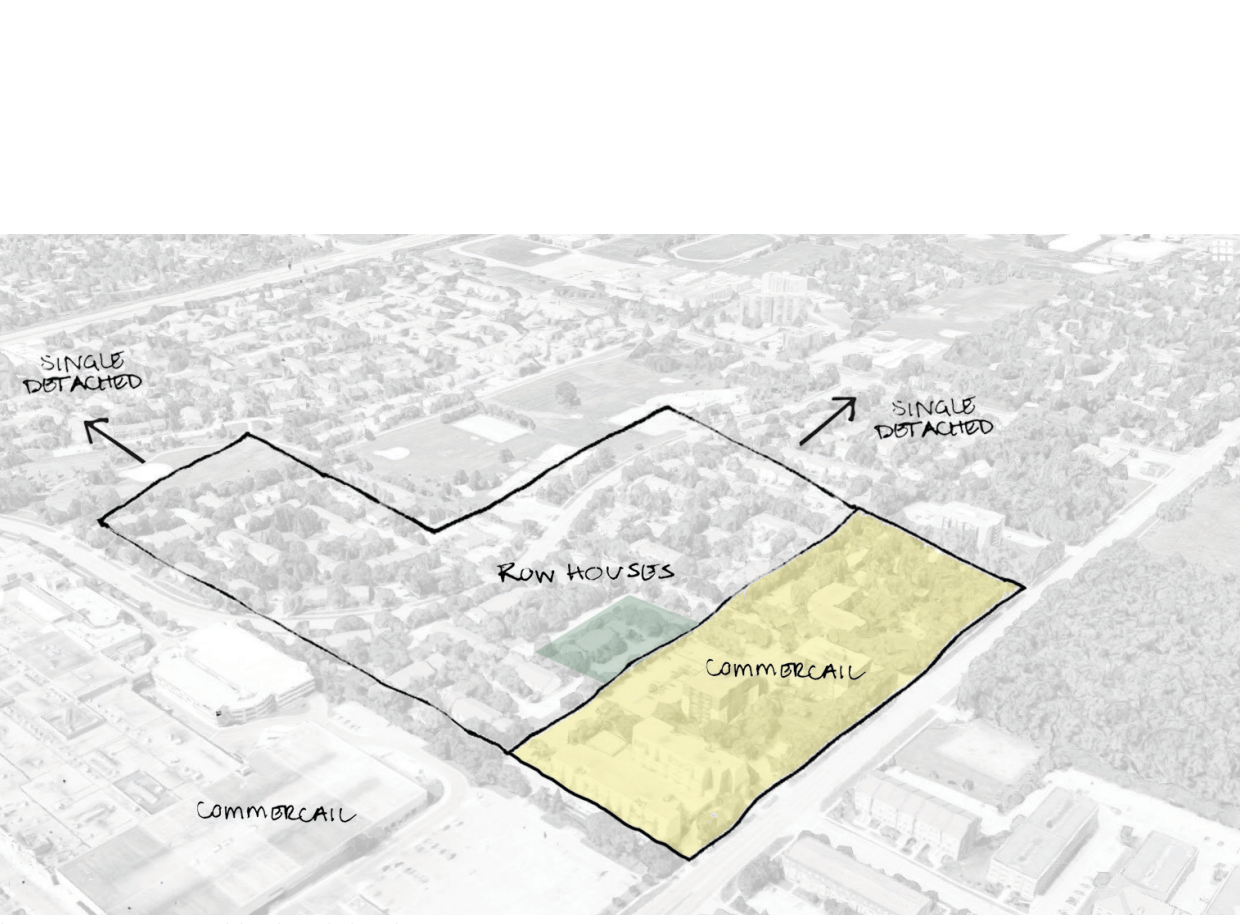

figure 28. Stone neighborhood sketch 


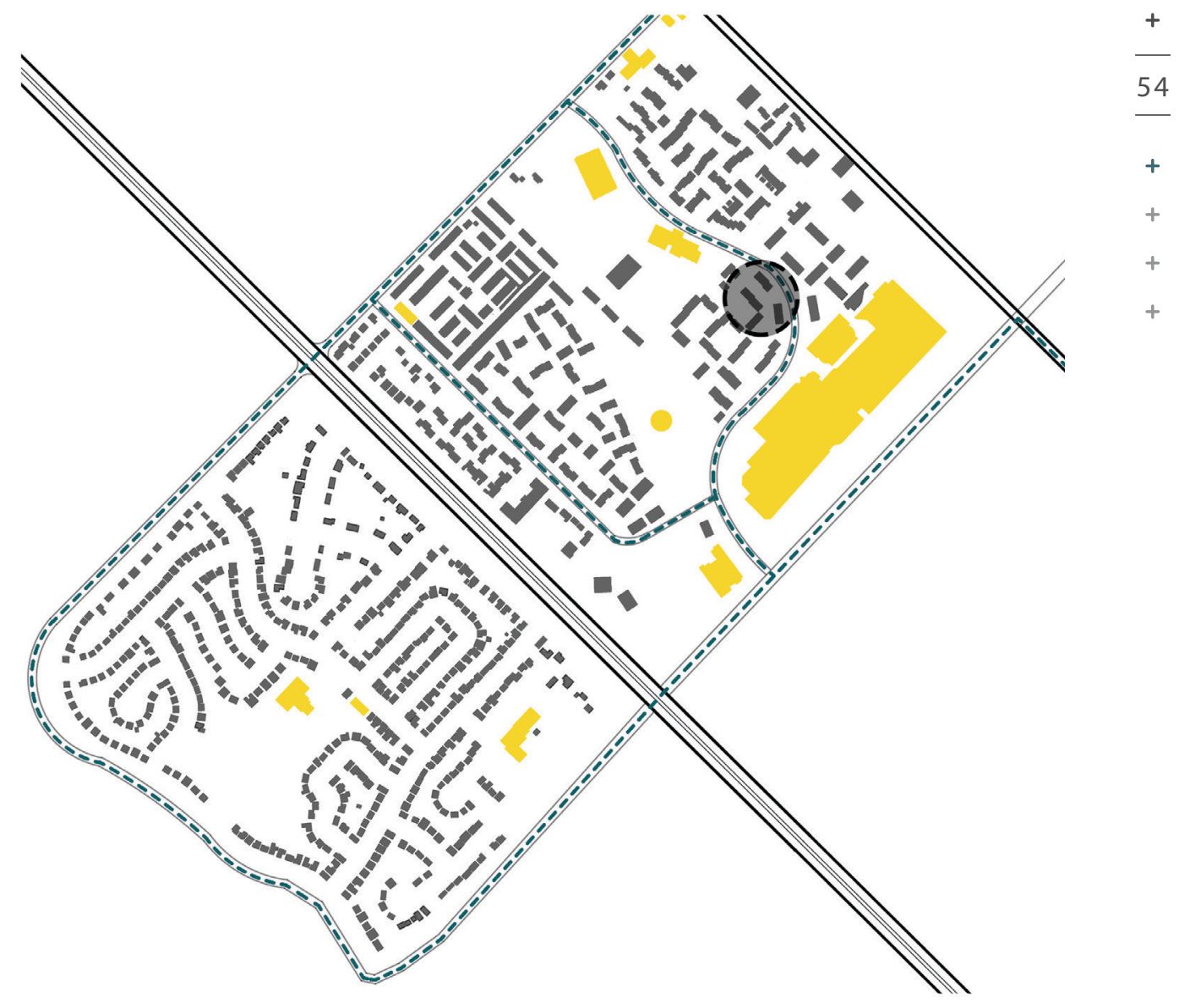

figure 29. Stone neighborhood plan 


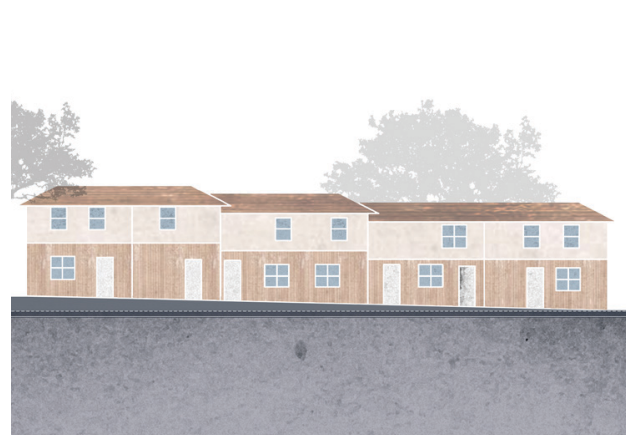

figure 30. existing elevation (NTS)

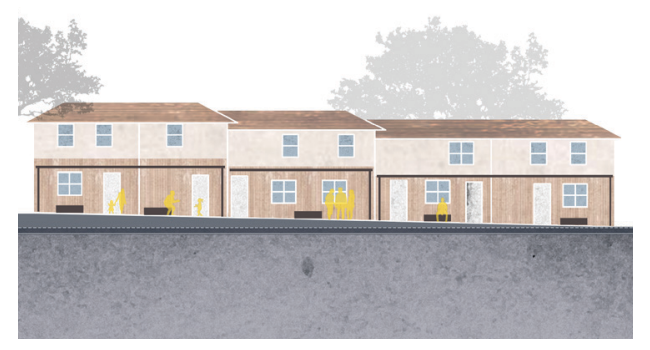

figure 31. retrofit elevation (NTS)

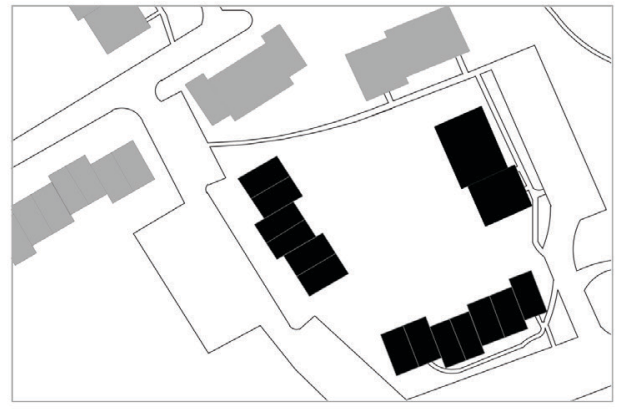

figure 32. existing low-rise attached neighborhood (NTS)

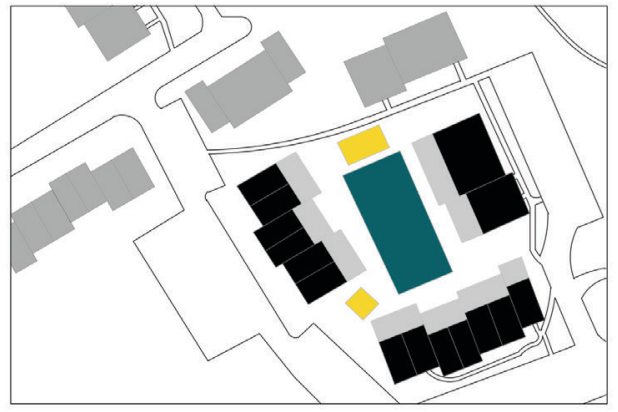

figure 33. retrofit project implemented on site (NTS) 


\section{Zone 03}

OLD CITY

The old city, shown in figure 34, is in the center of Guelph. This is a neighborhood that has been developed for a longer time than the previous two zones. In this zone, there are single detached homes with larger yards and spaces between the houses, deeming this area, low density.

In this instance there is room for infill units between the existing homes. Since there is more space than the last single detached case, there is room for a larger communal space like shared outdoor space, the common house and community gardens.

As shown in figure 36, there is space between the existing homes for infill houses. Currently this space is used for driveways. In this block of the neighborhood there are 18 existing houses. With the infill houses added to the site, there is a possibility to have up to 20 homes, larger shared outdoor space, and a parking lot at the periphery of the site.

The larger lots on the site give the possibility of a large community garden in the back central core of the homes. Also, with the space, a large communal house could be built, as there would be a larger community than the previous instances, having 20 homes on this block. 


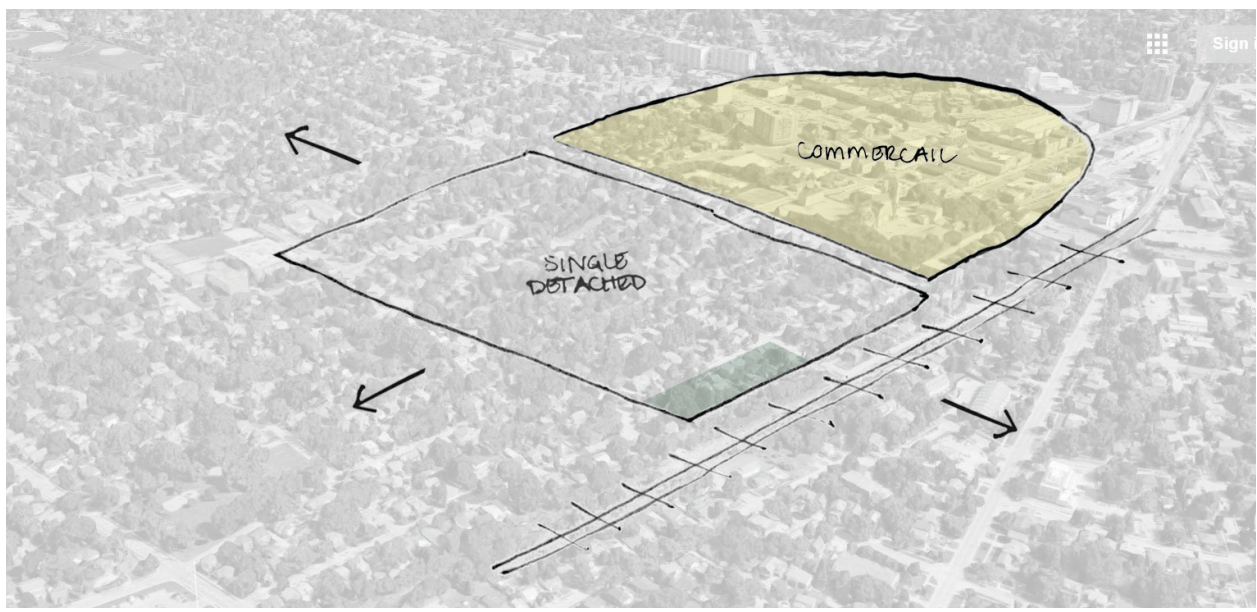

figure 34. Old City sketch 


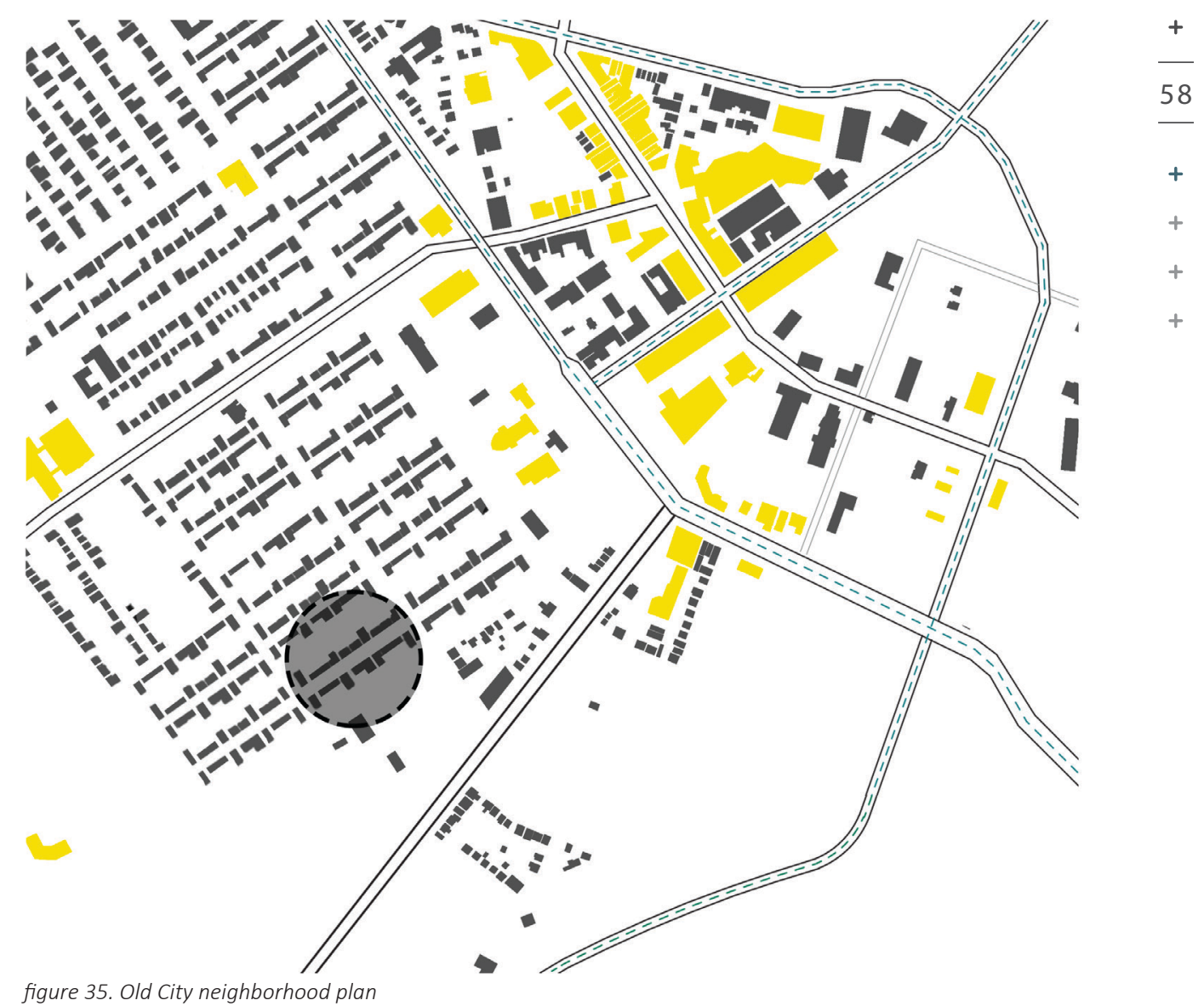

35. Old City neighborhood plan 


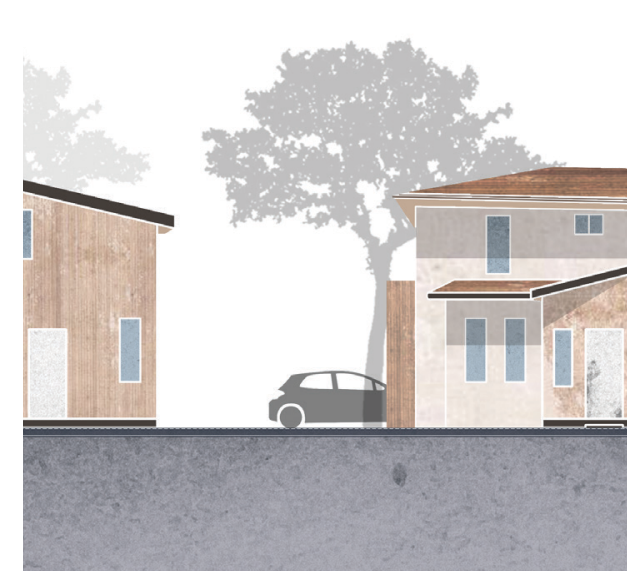

figure 36. existing elevation (NTS)

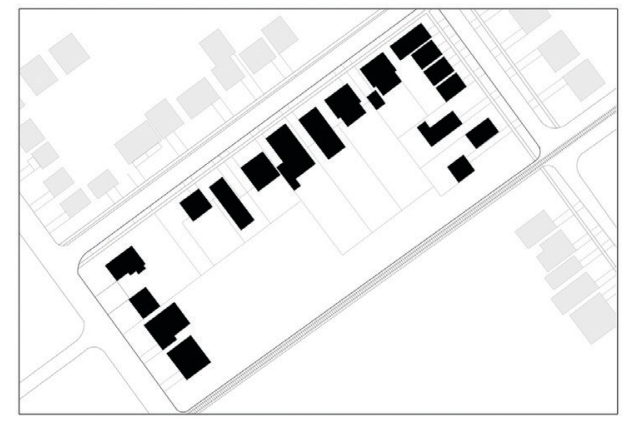

figure 38. existing single detached neighborhood (NTS)

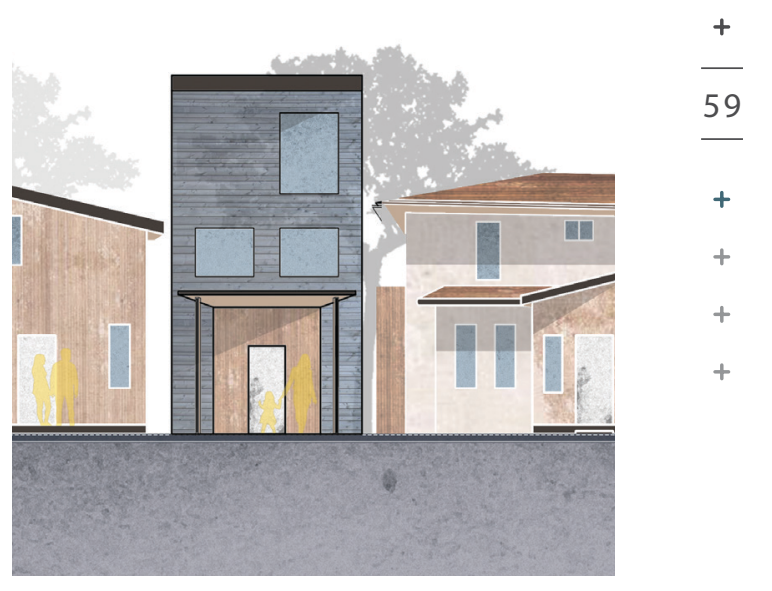

figure 37. retrofit elevation (NTS)

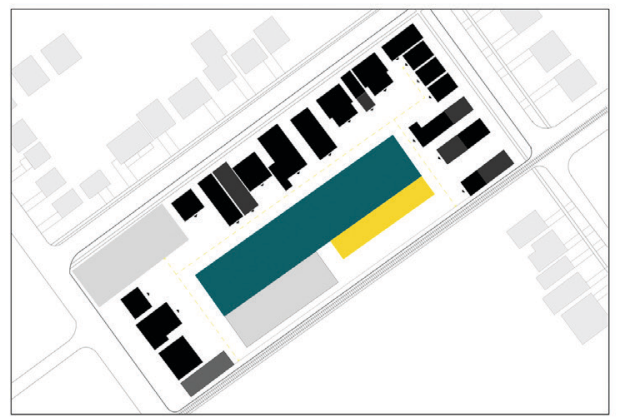

figure 39. retrofit project implemented on site (NTS) 


\section{Zone 04}

Two Rivers, shown in figure 40, is in the downtown area. It is the closest of the 4 zones to the center of the city. In this case I have found an unused old metal factory that can become co-housing as it is in a residential zone. In this case, the interior would have to be gutted and remodeled to fit private units and common spaces: formal and informal. There is also space on the site already allocated for parking, that would be sufficient for the members of the community. Behind the factory, there is outdoor space that could be used for a small garden, or playground for the community.

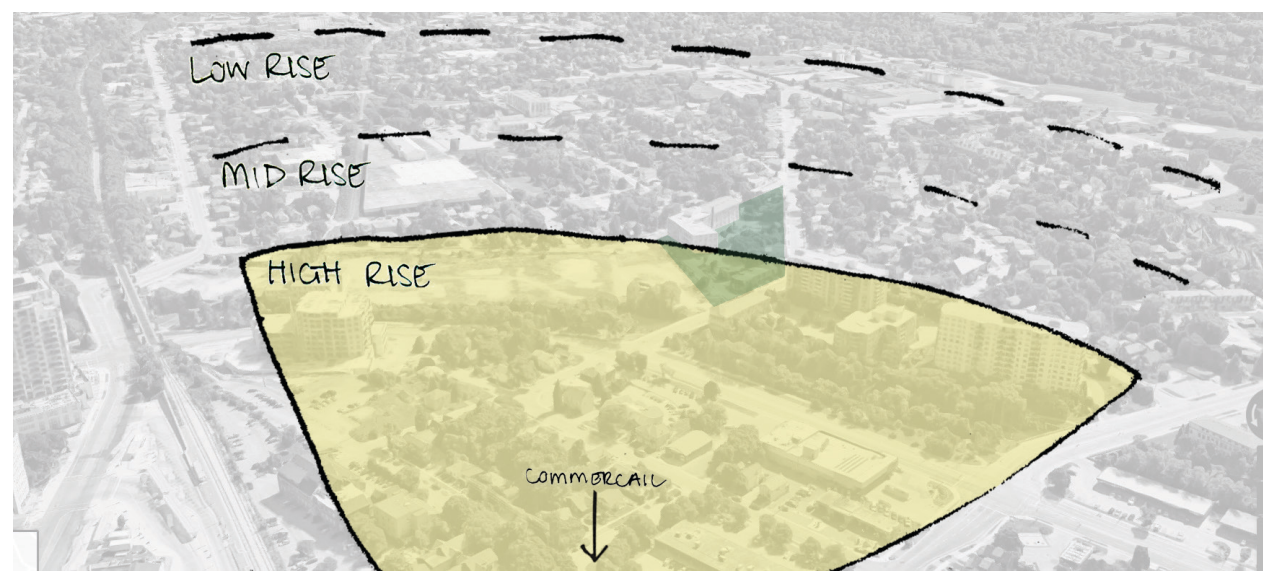

figure 40. two rivers sketch 


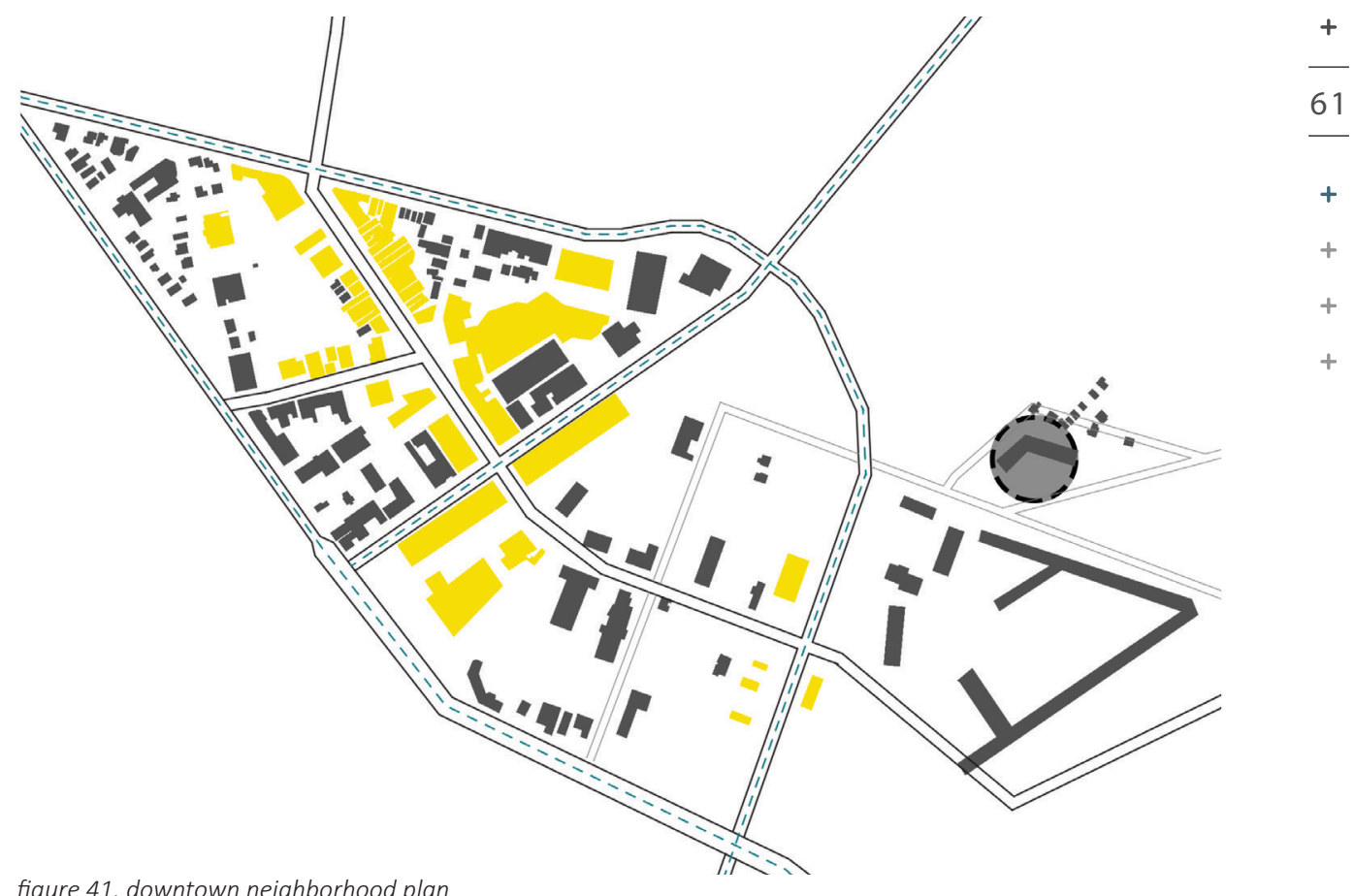
(NTS)

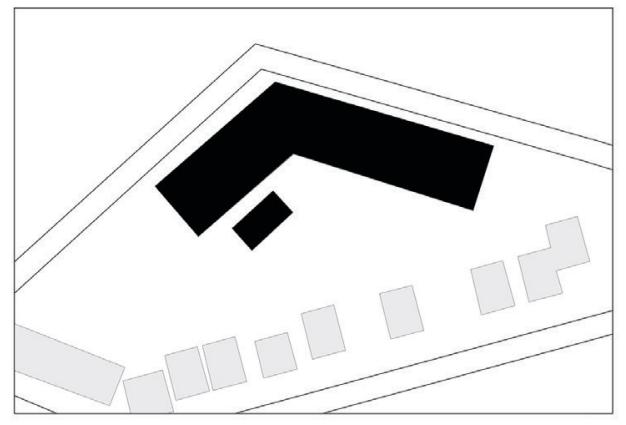

figure 42. existing warehouse (NTS)

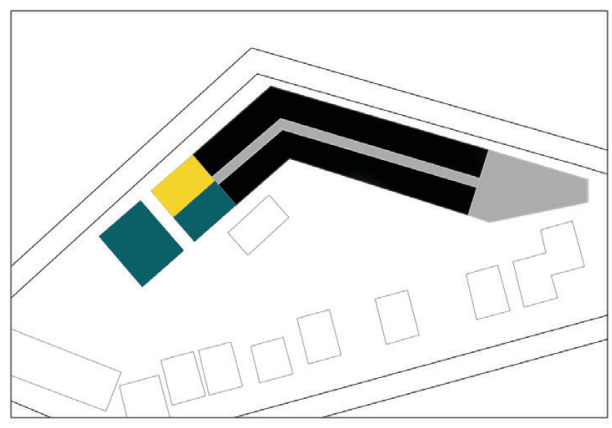

figure 43. retrofit project implemented on site (NTS) 


\section{City Demographics}

Age Demographics

Within the age demographic map, figure 45, each of the neighborhood zones have been outlined with a color that represents the average age demographic in that area. The black color represents the highest average aged neighborhood within Guelph, with an average age range of 81 years. The lighter the color of the suburb, the younger the average age is.

Out of the four zones I have focused on, the average age demographics are as follows;

Zone 1. 34

Zone 2. 29

Zone 3. 39

Zone 4. 37 


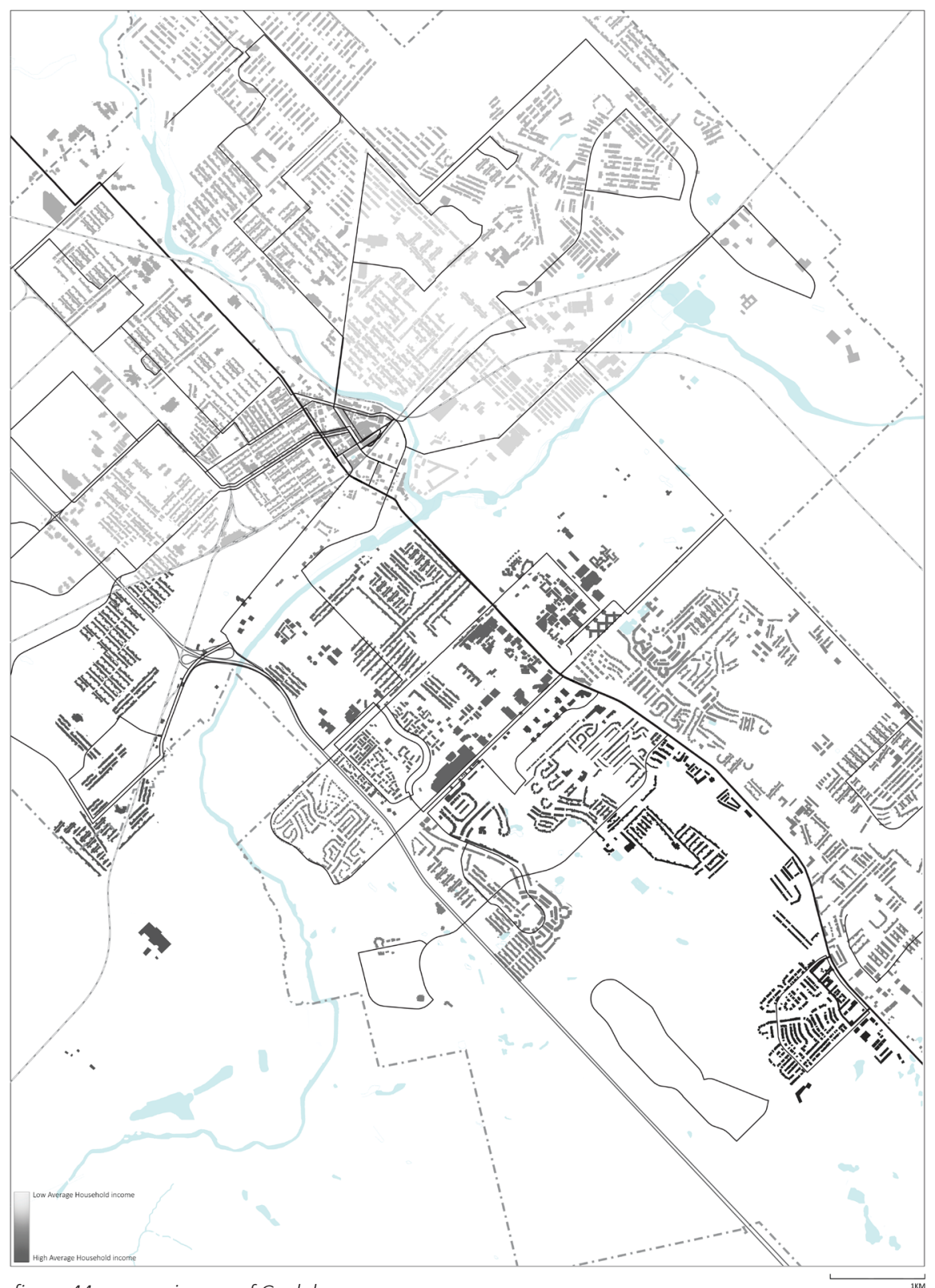

figure 44. economic map of Guelph 
Guelph has a diverse economy and one of the lowest unemployment rates in the country ${ }^{35}$. In order to create a co-housing community, finances play a large role in the creating of retrofit communities as there are often construction costs for the renovating and remodeling that needs to be done. Looking for areas that have lower average incomes can be helpful because this often means that the house prices might be lower. If the house prices are lower than average, there is a better chance that more homes in the neighborhood are not a fixed address meaning that there could be more opportunity for acquiring additional homes to be part of the retrofit community. Aside from this, lower costs for the homes will also mean that members will have more money to put towards renovation costs, which are inevitable.

Within the economic map, figure 44, each of the neighborhood zones have been outlined with a color that represents the average income in that area. The black color represents the wealthiest neighborhood within Guelph, with an average household income of $\$ 120,000^{36}$. The lighter the color, the less amount of average household income. Out of the four zones I have focused on, the average incomes are as follows; Zone 1. \$120,000/ household

Zone 2. \$52,000/ household

Zone 3. \$100,000/ household

Zone 4. \$78,000 / household

\footnotetext{
${ }^{35}$ Statistics Canada, 2016

${ }^{36} \mathrm{Ibid}$
} 


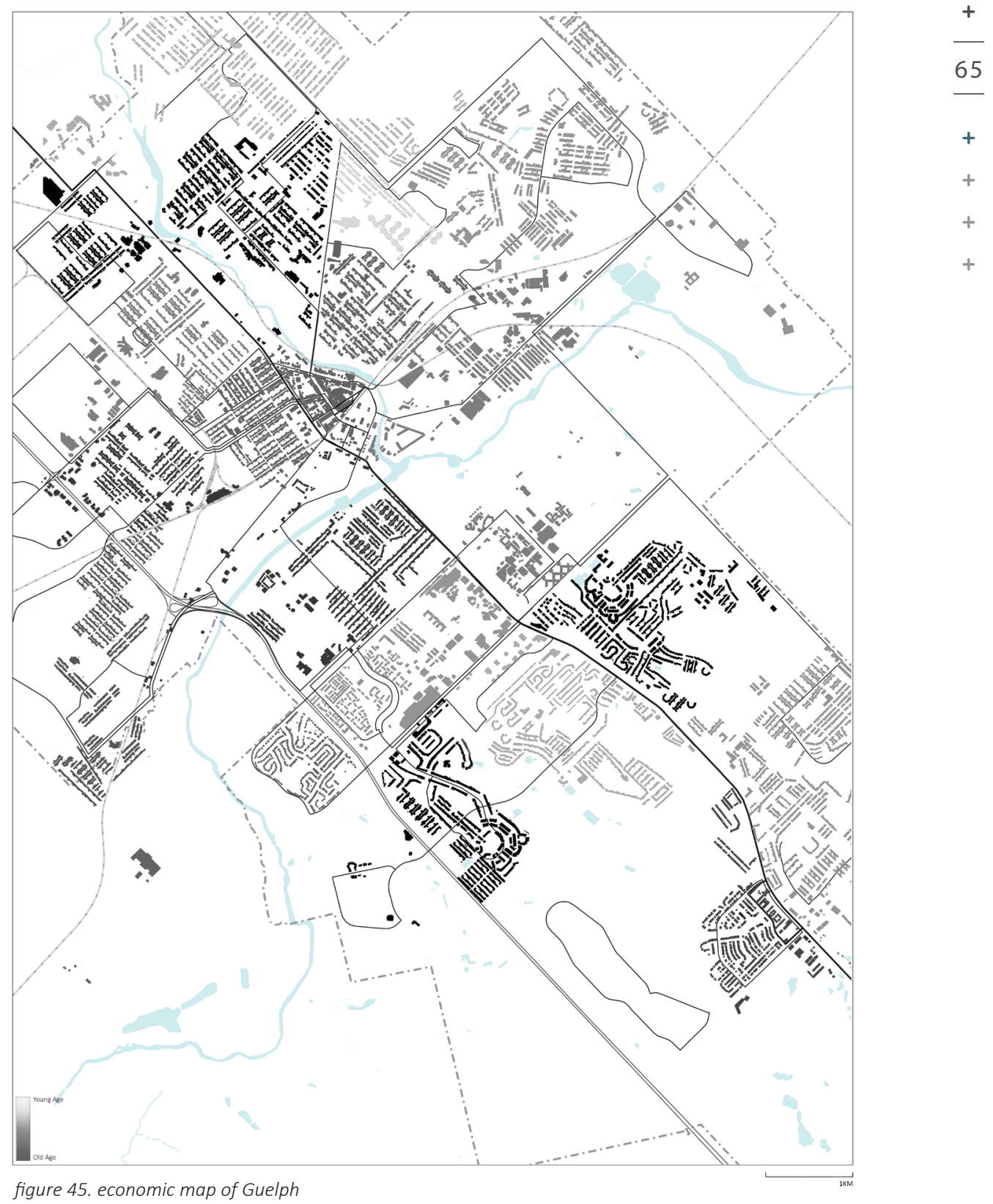




\section{Silent Shared Environment}

Although there are no official co-housing communities in Guelph. There are communal groups and living scenarios within the city that do adopt some of the co-housing attributes without being called or considered co-housing. Figure 46 will tell the stories of some of these invisible shared spaces. These shared spaces around the city include shared house temporary shared accommodation (Air BNB rooms), community gardens and residences (like retirement homes or condos) which try to create communal spaces and activities within their building. Other spaces that were mapped out include places that one would not assume to be 'communal' at first glance- the 'silent' shared spaces. These spaces include community centres, parks and coffee shops. 


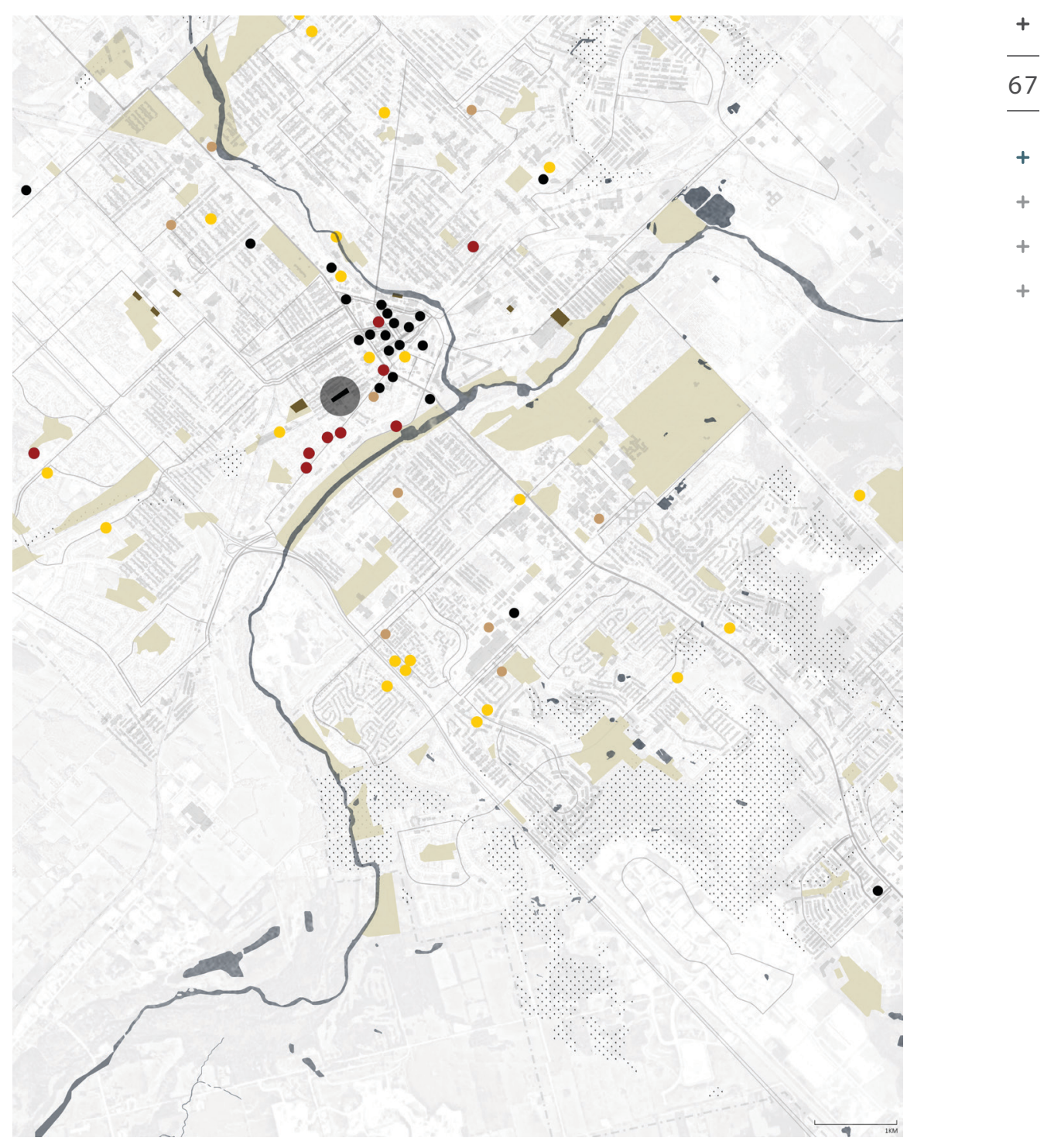

figure 46. shared space map

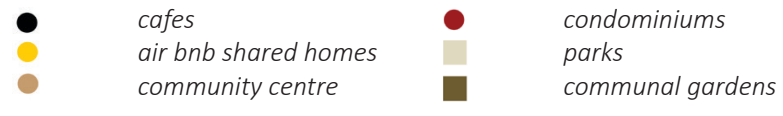




\section{'Old City'}

The decision to use one area to demonstrate how the retrofit model could transform an existing suburb was made to show ideas that do work well in this case but also have the possibility to work in different locations. In order to best express the retrofit model, I wanted to investigate the previous four zones in terms of their demographics, economics, and zoning to determine what location was optimal. With this information I concluded that a most appropriate suburb is zone 3, the 'Old City'. In this neighborhood of Guelph, the close amenities and being in a good school zone area combined with being in a diverse location in terms of income and age, make it an ideal place to start a retrofit co-housing community.

'Old City', Guelph, is known to have older homes, the majority of which were built in the 1960's or earlier (see figure 47). Houses built in that time were planned with less density, so the majority of the neighbourhood houses have large yards and plenty of space between the house; this is another reason for choosing to expand on the 'Old City' neighbourhood. Aside from the growth over the past 20 years, much of Guelph's housing is low density single detached homes, so I hoped to choose a neighbourhood that would display a case for many sites within Guelph, and other similar cities. Statistics Canada has a projected population growth up to 2028 in the 'Old City' (see figure 48). An option for additional housing is infill and vertical growth, both of which I will demonstrate within the case study block sample drawings. 

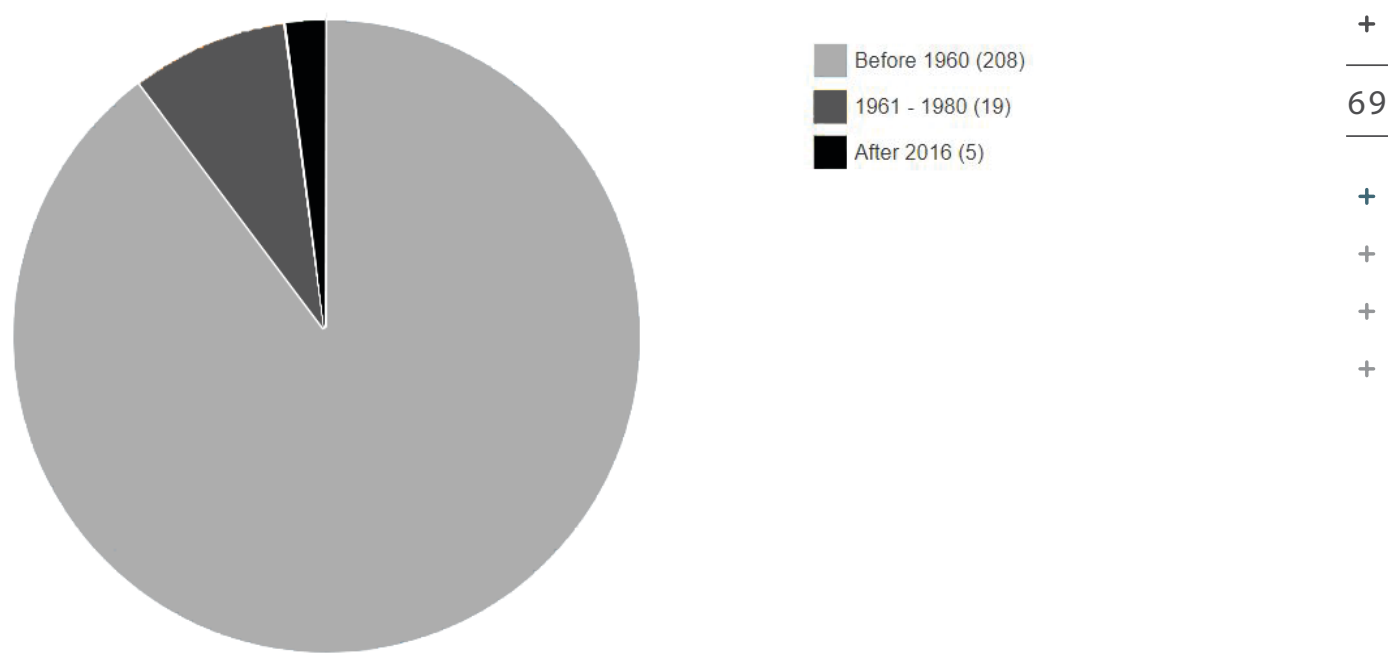

figure 47. Ranges of years properties were built in Old City

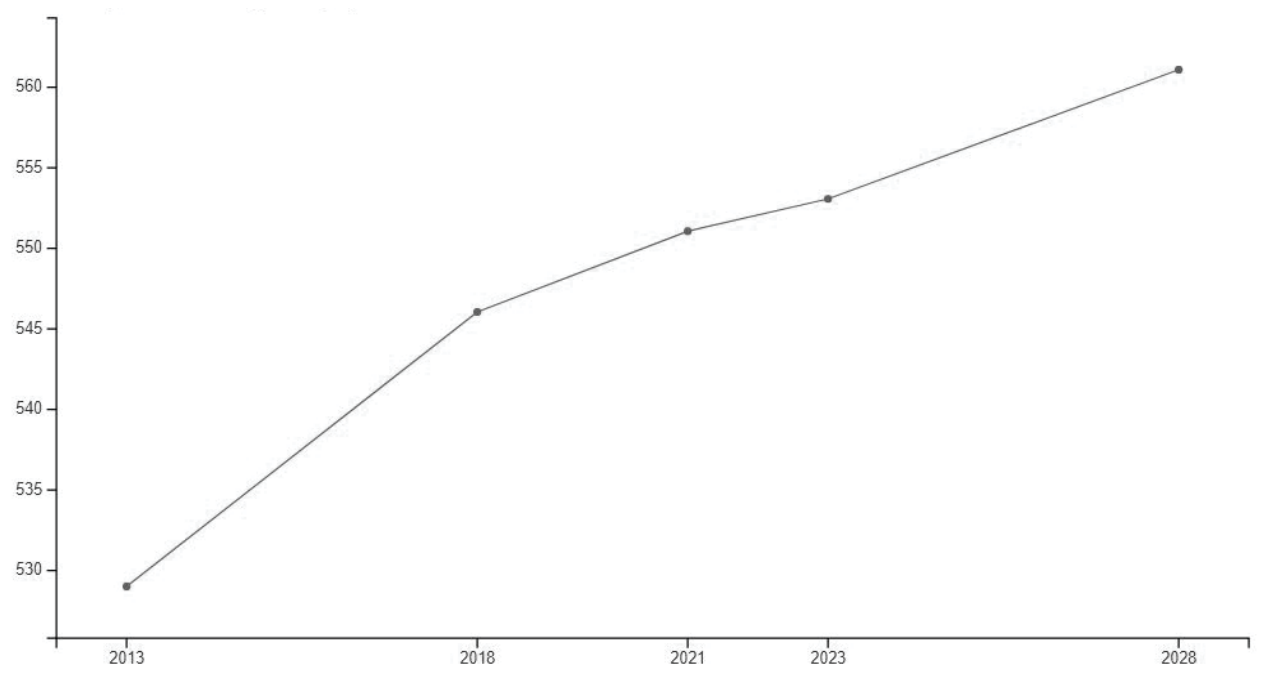

figure 48. Past and expected changes in population of Old City 
There are many blocks in this neighborhood that would have worked well to $\quad+$ start creating a retrofit community. In figure 49, the maps show some pos- $\overline{70}$ sibilities for futures development. For this thesis I have chosen to use block 02 on the map to tell the story of how the block could evolve from typical housing to co-housing.

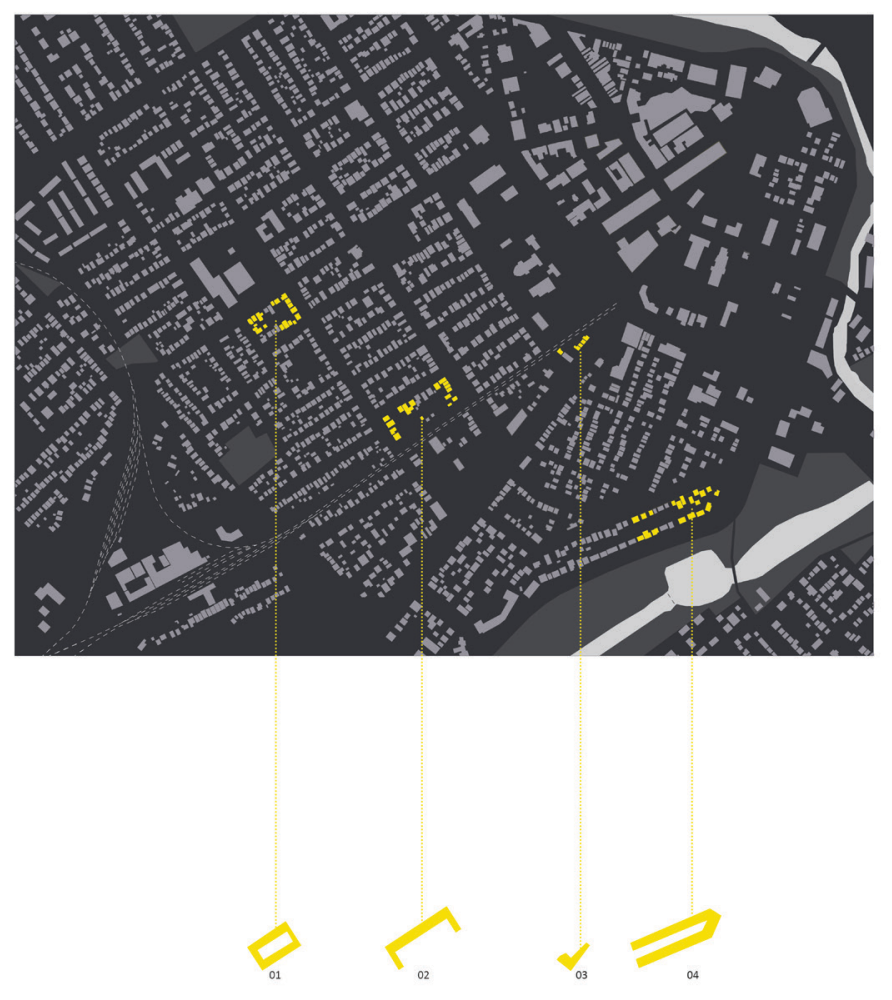

figure 49. map of Old City, Guelph (NTS) 


\section{The Evolution of the Block}

block. By orienting the main entrance of the individual houses toward the back (shared) yard and removing the fences between each house an internal courtyard is made to hold a variety of communal spaces. The common house is designed to be in the most public corner of the block, whereas the opposing corner of the site, the more private corner, will hold the shared parking lot and bike storage. The removal of the private driveway may seem difficult for some to adjust to, but like we have seen in high-rise apartments and condos, this adjustment can improve the use of the site and promote ride sharing and using different modes of transportation. There is an internal paved pathway from the parking lot to each individual home, but if there are members of the community who have mobility issues, permits can be purchased for street parking. Adjacent to the public side walk is the "connection layer" which is meant to be used as a place for members of the co-housing community to make a connection to the greater community. Much of the shared space is not fully visible to the greater community, as the individual units separate the shared courtyard, so the "connection layer" is designed to be a space to spark interactions and conversations with neighbors. The connection layer would incorporate landscaping and gardens to still have a clear distinction from the street and sidewalk, it is meant to be a space that physically separates the individual home from the 
street but also can be used to make social interactions with neighbors. +

Figure 51 shows the current site plan of the block. In the site plan we see that each house is clearly separated with fences and each home has an individual driveway. Figure 52 is a possible design of the evolution of the block and the community growth over 10 years. The brightest shades of each colour signify that those are key items that would be built or created first, as each colour becomes more transparent it is meant to signify that the space was built or created later within the 10 years. As noted throughout the thesis, retrofit co-housing usually occurs organically, adding new members to the community over a long period of time. For this representation I will use a 10-year time period to show small sections of the community and how they may be altered. The architectural demonstration of the different moments will be drawn in sketches, plan and three-dimensional section vignettes.

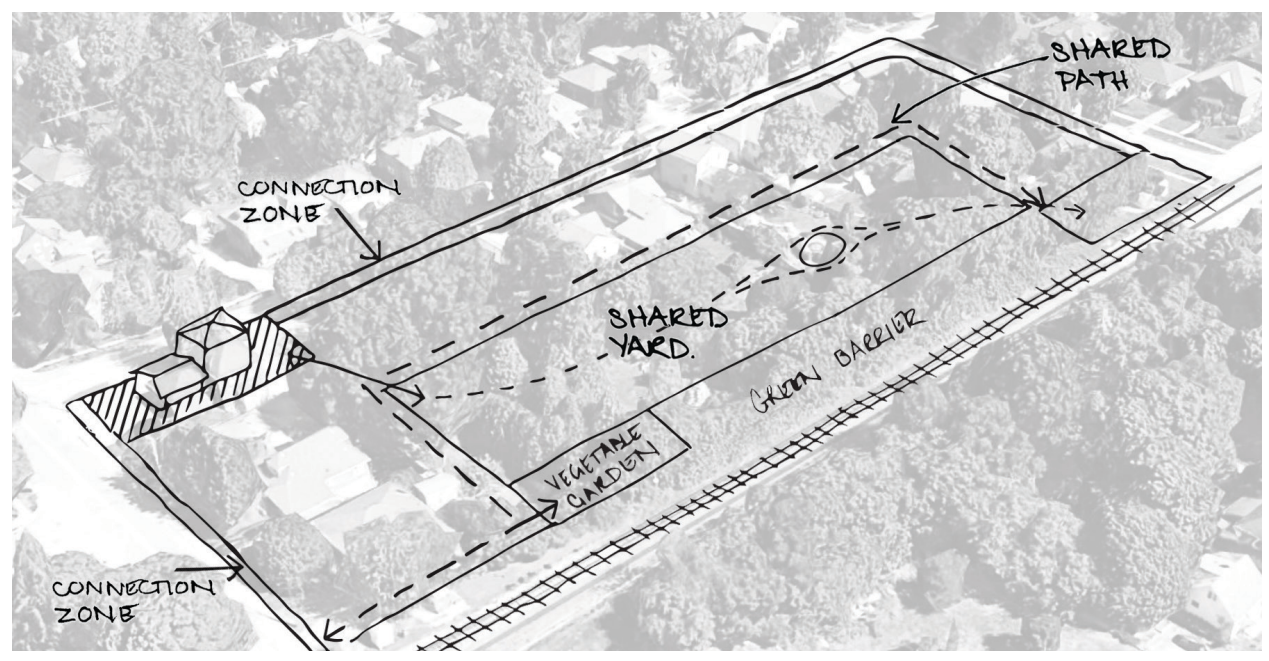

figure 50. sketch of Glasgow // Northumberland St block 
ISSUE ONE | DESIGN HANDBOOK FOR CANADIAN CO-HOUSING

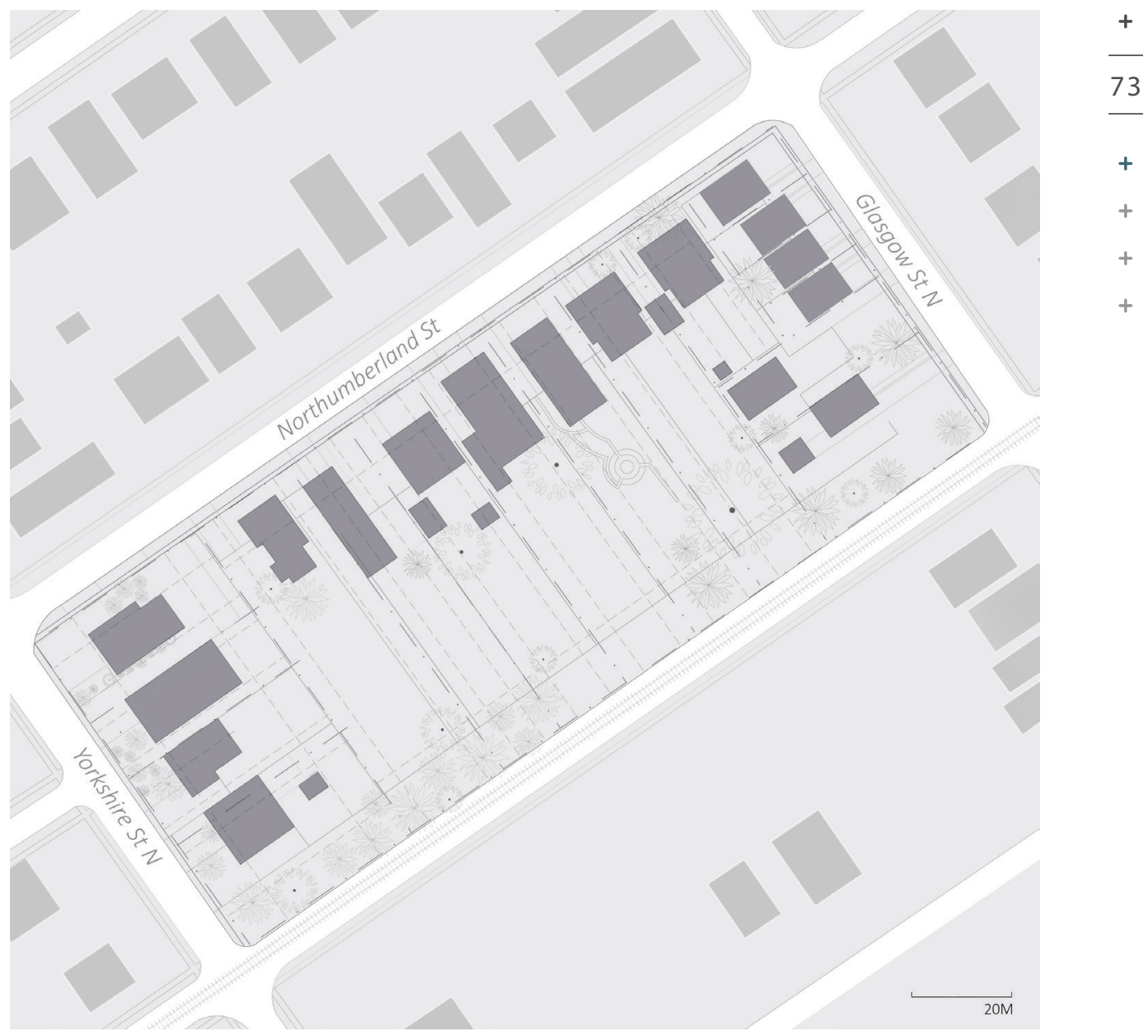

figure 51. Existing Site Plan 
ISSUE ONE | DESIGN HANDBOOK FOR CANADIAN CO-HOUSING

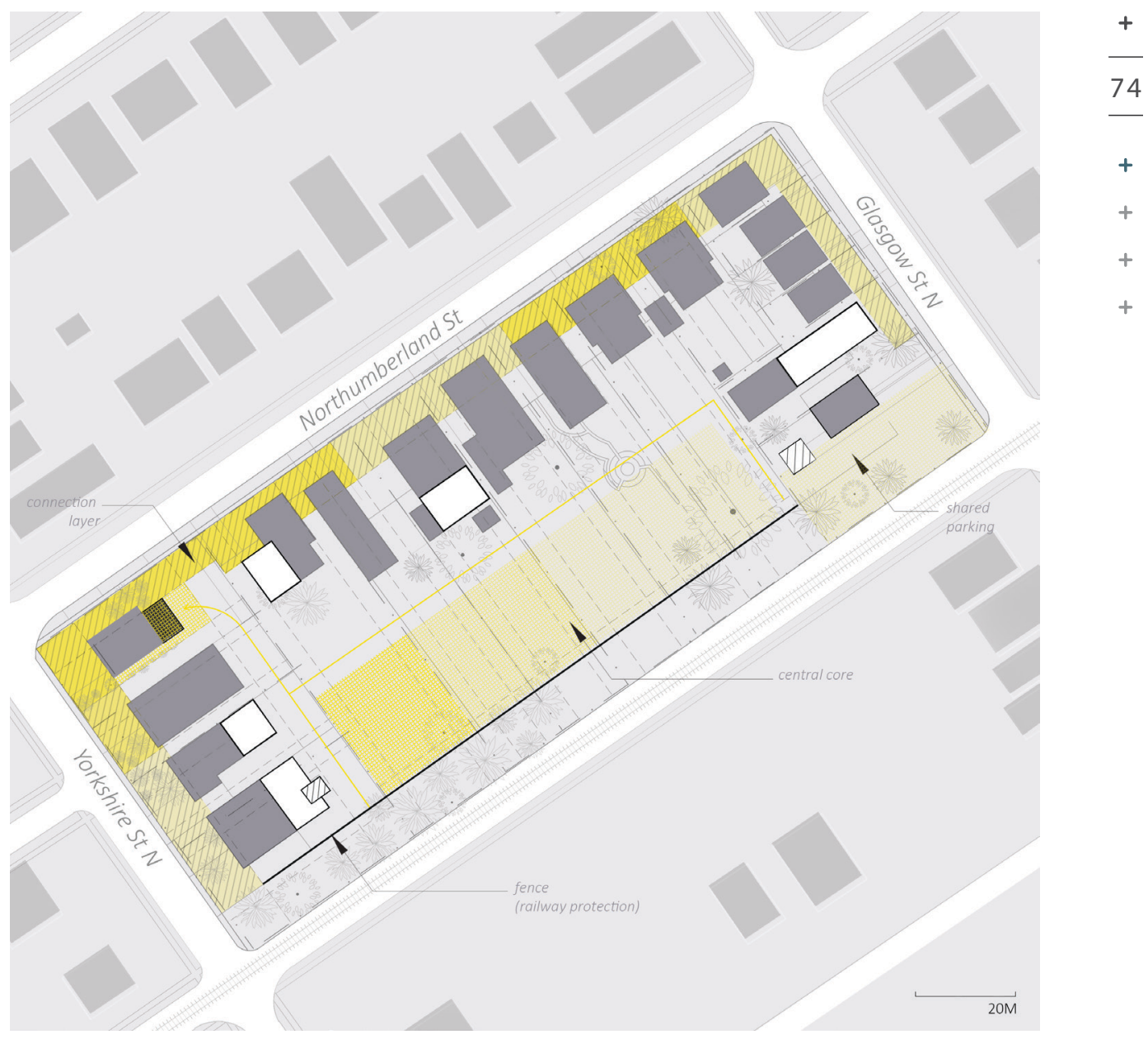

figure 52. Evolution Site Plan 
Starting a retrofit community can happen in many ways. In this case study the design of the neighborhood transformation begins with 131 and 133 Northumberland St. The first large move was to remove the fence that separated their backyards. By doing this the houses can have a chance to ease into the co-housing lifestyle and make small steps like sharing a garden, yard tools and having shared meals together. Next steps in the design include adding on a second unit to lot 131. This will increase the resident's proximity of living. Increasing physical closeness through design also increases the amount of contact between residents, to help form social interactions ${ }^{37}$. The design alterations made to unit 131 include changing the orientation of the front door access from the front yard to the back (see figure 53). The entrance foyer and laundry facilities are shared between the units to promote creating additional spontaneous interactions. The use of semi-private space (or buffer zones between public and private) are important to consider within the design as they provide a protection layer for the residents, "providing a degree of privacy and territorial control with options for active contact into adjacent public space" ${ }^{\prime 38}$. The semi private space occurs at both the front yard and backyard terraces of the house (see figure 55). The wide drive ways of both lot 131 and 133 are removed to make room for a shared front yard space. Street parking is available for free all year, and later as the community expands, a designated parking lot will be designed for the community.

\footnotetext{
${ }^{37}$ Kuper, 1953

${ }^{38}$ Skjaeveland, Garling \& Maeland, 1996: 193
} 


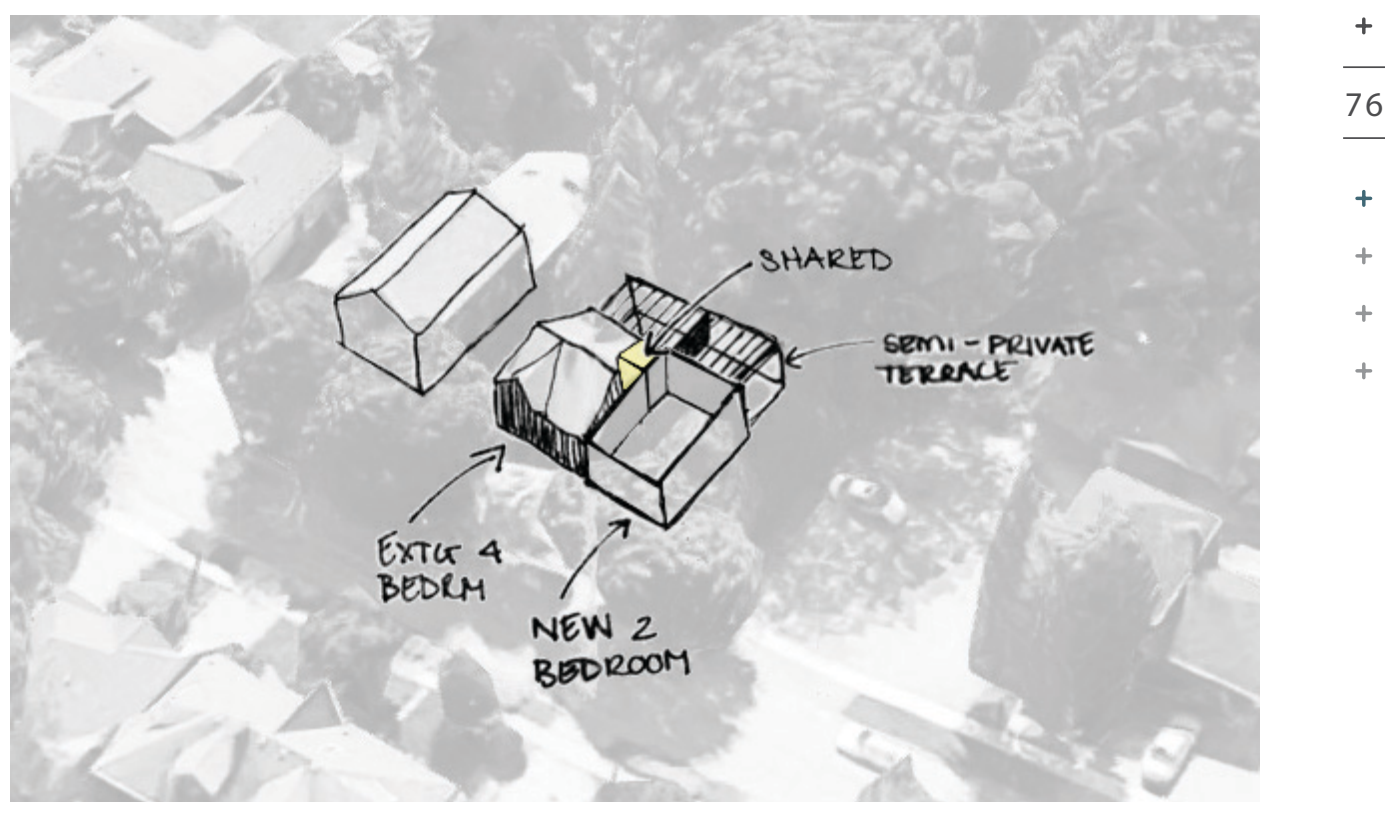

figure 53. sketch: first house 


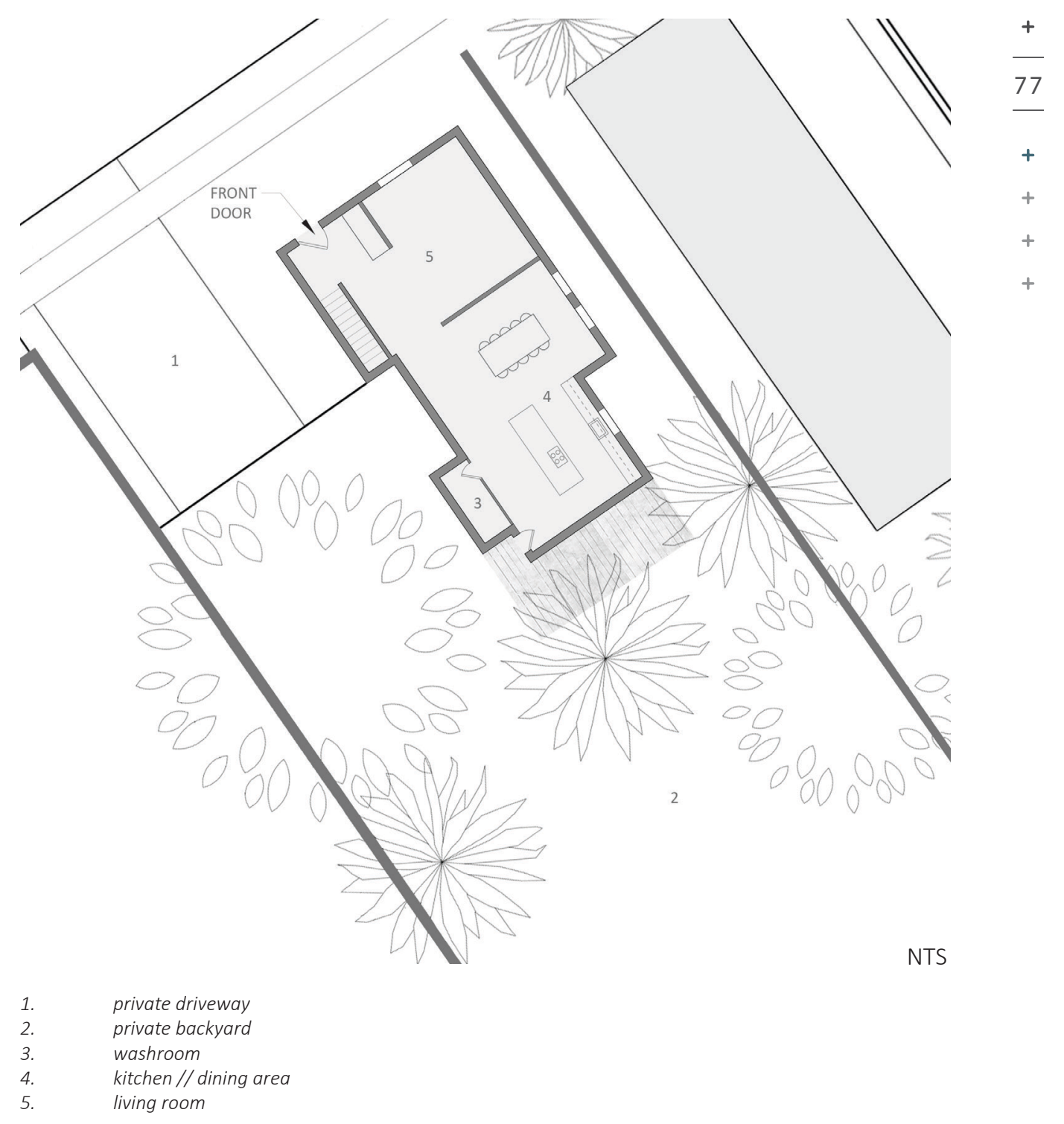

figure 54. Existing ground floor plan: first houses

(existing plan is an adaptation of a similar local typology which is available online) 


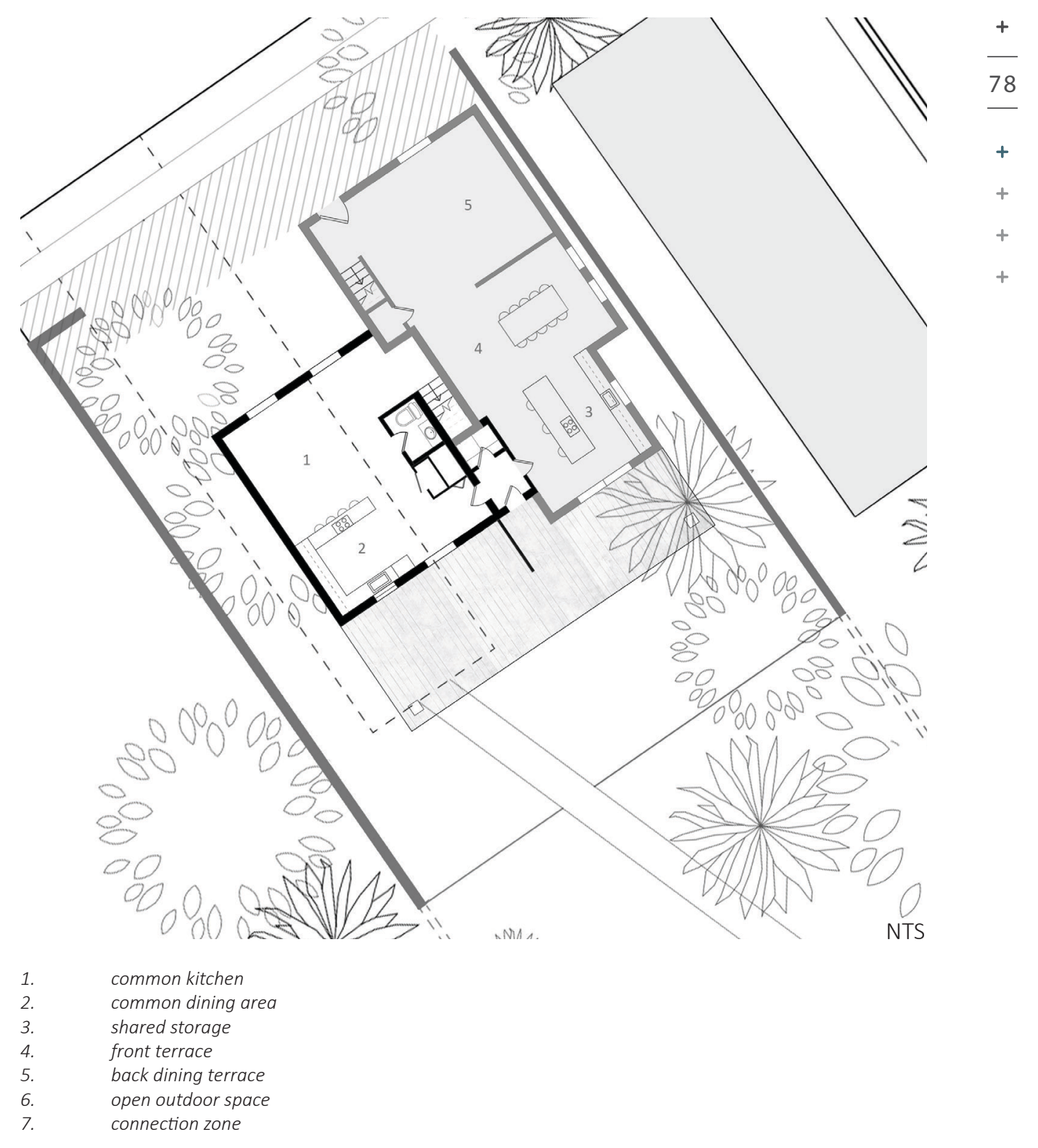

figure 55. Ground floor plan: first houses 


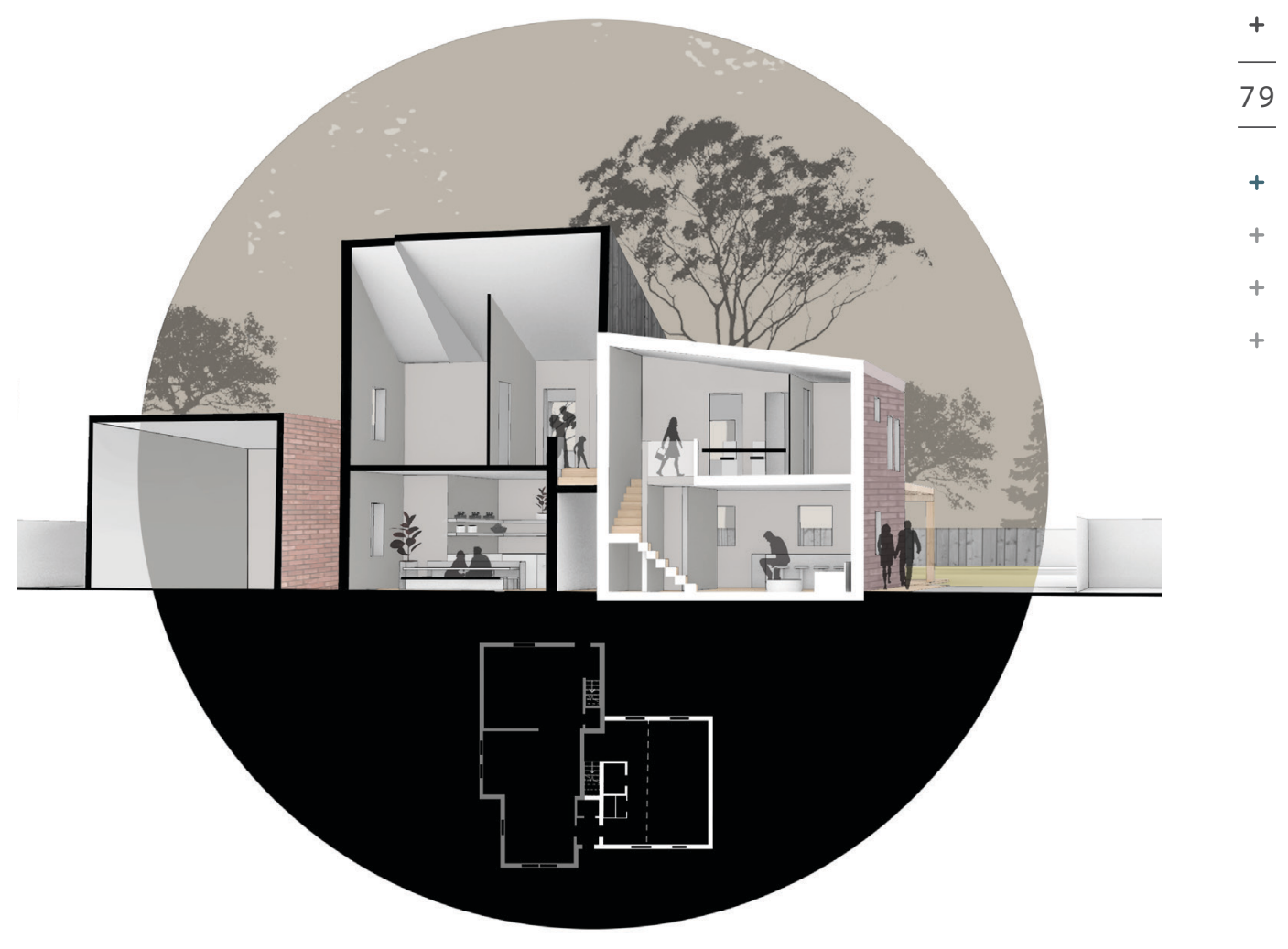

figure 56. section: first houses 
The Common House is often built after a significant amount of people are part of the community. On this block, the house will be in the existing corner home, at the most public corner of the site. This placement choice was made so that the surrounding community would be more inclined to interact with the co-housing community. Figure 57 shows that between the public sidewalk and the community there is a "connecting layer", which is a zone between the house and greater community designed to enhance social interactions with the surrounding neighbors. In this layer there can be gardens and benches.

The ground floor of the common house will hold the common kitchen, indoor dining space (which holds 40 people), and a small meeting room. As well the ground floor will include both a front and back terrace for shared gatherings and meals, and a shared open space for children to play and activities to be held. The second floor will hold an indoor living space, for gatherings and community movie nights as well as 2 guest rooms for visitors of the members of the community. The guest rooms are designed to be for short term visits. 


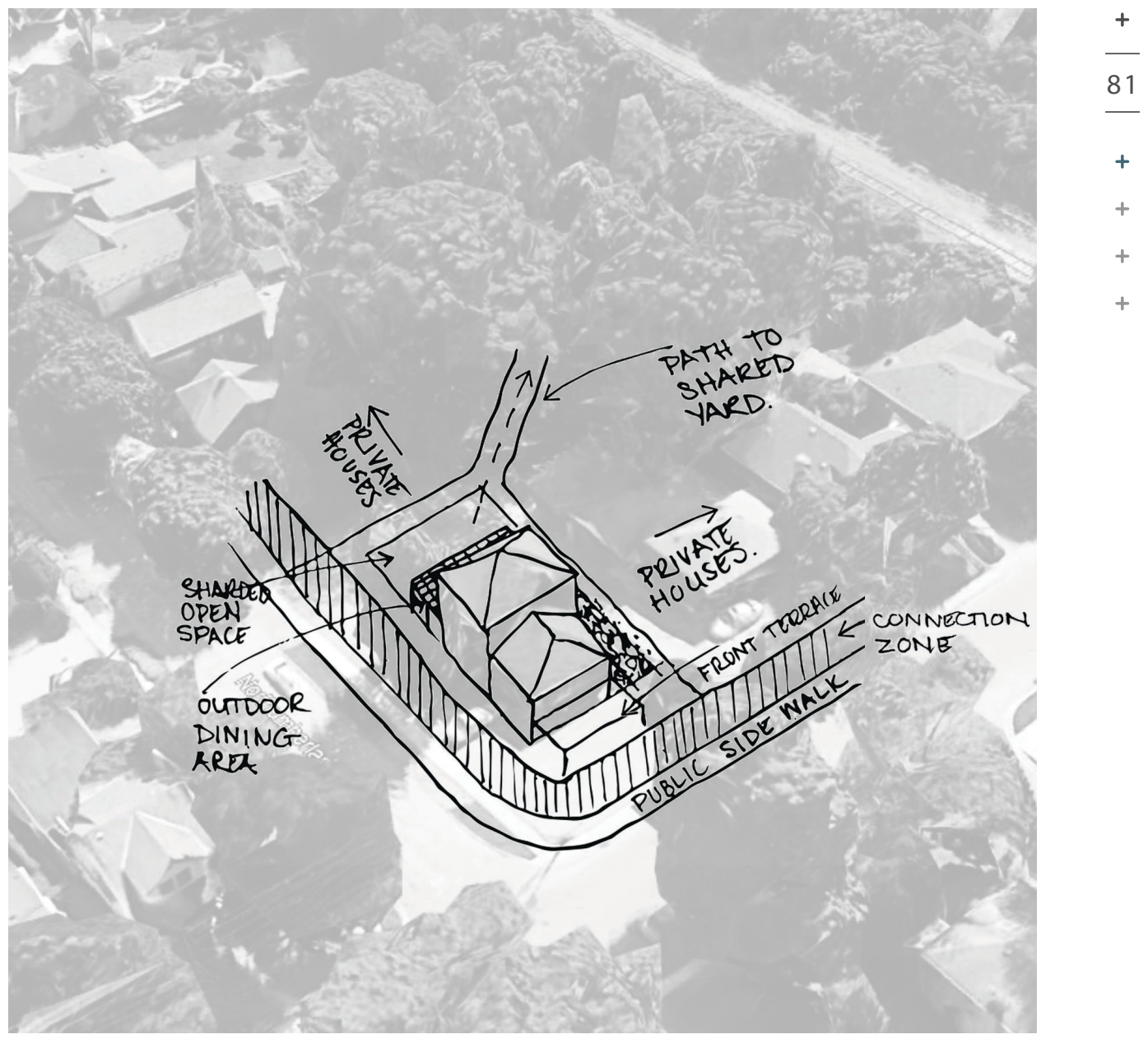

figure 57. sketch: common house 


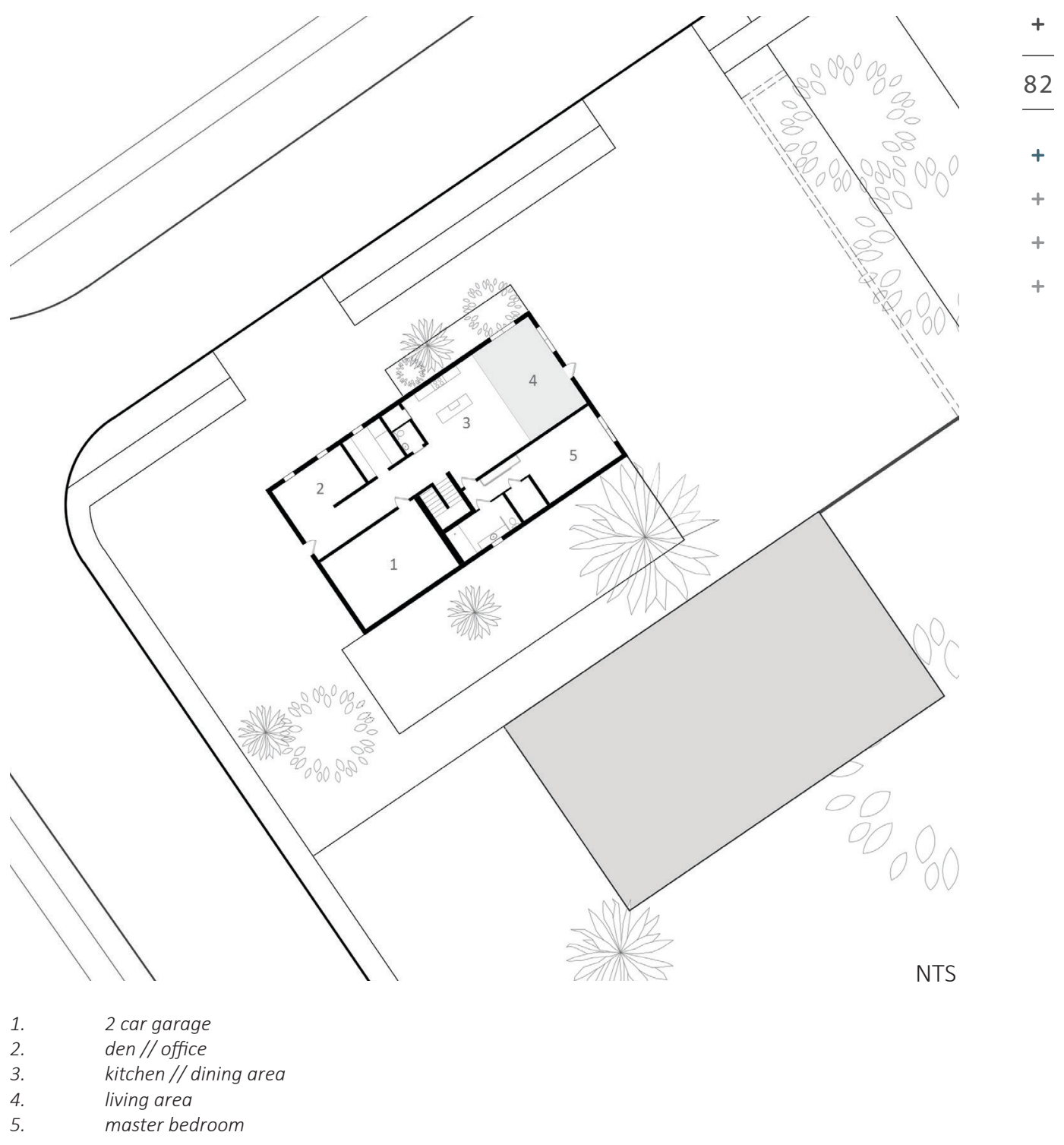

figure 58. Existing ground floor plan: common house

(existing plan is an adaptation of a similar local typology which is avaiable online) 


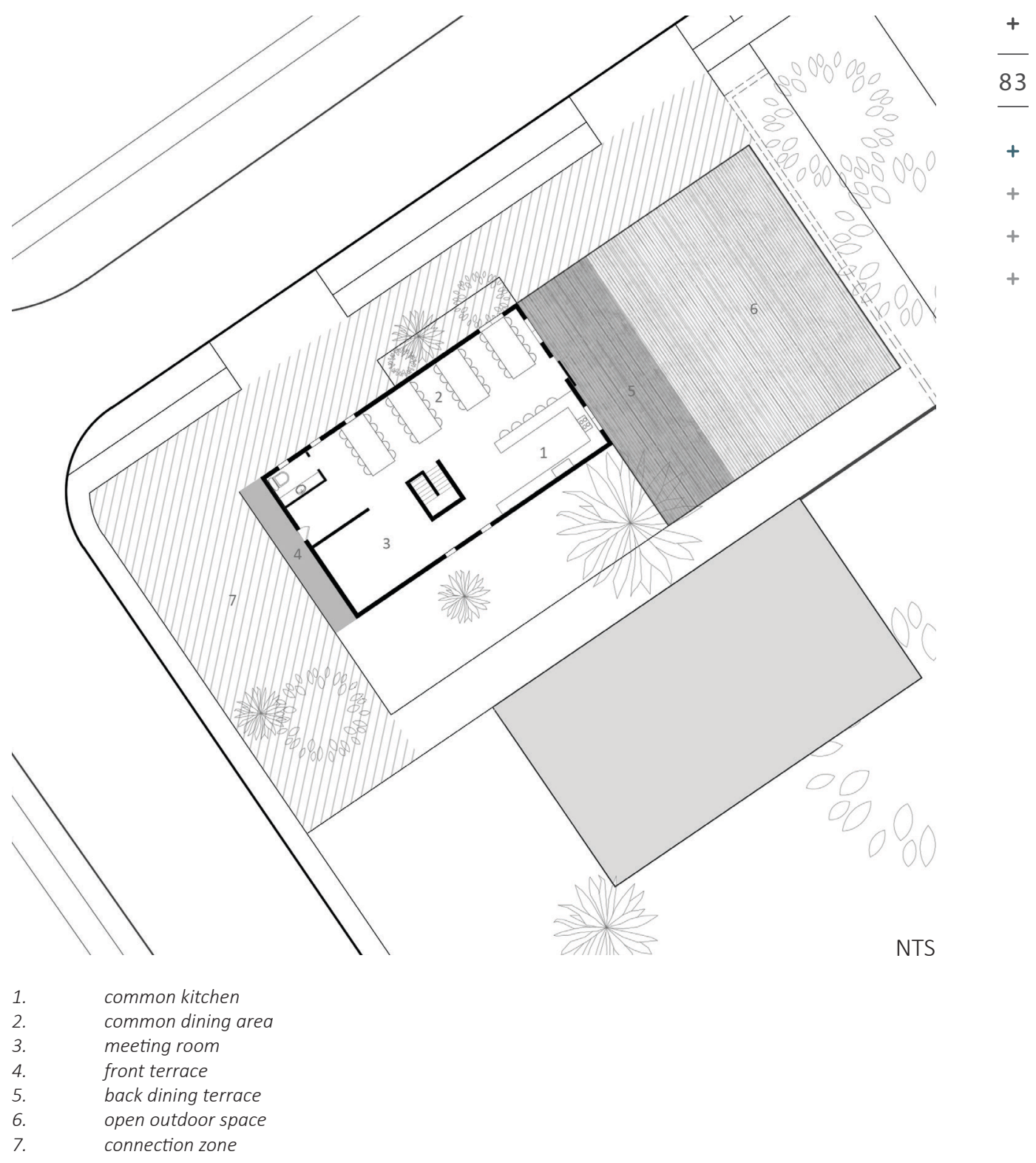

figure 59. Retrofit Ground floor plan: common house 


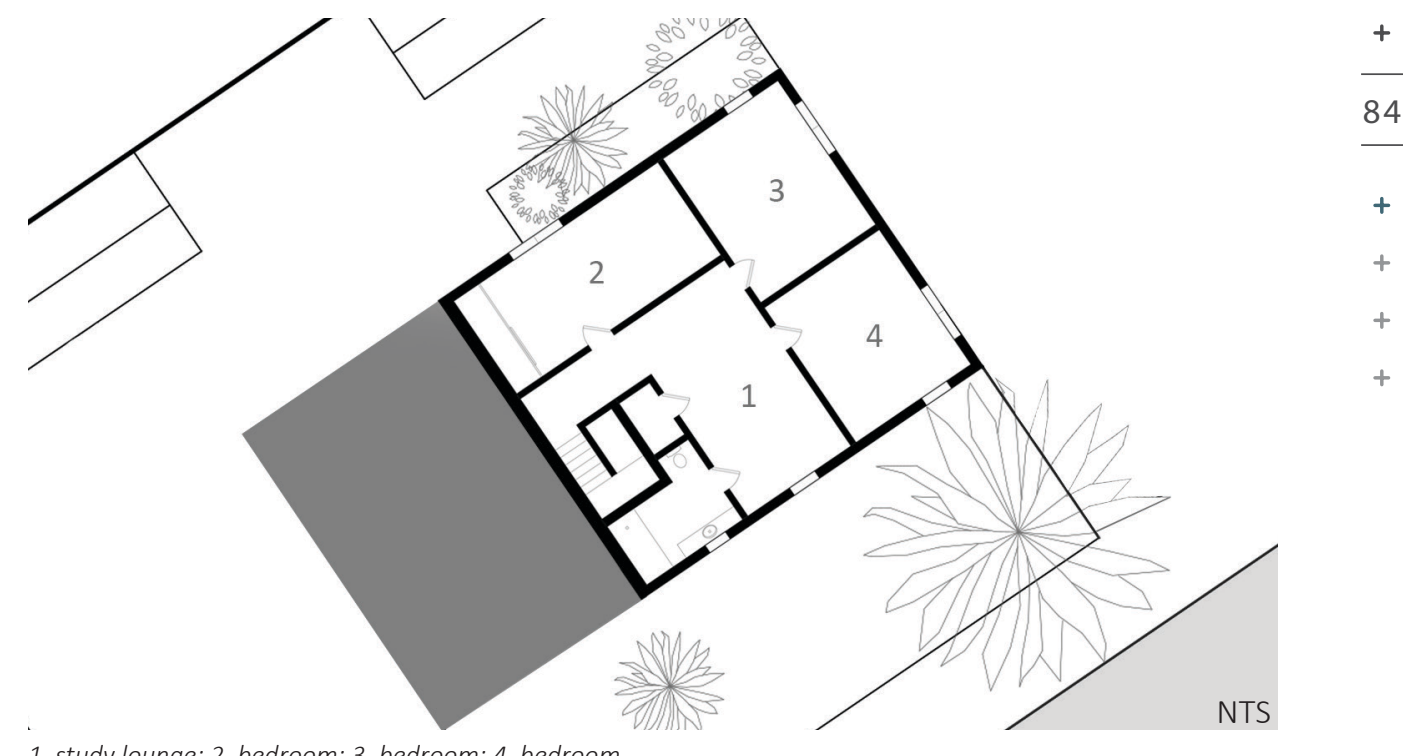

1. study lounge; 2. bedroom; 3. bedroom; 4. bedroom figure 60. Existing Second floor plan: common house

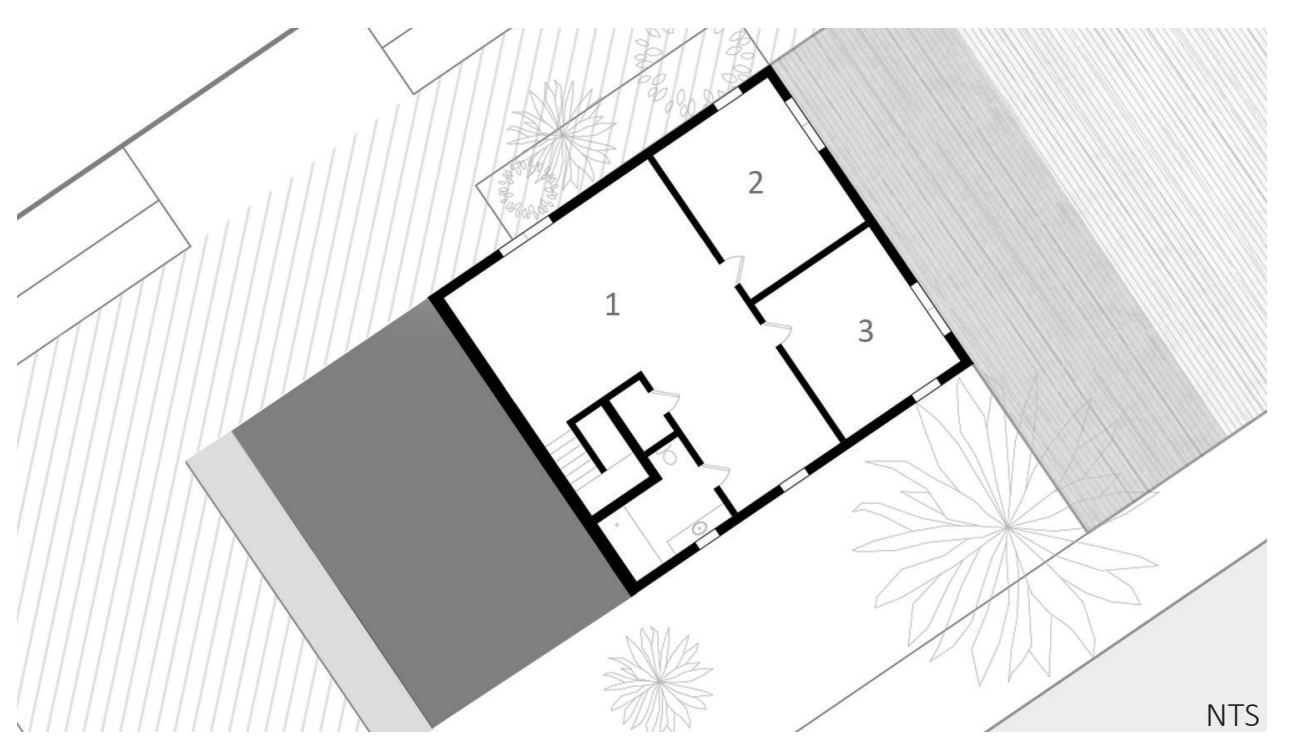

1. children play space; 2. guest bedroom; 3. guest bedroom

figure 61. Retrofit Second floor plan: common house 


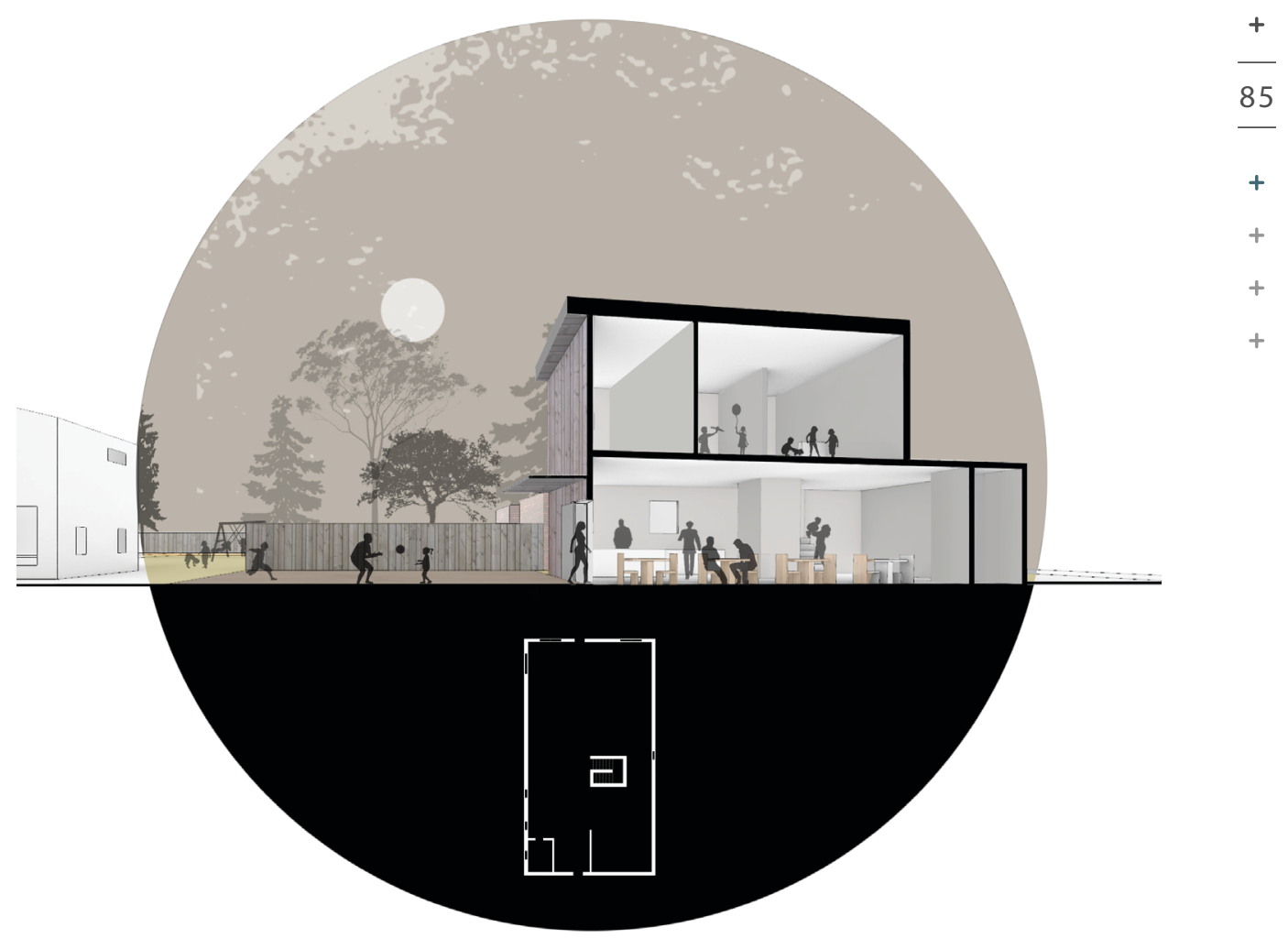

figure 62. section: common house 
The Shared Yard

Time Stamp: Year 10 (and further)

The shared yard is the aspect of the block that will evolve the most. As more members and houses join the community fences will be removed and the central shared courtyard will grow. Some outdoor elements are designed to be in the central shared yard like the vegetable garden, child play zone, fire pit and chicken coop. But there is plenty of open space still because the yard will continue to grow and evolve as the community does. The front yard also has some shared elements, the space at the front is smaller but is created to act as a connection layer between the community and the greater neighborhood.

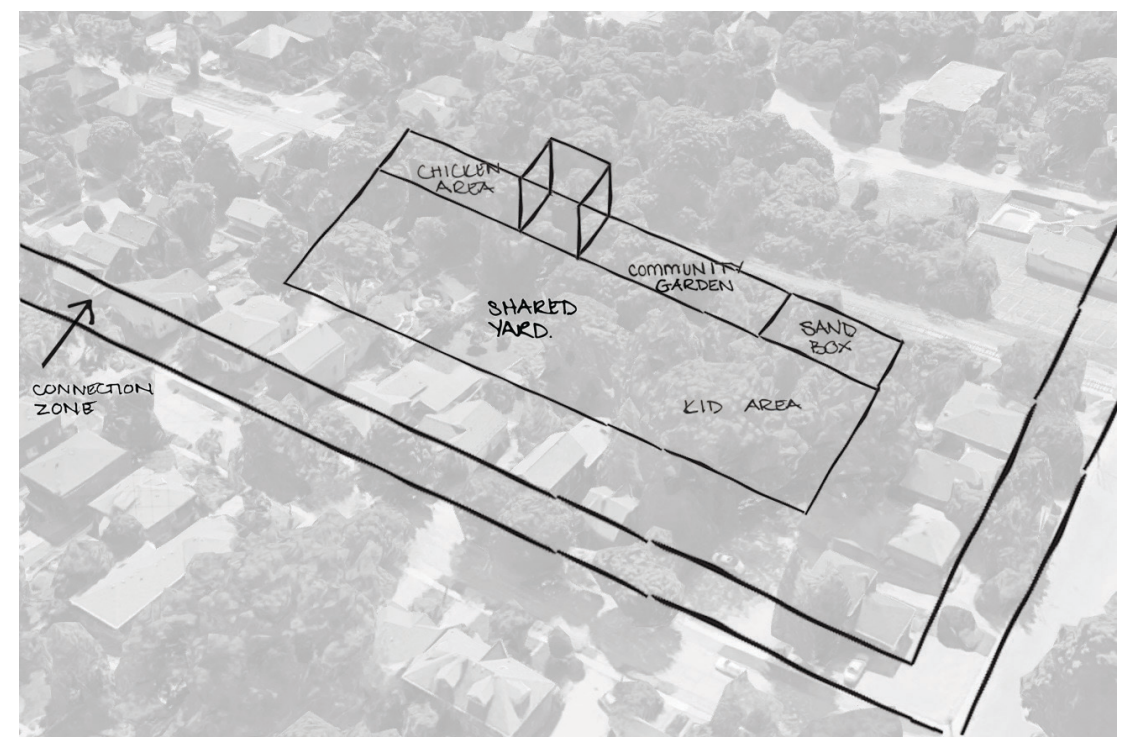

figure 63. sketch: shared yard 


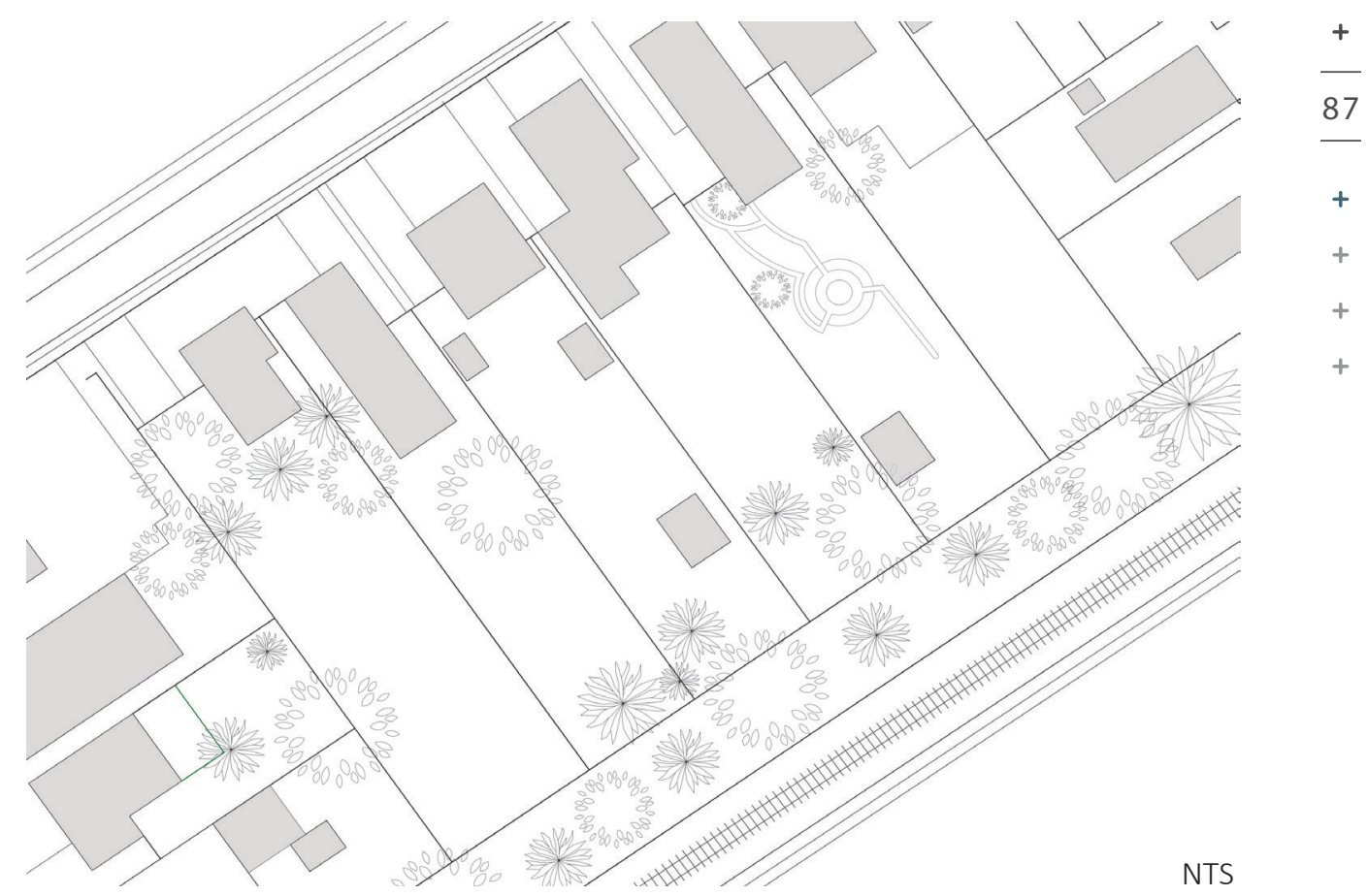

figure 64. existing yard plan 


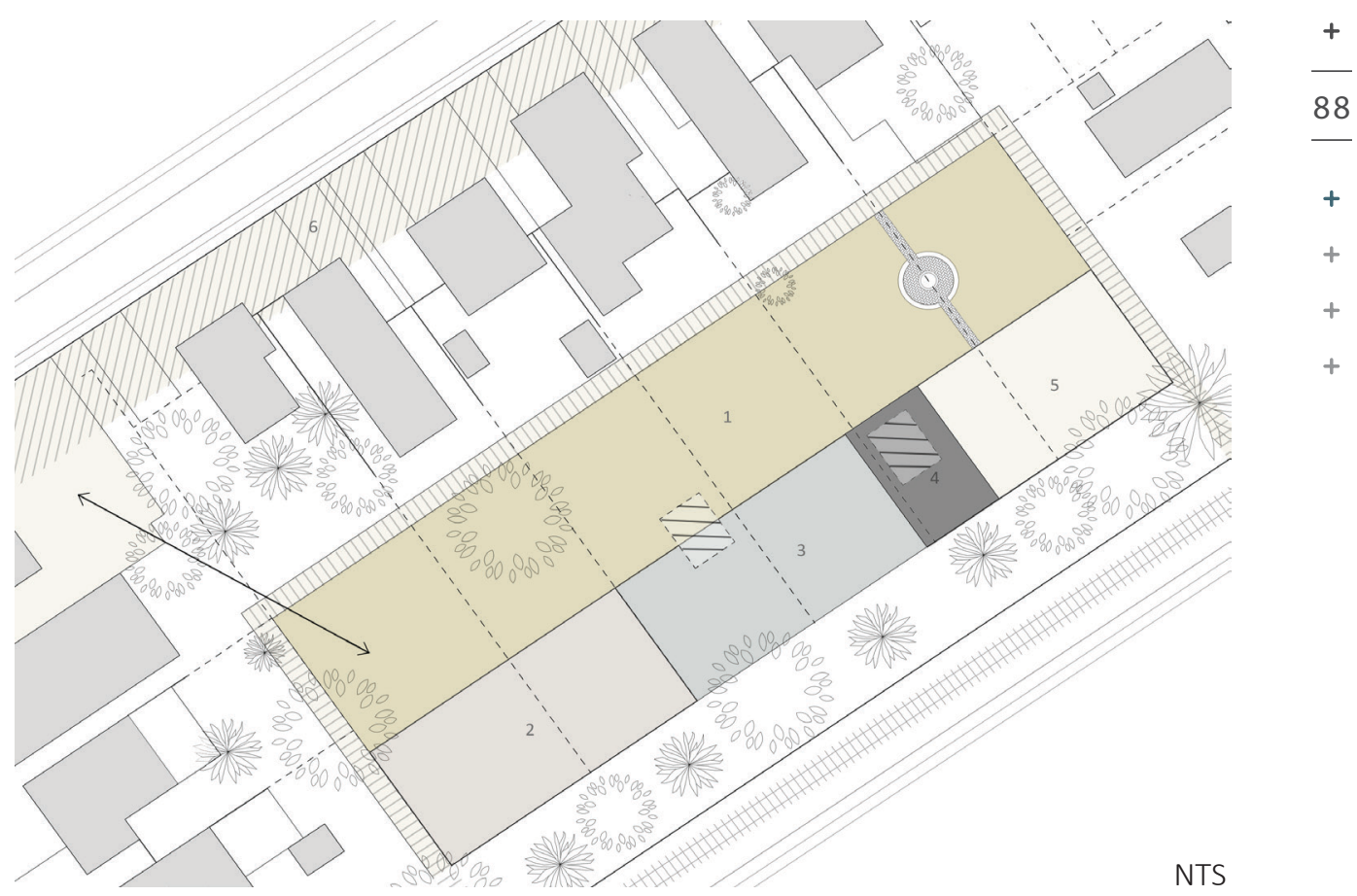

figure 65 shared yard plan

$\begin{array}{ll}\text { 1. } & \text { open shared yard } \\ \text { 2. } & \text { sandbox play area } \\ \text { 3. } & \text { common garden } \\ \text { 4. } & \text { chicken coop } \\ \text { 5. } & \text { chicken area } \\ \text { 6. } & \text { connection zone }\end{array}$




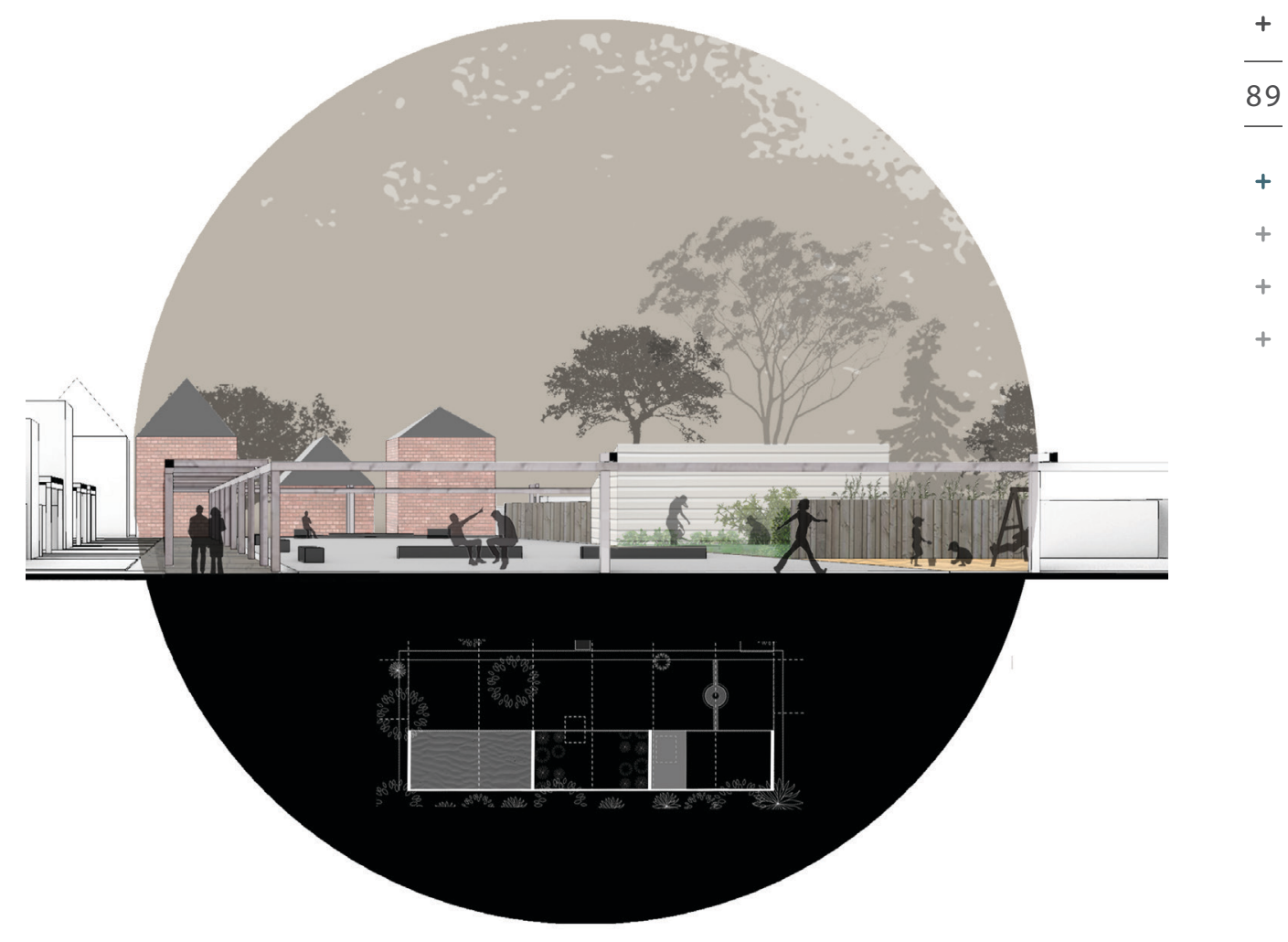

figure 66. section: shared yard 
The sample block shown above displays one example of how a retrofit block + may evolve. Depending on the group who inhabits the block and the site $\overline{90}$ restrictions, the overall design will be different case by case. Other groups may want to focus on designing for mobility as there are many seniors in the + area, or for creating live/work typologies as many people on the block are looking to work close to home. Expressing one block can show various de- + sign ideas but there are many ideas that were not addressed in the design that could work well depending on the co-housing group. 


\section{Morphology of Guelph}

Based on the areas of high-density public space (shown in zones 1-4) as a starting point for expansion zones, figures 67-68 display a proposed retrofit community plan of Guelph in year 2035. The map and model was created with the idea to implement co-housing attributes in the blocks of the city that would work best with the retrofit model, using the success strategies that were presented within the first section of the handbook, "Retrofit Strategies". With the four zones chosen as starting points, I used the case study, N Street Co-housing, to determine how large each community could possibly grow over the next 15 years. Between 1986 and 1992, the N Street Co-housing grew by 10 houses on the block ${ }^{39}$. With this growth rate of 1.7 added houses per year, the future map was designed.

The goal of this drawing is not to express how these communities would be developed or an exact time-line of the germination of retrofit communities but is meant to display a possible future for the city if retrofit communities were to be implemented into existing neighborhoods.

\footnotetext{
${ }^{39}$ N Street Cohousing, 2018
} 


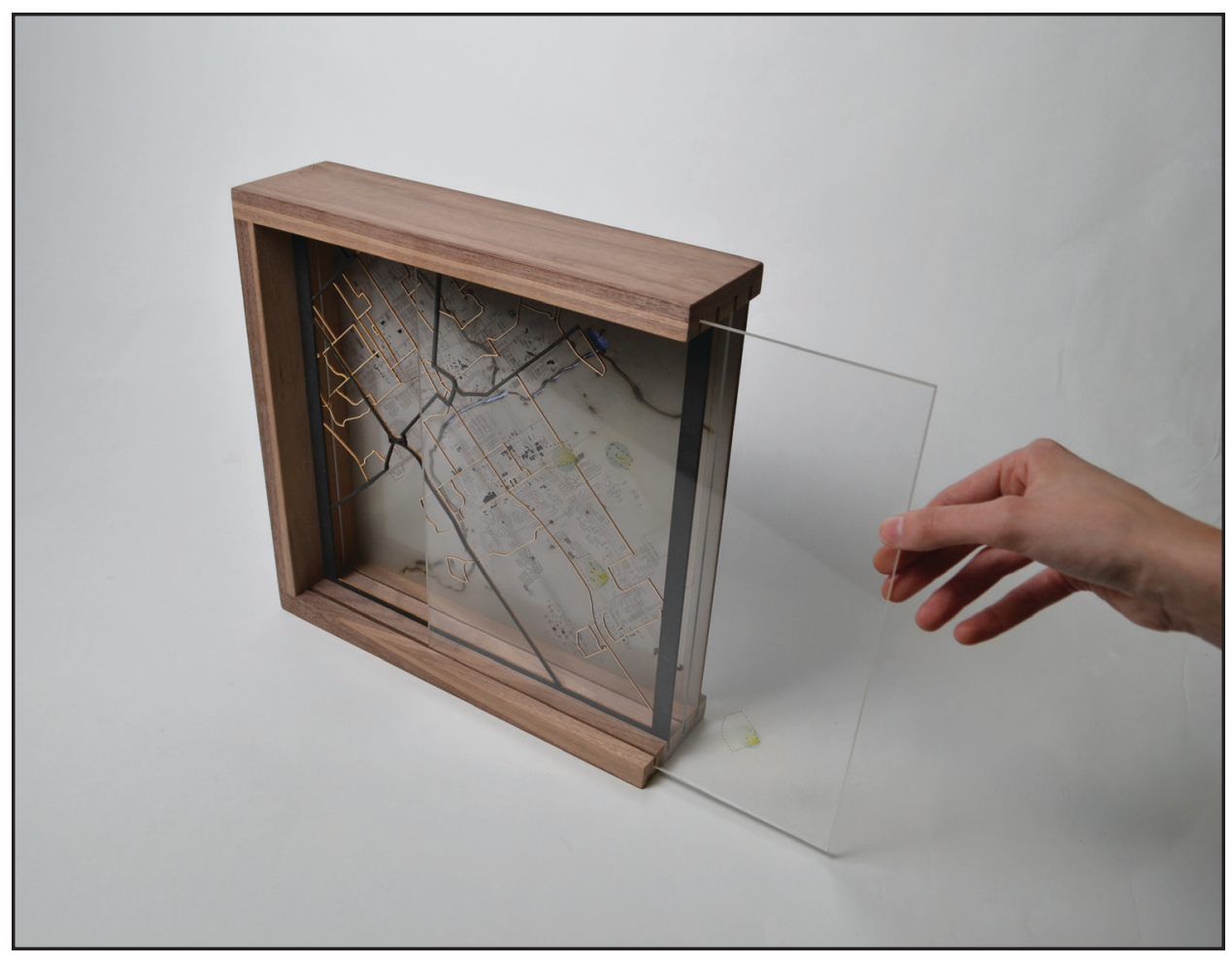




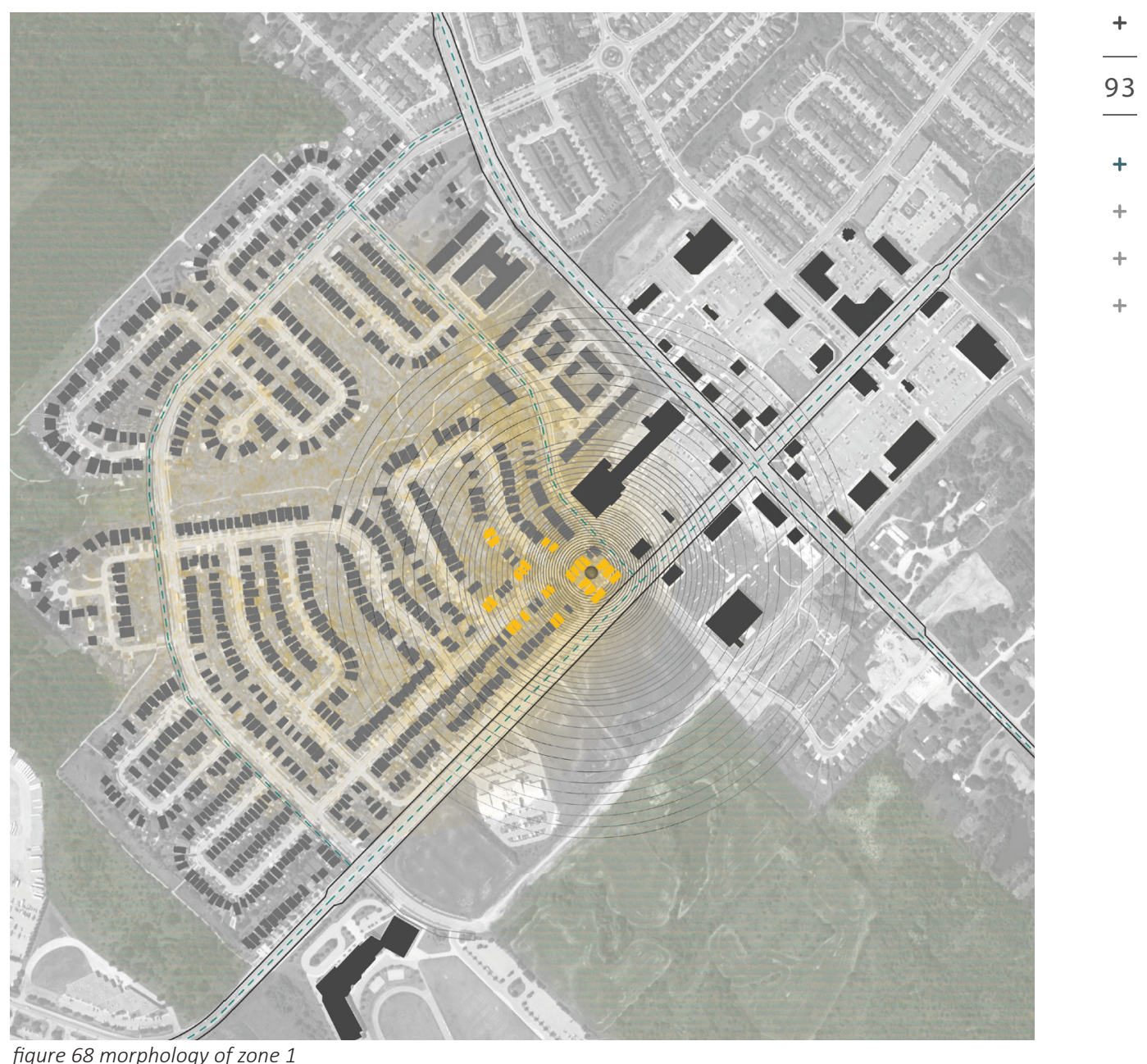




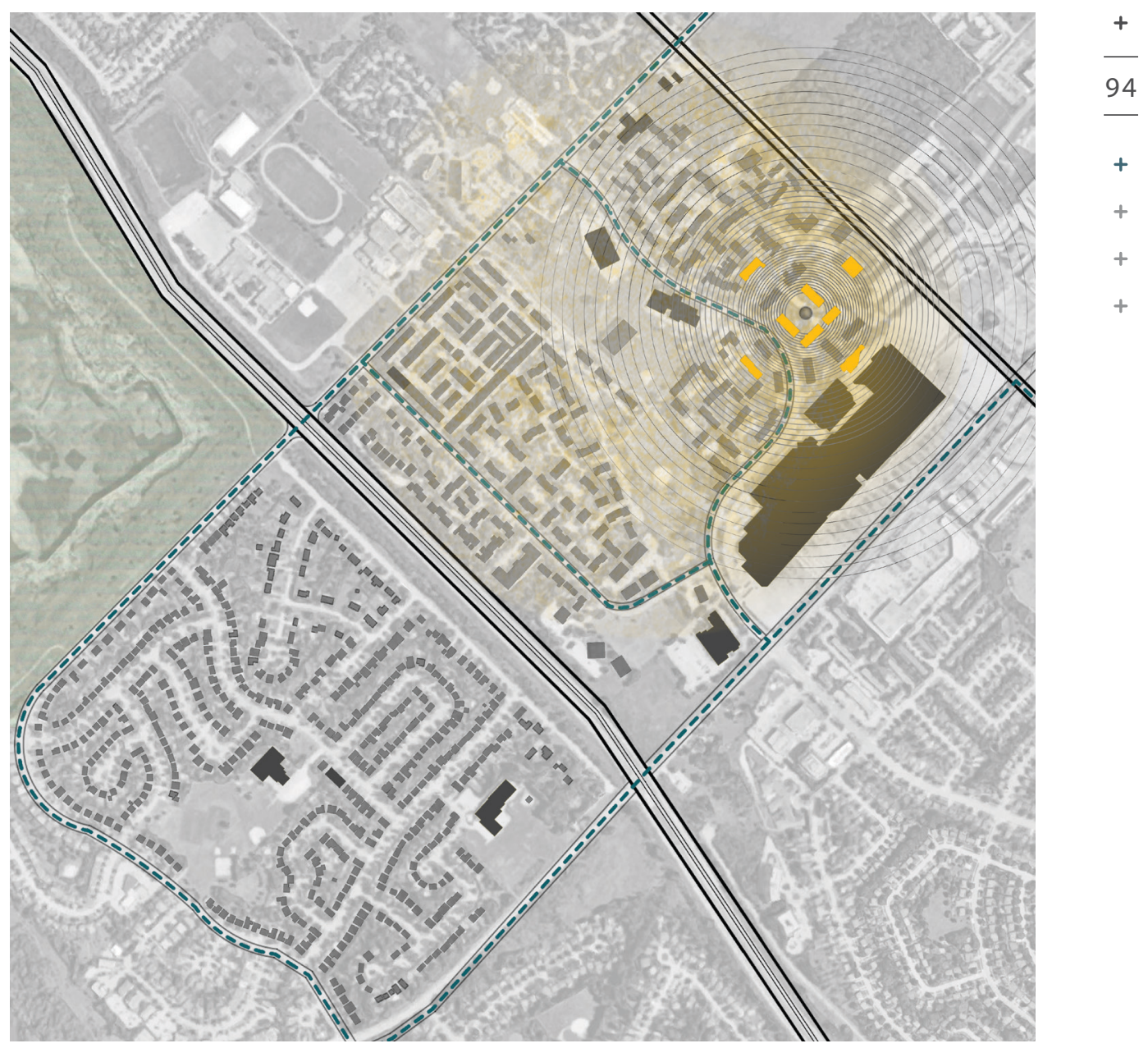

figure 69 morphology of zone 2 


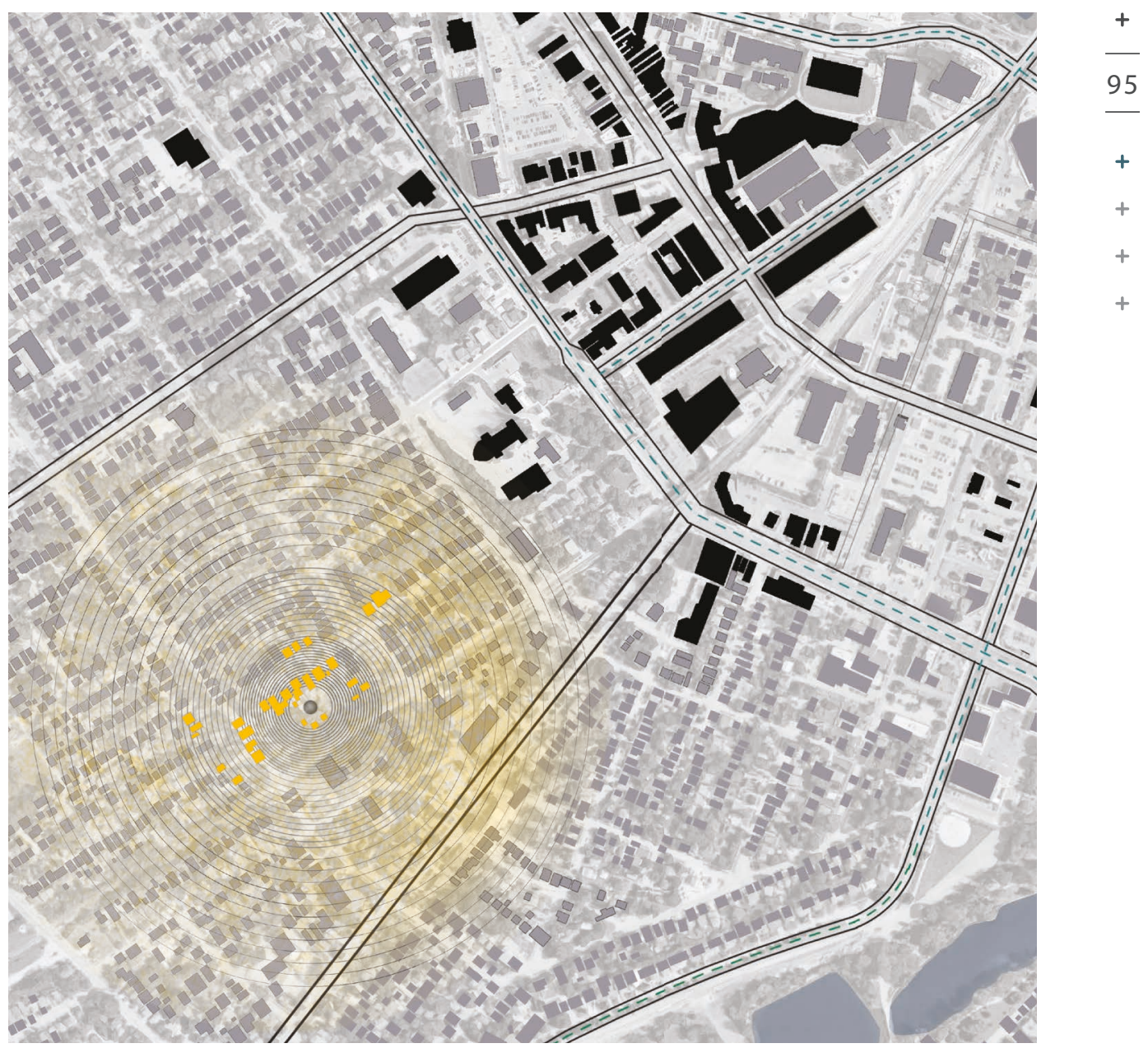

figure 70 morphology of zone 3 
ISSUEONE | DESIGN HANDBOOK FOR CANADIAN CO-HOUSING

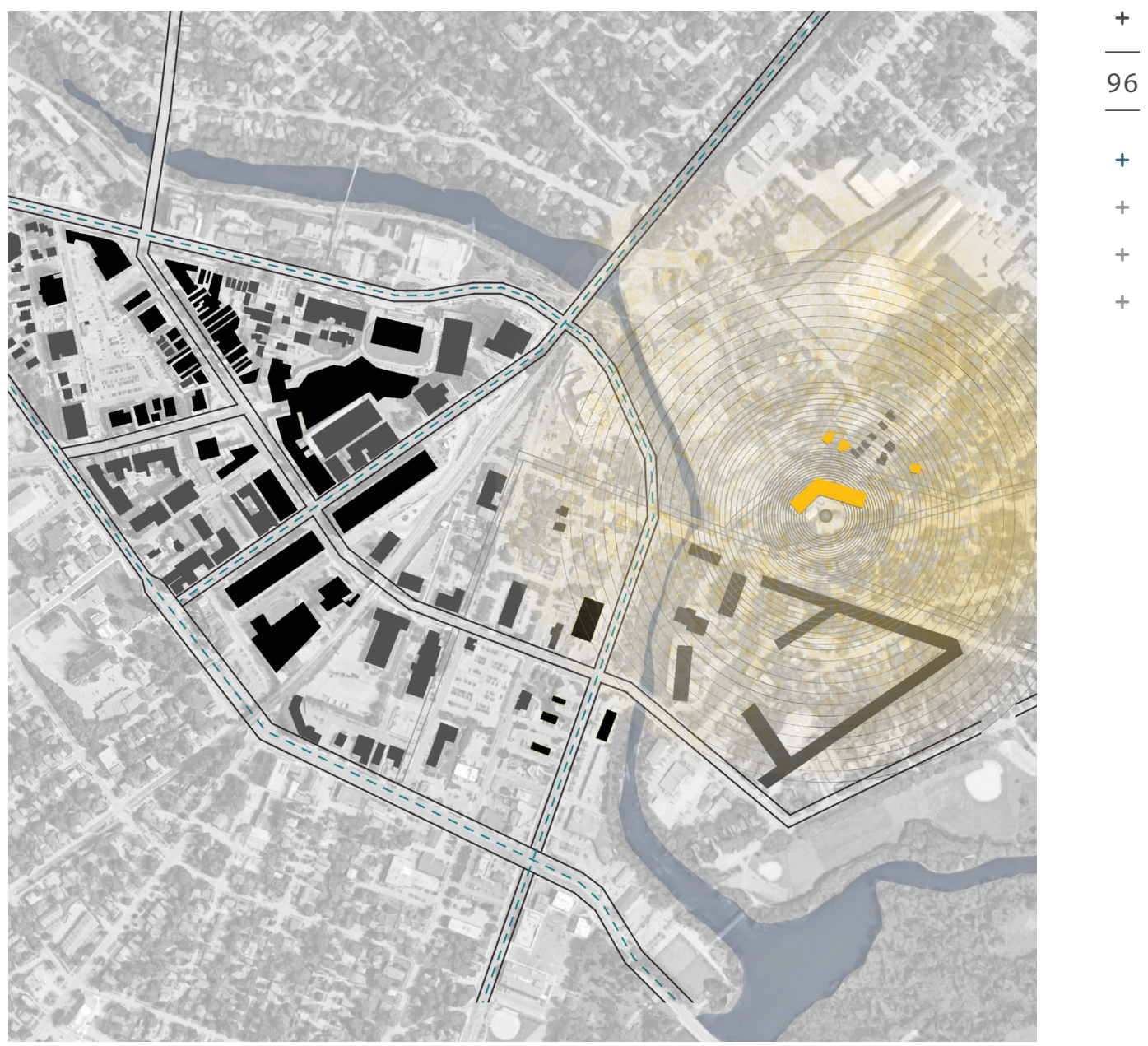

figure 71 morphology of zone 4 

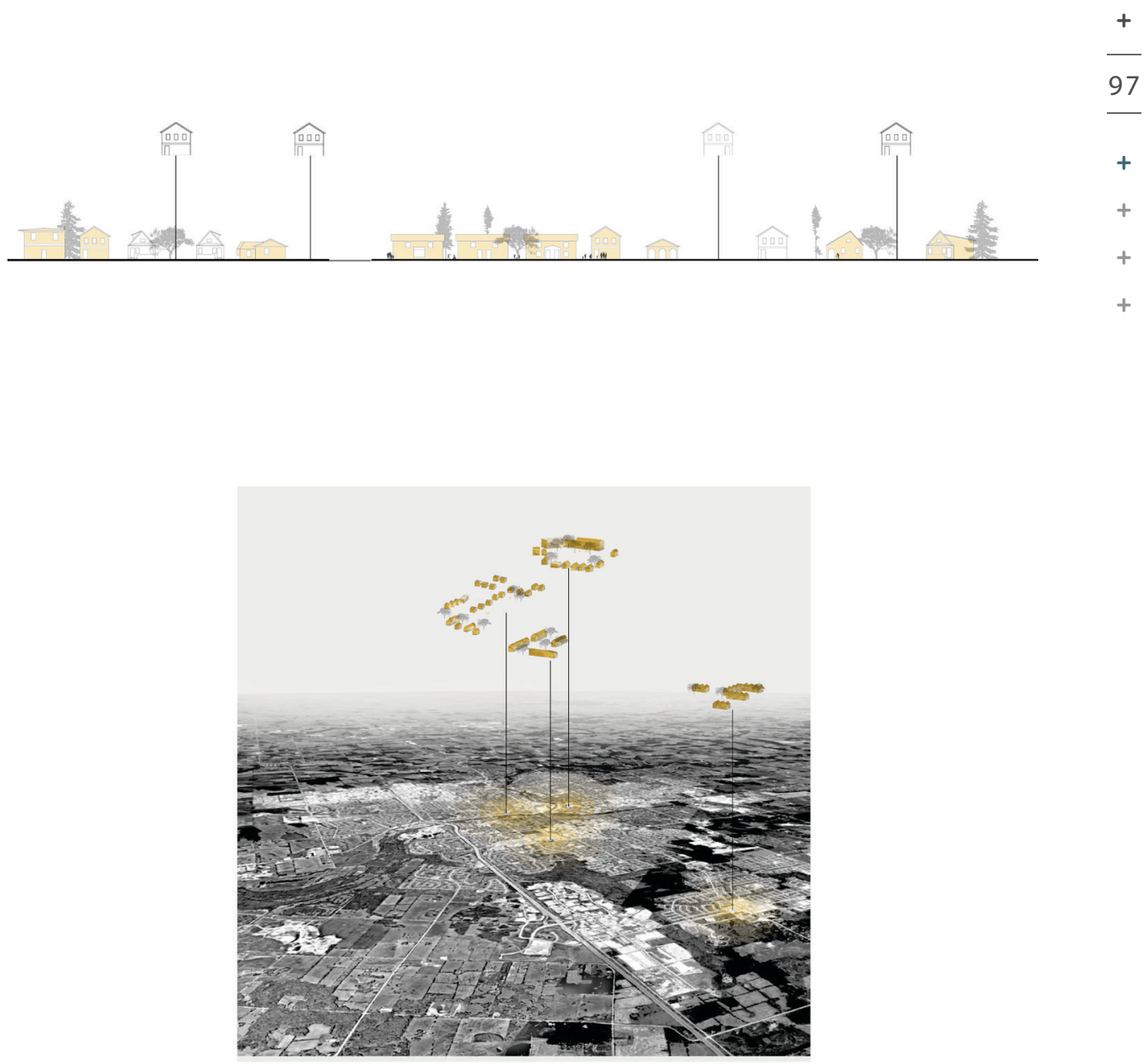

MORPHOLOGY OF GUELPH | 2035

retrofit co-housing implemented onto existing city fabric

figure 72 morphology drawing 


\section{Conclusion}

The goal of this thesis was never to solve the issues that arise when creating co-housing. As someone who has never lived in a co-housing community, I am aware that I do not have enough first-hand experience in co-housing, nor do I believe that this thesis is meant to offer a solution to a problem. Rather, it is a means to open a discussion and bring attention to the possibilities inherent in the co-housing model, with particular attention to the remodeling option, which has never been taken on in Canada as yet. This housing model is proposed as one that could support and foster the construction of a stronger sense of community lessening the sense of isolation that the current housing typologies implicitly embody. One thing that stood out to me throughout this thesis is that the construction of a co-housing community is complex. It's a type of living that requires a great amount of interaction and communication, and I do not believe that it will suit everyone. However, my goal was to contribute to constructing the questions about co-housing and offer a guidebook about the retrofit co-housing model in a Canadian context, which could be taken up as a starting point for community discussions for those who may be interested in establishing one such community. The reason I chose to create a handbook rather than a project was to create ideas that could be used as functioning tools, if the retrofit model does become integrated within the Canadian context. I have come to believe that the more co-housing becomes accessible to a wide range of people and places, the higher the chances are that we may see it integrated within Canadian housing.

SECTION [02] 
My hopes throughout this thesis were to show the many faces of co-housing and give a visual representations of how traditional housing typologies could adapt co-housing attributes using the retrofit model in Canada. The way a co-housing community is architecturally designed, alone will not resolve the many challenges that arise within co-housing, but it will be a contributor to the success of a community. The spaces that are designed will greatly impact the way a co-housing community will coincide. As architects, we can use the tool of design to tell past co-housing stories and offer future co-housing ideas. That was what I hoped to achieve during this thesis.

Although the case study design project I created for the City of Guelph did show samples and ideas of co-housing possibilities, I believe the beauty of co-housing is that no two communities can be the same. The people who fill these architectural spaces largely contribute to the design and construction of the co-housing community, and for this reason I chose to draw ideas rather than a solved project. I learned in my research that the retrofit model of co-housing has proven to be more accessible for a diverse group of people. I think that architecturally sharing how a retrofit model may transform is a great way to move forward in the process of teaching the public about the co-housing lifestyle. 


\section{Bibliography}

Adam-Smith, Ben. "Can You Retrofit Cohousing into an Existing Neighbourhood?" House Planning Help. December 13, 2013. Accessed March 30, 2019. https://www.houseplanninghelp.com/can-you-retrofit-cohousing-into-an-existing-neighbourhood/.

Belk, Charles L. "Cohousing Communities: A Sustainable Approach to Housing Development." Master's thesis, UC Davis, 2006.

"Canadian Cohousing Network." Canadian Cohousing Network. Accessed March 21, 2019. https://cohousing.ca/.

Durrett, C.; McCamant, Kathryn. 2011. Creating Cohousing: Building Sustainable Communities. Gabriola Island, British Columbia. New Society Publishers.

Galloway, Gloria. "Census 2016: More Canadians than Ever Living alone." The Globe and Mail. November 12, 2017. Accessed March 30, 2019. http://www.theglobeandmail.com/news/national/census-2016-statscan/ article35861448/.

"Guelph Population 2019." Guelph Population 2019 (Demographics, Maps, Graphs). Accessed March 21, 2019. http://worldpopulationreview. com/world-cities/guelph-population/.

Jacobs, Greg. "Co-Op vs. Condo: What You Need to Know." The Huffington Post. August 28, 2013. Accessed March 21, 2019. http://www. huffingtonpost.com/greg-jacobs/coop-vs-condo-what-you-ne_b_3460551. html.

Killock, John. "Centraal Wonen in Haarlem." The Huffington Post. July 15, 2013. Accessed October 01, 2018. https://www.huffingtonpost. co.uk/john-killock/centraal-wonen-in-haarlem_b_3586875.html. 2017.

Kim, Grace. "TED ." How Co-Housing Can Make Us Happier, Apr. 
Kuper, L. (1953) Living in Towns (London: Crescent).

Mcnaughton, Graeme. "Guelph Couple Looking Back and Looking 101 Forward with Proposed Co-Housing Development." February 27, 2019. Accessed March 01, 2019. www.guelphmercury.com/.

Nechyba, Thomas J, and Randall P Walsh. "Urban Sprawl." Journal of Economic Perspectives, vol. 18, no. 4, 2004, pp. 177-200., doi:10.1257/0895330042632681.

"ONE SHARED HOUSE - an Interactive Documentary." ONE SHARED HOUSE. Accessed March 30, 2019. http://onesharedhouse.com/.

"Our History." N Street Cohousing. 2019. Accessed March 30, 2019. http://nstreetcohousing.org/.

Peplau, L. A., \& Perlman, D. (1982). Perspective on loneliness. In L. A. Peplau \& D. Perlman (Eds.), Loneliness: A sourcebook of current theory, research and therapy (pp. 1-18). New York: John Wiley and Sons.

Politis. "Mapping 40 Years of Canadian Urban Expansion." Canadian Geographic. June 13, 2016. Accessed March 22, 2019. https://www.canadiangeographic.ca/article/mapping-40-years-canadian-urban-expansion.

Roth, Chris. "Community and the Law." Community and the Law(Missouri), 2015.

Sanguinetti, Angela. "Transformational Practices in Cohousing: Enhancing Residents Connection to Community and Nature." Journal of Environmental Psychology, vol. 40, 2014, pp. 86-96.

Skjaeveland, O., Garling, T. \& Maeland, J. G. (1996) A Multi-Dimensional Measure of Neighbouring, American Journal of Community Psychology, 24, pp. 193

Speer, Sean. "Federal Housing Strategy Ignores Market-Based Issues". Special to Postmedia Network. Nov. 24, 2017 
Statistics Canada. "Housing in Canada: Key Results from the 2016 Census." Women and Paid Work, Government of Canada, Statistics Canada, 27 Oct. 2017, www150.statcan.gc.ca/n1/daily-quotidien/171025/ dq171025c-eng.htm.

Strobel, 2006) Building reuse, cohousing, and the land ethic. Urban Action: A Journal of Urban Affairs 2006: 13-18

Milman, Danny. "The Growth of Cohousing in Europe." The History of Cohousing. 1994. Accessed March 01, 2019. http://www.cohousing.org/.

Webmaster. "City of Guelph." City of Guelph, City of Guelph, 3 Jan. 2019, Accessed January 30, 2019. guelph.ca/.

"Why Canada's Cult of Home Ownership Is in Trouble." The Globe and Mail, The Globe and Mail, 12 May 2018, Accessed March 30, 2019. www. theglobeandmail.com/globe-investor/personal-finance/household-finances/why-canadas-cult-of-home-ownership-is-in-trouble/article16419965/.

"Vrijburcht, Amsterdam." Right to Build Toolkit. Accessed March 30, 2019. https://righttobuildtoolkit.org.uk/case-studies/vrijburcht-amsterdam/\#.

"Woongroep Haarlem - Woongroep Lavendelstraat Haarlem." Woongroep Haarlem. Accessed March 22, 2019. http://www. woongroep-haarlem.nl/. 